MISCELLANEOUS PUBLICATIONS

MUSEUM OF ZOOLOGY, UNIVERSITY OF MICHIGAN, NO. 150

\title{
Systematics and Evolutionary Relationships Among the Herons (Ardeidae)
}

ROBERT B. PAYNE and CHRISTOPHER J. RISLEY 


\title{
MISCELLANEOUS PUBLICATIONS \\ MUSEUM OF ZOOLOGY, UNIVERSITY OF MICHIGAN
}

\author{
FRANCIS C. EVANS, EDITOR
}

The publications of the Museum of Zoology, University of Michigan, consist of two series-the Occasional Papers and the Miscellaneous Publications. Both series were founded by Dr. Bryant Walker, Mr. Bradshaw H. Swales, and Dr. W. W. Newcomb.

The Occasional Papers, publication of which was begun in 1913, serve as a medium for original studies based principally upon the collections in the Museum. They are issued separately. When a sufficient number of pages has been printed to make a volume, a title page, table of contents, and an index are supplied to libraries and individuals on the mailing list for the series.

The Miscellaneous Publications, which include papers on field and museum techniques, monographic studies, and other contributions not within the scope of the Occasional Papers, are published separately. It is not intended that they be grouped into volumes. Each number has a title page and, when necessary, a table of contents.

A complete list of publications on Birds, Fishes, Insects, Mammals, Mollusks, and Reptiles and Amphibians is available. Address inquiries to the Director, Museum of Zoology, Ann Arbor, Michigan 48109. 


\section{Systematics and Evolutionary Relationships Among the Herons (Ardeidae)}

BY

ROBERT B. PAYNE and CHRISTOPHER J. RISLEY 



\section{CONTENTS}

PAGE

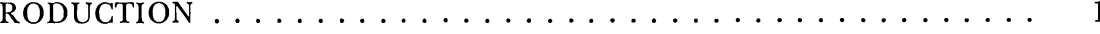

ACKNOWLEDGMENTS . . . . . . . . . . . . . . . . 4

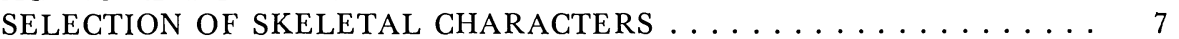

METHODS AND MATERIALS $\ldots \ldots \ldots \ldots \ldots \ldots \ldots \ldots \ldots$

THE SKELETAL CHARACTERS OF HERONS $\ldots \ldots \ldots \ldots$

Skull ........................ 10

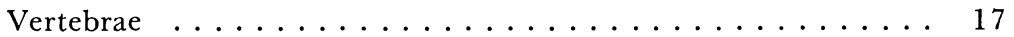

Pectoral Assemblage ................. 20

Pelvic Assemblage . . . . . . . . . . . . . . 28

ESTIMATING THE PRIMITIVE CHARACTER STATES . . . . . 32

METHODS OF NUMERICAL TAXONOMY AND PHYLOGENETIC

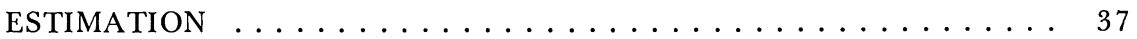

RESULTS OF ANALYSIS OF PHENETIC VARIATION AMONG THE

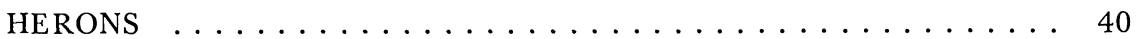

ESTIMATING THE EVOLUTIONARY HISTORY OF THE HERONS . . . 51

DISCUSSION OF THE NUMERICAL TAXONOMIC RESULTS . . . . . . . 60

RELATIONSHIPS AMONG THE GENERA AND SPECIES OF HERONS . 67

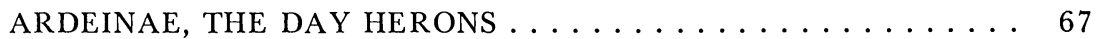

NYCTICORACINAE, THE NIGHT HERONS . . . . . . . . . 91

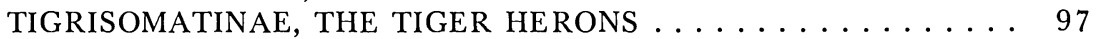

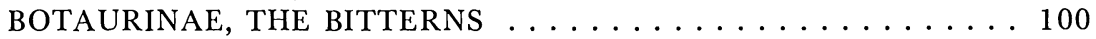

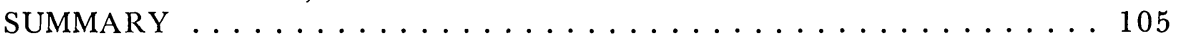

APPENDIX I: LIST OF SKELETAL SPECIMENS EXAMINED . . . . . . 107

LITERATURE GITED . . . . . . . . . . . . . . . . . . . . . . 109 


\section{ILLUSTRATIONS}

1. Skull of Ardea herodias ..................... 10

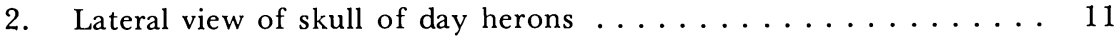

3. Lateral view of skull of night herons $\ldots \ldots \ldots \ldots \ldots \ldots \ldots \ldots$

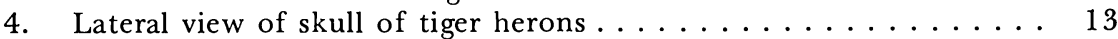

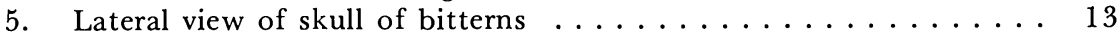

6. Skull, oblique view, and lacrimal-ectethmoid complex of eight day herons ...................... 14

7. Lacrimal-ectethmoid complex of four night herons . . . . . . 16

8. Lacrimal-ectethmoid complex of five bitterns and tiger herons . . 17

9. Skull, ventral view $\ldots \ldots \ldots \ldots \ldots \ldots \ldots \ldots \ldots$

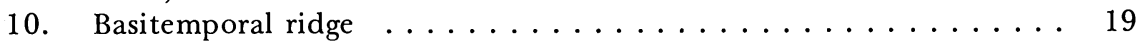

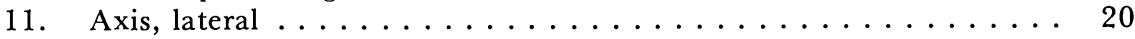

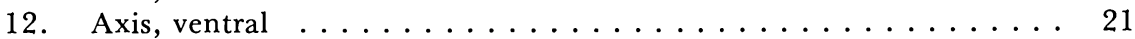

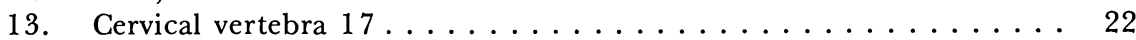

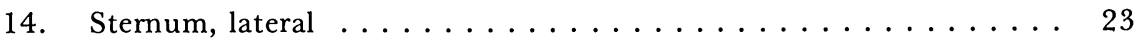

15. Sternum, ventral .................... 24

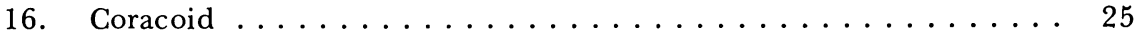

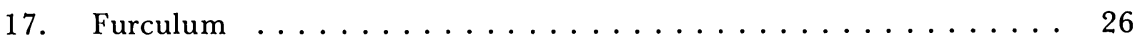

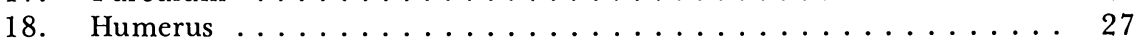

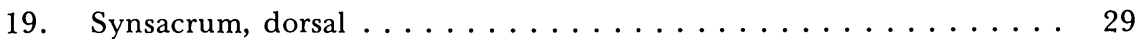

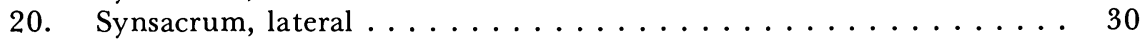

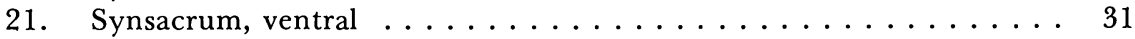

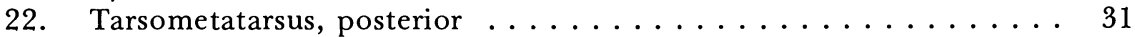

23. Tarsometataruss, proximal ................ 32

24. Minimally connected graph, all complete species, 33 characters 41

25. Minimally connected graph, herons including Zebrilus, 26 characters ........................ 42

26. Principal Components Analysis, all complete species . . . . . . . . 44

27. Minimally connected graph of phenetic similarity of herons . . . . . 45

28. Principal Components Analysis, Ardeinae, PC $1 \times 2 \ldots \ldots 46$

29. Minimally connected graph of phenetic similarity of Ardeinae . . . 47

30. Principal Components Analysis including Zebrilus and "primardea" . 50

31. Minimally connected graph of phenetic similarity including Zebrilus and "primardea" ..................... 51

32. Phenogram-simple matching coefficient ........... 52

33. Phenogram-product-moment correlation coefficient . . . . . . 53

34. Phylogenetic estimate, Wagner Tree . . . . . . . . . . . . 54

35. Phylogenetic estimate, Wagner Tree, including Zebrilus . . . . . . . 54

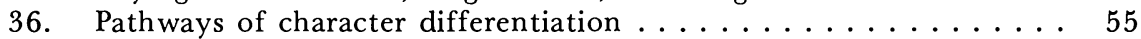

37. Diagram of cladistic compatibility, all herons ........... 56

38. Diagram of cladistic compatibility, Ardeinae . . . . . . . . . . 57

39. Diagram of cladistic compatibility, Nycticoracinae . . . . . . . 58

40. Diagram of cladistic compatibility, Tigrisomatinae . . . . . . 58

41. Diagram of cladistic compatibility, Botaurinae . . . . . . . . . 59

42. Diagram of cladistic compatibility, composite, all herons . . . . . . 6 60

43. Display of captive Syrigma sibilatrix . . . . . . . . . . . . 72

44. Stretch display of Ardea alba . . . . . . . . . . . . . . 78

45. Interspecific supplanting attack in two egrets . . . . . . . 81

46. Feeding Nyctanassa violacea . . . . . . . . . . . . . . 93

47. Agonistic display in feeding Nyctanassa violacea . . . . . . . . 94 


\section{INTRODUCTION}

Bird systematics has long been based on the idea that biological classification should reflect evolutionary history. In contrast to studies on some groups of invertebrates in which the species are not well known, studies of birds have led to classifications that reflect various authors' assumptions about evolutionary histories (e.g. Mayr and Amadon, 1951; Wetmore, 1960; Storer, 1971; Sibley and Ahlquist, 1972). In spite of the agreement among avian systematists on the importance of deriving a classification scheme that reflects evolutionary history the arrangements of taxa of birds differ considerably. In part this may be because different authors consider certain kinds of characters to reflect evolutionary relationships more accurately than others. Differences also derive from different assumptions of the relative importance of overall similarity versus coevolving sets of characters. And in part the differences are attributable to the different assumptions and logic in constructing a set of hypotheses of relationships that are compatible with evolutionary processes. In the present study we compare the results of different numerical taxonomic approaches using both multivariate phenetic descriptions and phylogenetic estimates in a systematic review of relationships among the species in the family Ardeidae, the herons.

The herons are a group of large wading birds, resembling the other families included in the order Ciconiiformes in being longlegged, long-necked, generally aquatic birds. They live in most parts of the world except the highest latitudes. A few species have colonized oceanic islands and archipelagos. The Ardeidae differ from other Ciconiiformes such as the storks and ibises in having a long, spearlike bill, a pectinate middle toe claw, a generally more slender body with a long neck, and an elaborate variation in display feathers on the head, neck, and back. Sibley and Ahlquist (1972) have summarized the anatomical and other evidence of the general relationships of the herons to the other Ciconiiformes, and have given a brief history of the characters and reasoning used by earlier systematists in their classifications. One species, the Boat-billed Heron Cochlearius cochlearius, has been regarded as an ardeid by some but not all investigators (Wetmore, 1960; Van Tyne and Berger, 1959; Bock, 1956; Sibley and Ahlquist, 1972).

Evolutionary history within the herons has been interpreted differently by various systematists. The "day herons" (Ardea and closely similar forms) were considered the most primitive (i.e., the least differentiated from the ancestral herons) by Peters (1931) in his linear sequence of taxa. Bock (1956) suggested that the "primitive stock" of the herons probably resembled the modern tiger herons more closely than it did any of the other modern herons, but in his classification he lists the bitterns first, implying primitiveness. The 
bitterns are also regarded as the most primitive by Meyerriecks (1960) and by Curry-Lindahl (1971) on behavioral grounds, though the latter does not describe the supposed differences on which his classification would depend. In none of these studies did the authors compare the character states of the herons with those of other Ciconiiformes, though this would seem to be necessary to determine the relative "primitiveness" of character states within the group. A second area of varying interpretation in the herons is the relationship of certain species to the major groups of genera. The Capped Heron Pilherodius pileatus and the Whistling Heron Syrigma sibilatrix, both of South America, were regarded by Bock (1956) as night herons of the genus Nycticorax. Pilherodius was listed among the day herons and Syrigma was placed between the day herons and night herons in Peters (1931), and Humphrey and Parkes (1963) discussed Syrigma as a day heron. The heron whose relationships are perhaps least known, the Zigzag Heron Zebrilus undulatus, was regarded as a bittern by Sharpe (1898) and Peters (1931) but as a tiger heron by Bock (1956). Except for a comparison of the axis vertebra of Syrigma with the axis of a few other species by Humphrey and Parkes (1963), no anatomical comparisons of these forms with the other herons have been described. Finally, the number of genera and the arrangement of species within the genera have not been studied by earlier heron systematists in any consistent and systematic manner.

Herons have been revised or relisted several times but usually without discussion of the reasoning used in the decisions. In the only published rationale (Bock, 1956) of the classification of herons, the characters used to distinguish the major groups, genera, and superspecies were derived mainly from those of doubtful phylogenetic significance and of probable multiple evolutionary history among different species. The characters included the dispersion of nesting pairs and the structure of feathers used in courtship display. These very likely change rapidly due to selective pressures of local feeding ecology and species recognition, and so they carry little information about evolutionary changes over the long periods of time involved in the differentiation of genera and subfamilies. In contrast, the skeletons of the herons vary in such a manner that many corresponding character states can be found among the most closely related groups outside the herons, the other ciconiiform birds, and they are usually more similar among closely related species than are the plumes of the species, indicating that differences reflect phylogenetic relationships. We also wished to follow Bock's (1956) suggestion that careful studies of the anatomy of the heron species would provide the most reliable kind of information about relationships in the group. In addition we were interested in using a set of characters in a consistent and logical manner for the group of species, and in comparing the patterns of similarities and relationships resulting from different analytical approaches. In the study we used several revisions 
of data sets of skeletal characters in three kinds of algorithms based on phenetic similarity-minimum length nondirected trees (Prim Networks), cluster analysis, and principal components analysis (Sneath and Sokal, 1973, pp. 264-265, 259-264, and 245-246) and also two programs that are based, according to their proponents, on phylogenetic principles (Kluge and Farris, 1969; Estabrook, 1972; Estabrook, Johnson, and McMorris, 1975). Evolutionary assumptions of these latter two approaches include (1) phylogenetic changes between closely related forms have involved intermediate species with different combinations of skeletal character states, and (2) the character states of the ancestral forms are represented in modern day herons. In the phylogenetic tree or Wagner Tree rationale, the species are all compared one at a time with the ancestor, with each other, and with hypothetical character state combinations that link the modern species through the smallest number of character state changes (Kluge and Farris, 1969). In the other rationale, the cladistic compatibility test of Estabrook (1972) and Estabrook et al. (1975), the cladistic relationships among species are estimated by selecting the largest set of characters that show no evidence of reversals or independent changes of character state among these species. It is assumed that those characters which have undergone apparent evolutionary reversals are unreliable indicators of common ancestry at all levels and should be deleted from the set of characters used to estimate cladistic history. Thus, the cladistic history of the group is based on characters found to be internally compatible. We refer the reader to other sources for discussions of the philosophy of biological systematics and of theories of quantitative phyletics and numerical taxonomy (Kluge and Farris, 1969; Estabrook, 1972; Michener, 1970; Sneath and Sokal, 1973; Cracraft, 1974a; Mayr, 1974). The present work summarizes the reasoning behind the systematic classification of the Ardeidae for a revised edition of Peters' Checklist of the Birds of the World (Payne, in prep.). We were guided by the results of the quantitative treatments of skeletal characters, particularly when different evolutionary assumptions yielded consistent results, but we have also considered other kinds of characters including feather arrangement and structure, myology, and behavior, especially at the level of closely related species. Our overall interpretation of the evolutionary history within the herons as well as our systematic arrangement is based mainly on the estimated quantitative phenetic and phylogenetic relationships in the analyses of skeletal characters in the herons.

The methods of numerical taxonomy have been used in describing phenetic relationships of several groups of animals but have been little used by ornithologists (Sneath and Sokal, 1973). Phenetic routines including principal components analysis and also correlation and distance expressions of phenetic relationships have been applied to groups of related species and to local populations with particular 
success using skeletal characters (Johnston, 1969; Schnell, 1970). Phylogenetic programs have received less attention by students of birds, though some attempts have been made using character variation among modern species to give estimates of cladistic history (Cracraft, $1974 b)$. It seems of interest to analyze the variation among species in more than one way in order to give some degree of robustness to the conclusions of a systematic study. For the present study we attempt (1) to use rationales based on phylogenetic assumptions in order to estimate the phylogenetic history of the herons, (2) to test the phylogenetic estimates with each other for agreement, (3) to compare the phylogenetic estimates with the results of phenetic analysis, and (4) to propose a systematic classification of the species and genera of the herons, based primarily on their estimated evolutionary relationships. There appears to have been no previous systematic study of a group of bird species that includes both numerical phenetic descriptions of variation and also an estimate of phylogeny. The results of the study provide a comparison of phenetic relationships and phylogenetic estimations in this family.

In Table 1 we summarize the genera and species of herons as determined from the results of the present study, together with the genera and species recognized by Peters (1931) and Bock (1956). The details and the reasons for these systematic conclusions and a more complete outline classification (Table 7) are included later. Table 1 introduces the herons and is a guide to the use of the names of the species in the remainder of this paper where some names have been changed from earlier classifications.

\section{ACKNOWLEDGMENTS}

We thank the curators and other workers of several large collections for allowing us access to their specimens, particularly P. Brodkorb = PB (University of Florida), J. Farrand, J. J. Moroney, and W. E. Lanyon (American Museum of Natural History = AMNH), G. S. Cowles (British Museum (Natural History) = BM(NH)), L. C. Binford (California Academy of Sciences), M. A. Traylor (Field Museum of Natural History), N. K. Johnson (Museum of Vertebrate Zoology = MVZ, University of California), G. van Tets (CSIRO, Australia), and R. L. Zusi (National Museum of Natural History = NMHN). G. Estabrook, K. Fiala, G. R. Smith, and J. G. Strauch provided access to their computer programs or made suggestions on technique. For their critical comments on earlier versions of the manuscript we thank J. Cracraft, R. W. Dickerman, F. C. James, E. Mayr, D. W. Mock, R. I. Orenstein, W. B. Robertson, J. G. Strauch, and R. W. Storer. Additional comments by C. W. Benson, M. D. Bruce, M. P. S. Irwin, H. F. Recher, and R. R. Sokal are appreciated. P. Brodkorb kindly provided access to the unpublished thesis of $\mathrm{C}$. 
TABLE 1

A BRIEF SYNONYMY OF THE NAMES OF GENERA AND SPECIES OF THE HERONS ${ }^{a}$

\begin{tabular}{|c|c|c|}
\hline Peters, $1931^{b}$ & Bock, $1956^{c}$ & This Study $d$ \\
\hline Syrigma sibilatrix & Nycticorax sibilator & Syrigma sibilatrix \\
\hline Pilherodius pileatus & Nycticorax pileatus & Pilherodius pileatus \\
\hline Ardea cinerea & Ardea cinerea & Ardea cinerea \\
\hline $\begin{array}{l}\text { A. herodias } \\
\text { A. occidentalis }\end{array}$ & $\begin{array}{l}\text { A. herodias, } \\
\text { (A. occidentalis) }\end{array}$ & $\begin{array}{l}\text { A. herodias (including } \\
\text { occidentalis) }\end{array}$ \\
\hline $\begin{array}{l}\text { A. occidentalis } \\
\text { A. cocoi }\end{array}$ & A. cocoi & A. cocoi \\
\hline A. pacifica & A. pacifica & A. pacifica \\
\hline A. melanocephala & A. melanocephala & A. melanocephala \\
\hline A. humbloti & A. humbloti & A. humbloti \\
\hline A. imperialis & A. imperialis & A. imperialis \\
\hline A. sumatrana & A. sumatrana & A. sumatrana \\
\hline A. goliath & A. goliath & A. goliath \\
\hline A. (Pyrrherodia) purpurea & A. purpurea & A. purpurea \\
\hline Casmerodius albus & Egretta alba & A. alba \\
\hline Dichromanassa rufescens & Hydranassa rufescens & Egretta rufescens \\
\hline Notophoyx picata & H. picata & E. picata \\
\hline Melanophoyx vinaceigula & & E. vinaceigula \\
\hline M. ardesiaca & $\begin{array}{l}\text { H. ardesiaca (in- } \\
\text { cluding "vinaceigula") }\end{array}$ & E. ardesiaca \\
\hline Hydranassa tricolor & Hydranassa tricolor & E. tricolor \\
\hline Mesophoyx intermedia & Egretta intermedia & E. intermedia \\
\hline Bubulcus ibis & Ardeola ibis & E. ibis \\
\hline $\begin{array}{l}\text { Notophoyx } \\
\text { novaehollandiae }\end{array}$ & Ardea novaehollandiae & E. novaehollandiae \\
\hline Florida caerulea & Hydranassa caerulea & E. caerulea \\
\hline Leucophoyx thula & Egretta thula & E. thula \\
\hline Egretta garzetta & E. garzetta & E. garzetta \\
\hline $\begin{array}{l}\text { Demigretta gularis, } \\
\text { D. (gularis?) schistacea, } \\
\text { D. asha }\end{array}$ & E. gularis & E. gularis \\
\hline Egretta dimorpha & E. dimorpha & E. dimorpha \\
\hline $\begin{array}{l}\text { Egretta (Hemigarzetta) } \\
\text { eulophotes }\end{array}$ & E. eulophotes & E. eulophotes \\
\hline Demigretta sacra & E. sacra & E. sacra \\
\hline Ardeola ralloides & Ardeola ralloides & Ardeola ralloides \\
\hline A. grayii & A. grayii & A. grayii \\
\hline A. bacchus & A. bacchus & A. bacchus \\
\hline A. speciosa & A. speciosa & A. speciosa \\
\hline A. idae & A. idae & A. idae \\
\hline Erythocnus rufiventris & A. rufiventris & A. rufiventris \\
\hline $\begin{array}{l}\text { Butorides striatus, } \\
\text { B. rogersi }\end{array}$ & B. striatus & $\begin{array}{l}\text { A. striata (including } \\
\text { virescens and sundevalli) }\end{array}$ \\
\hline B. virescens & B. virescens & $\longrightarrow$ \\
\hline B. sundevelli & B. sundevalli & $\overline{-}$ \\
\hline Agamia agami & Agamia agami & Agamia agami \\
\hline Nyctanassa violacea & Nyticorax violaceus & Nyctanassa violacea \\
\hline Nycticorax nycticorax & N. nycticorax & Nycticorax nycticorax \\
\hline
\end{tabular}




$$
\text { Peters, } 1931^{b}
$$

Table 1, Continued

N. caledonicus
Calherodius leuconotus
Oroanassa magnifica
Gorsachius goisagi
G. melanolophus
Cochlearius cochlearius
Heterocnus cabanisi
Tigrisoma (lineatum ?)
fasciatum
T. salmoni
T. lineatum (lineatum,
$\quad$ marmoratum), T.
$\quad$ (lineatum?) bolivianum

Zonerodius heliosylus

Tigriornis leucolopha

Zebrilus undulatus

Ixobrychus involucris

I. exilis

I. minutus

I. sinensis

I. eurhythmus

I. cinnamomeus

I. sturmii

Dupetor flavicollis

Botaurus pinnatus

B. lentiginosus

B. stellaris

B. poiciloptilus
N. caledonicus

Gorsachius leuconotus

G. magnificus

G. goisagi

G. melanolophus

Cochlearius cochlearius

Tigrisoma mexicanum

$\mathrm{T}$. lineatum fasciatum (after Peters, and Hellmayr and Conover)

T. salmoni

T. lineatum (after Peters, and Hellmayr and Conover)

Zonerodius heliosylus

Tigriornis leucolophus

Zebrilus undulatus

Ixobrychus involucris

I. exilis

I. minutus

I. sinensis

I. eurhythmus

I. cinnamomeus

I. sturmii

I. flavicollis

Botaurus pinnatus

B. lentiginosus

B. stellaris

B. poiciloptilus

This Study $d$

\author{
N. caledonicus \\ $\mathrm{N}$. leuconotus \\ N. magnificus \\ $\mathrm{N}$. goisagi \\ N. melanolophus \\ Cochlearius cochlearius \\ Tigrisoma mexicanum \\ T. fasciatum (including \\ salmoni)
}

T. lineatum

Zonerodius heliosylus

Tigriornis leucolophus

Zebrilus undulatus

Ixobrychus involucris

I. exilis

I. minutus

I. sinensis

I. eurhythmus

I. cinnamomeus

I. sturmii

I. flavicollis

Botaurus pinnatus

B. lentiginosus

B. stellaris

B. poiciloptilus

$a_{\text {Names in parentheses are recognized as subgenera. }}$

$b_{\text {Totals: }} 30$ genera and 2 subgenera or, 67 species (excluding questionable species listed in parentheses).

${ }^{c}$ Totals: 15 genera, 64 species.

$d_{\text {Totals: }} 15$ genera, 62 species.

Adams, and R. L. Zusi allowed us to read the unpublished thesis of C. J. LaRue. Janet Hinshaw and Pat Theiler helped type the manuscript. The skeletal illustrations were drawn by Patricia J. Wynne, the graphs by Mark Orsen and Lana Tackett. The work was supported in part by the F. M. Chapman Memorial Fund of the American Museum of Natural History. Computer funds were provided by the Museum of Zoology, the University of Michigan (UMMZ). 


\section{SELECTION OF SKELETAL CHARACTERS}

Characters that have been used in the systematic classifications include features of the plumage, skeleton, myology, distribution, and behavior of birds. The present study is based on skeletal comparisons for two main reasons. First, differences in bone elements are codable and can be treated as independent characters. Bones are functionally correlated with each other and with the functional aspects of the muscle attachments, and we were able to see to what extent any functional correlation among the skeletal elements might affect the systematic groupings of the species by comparing the numerical importance of the various elements in the principal components analysis. As discussed later, the species groupings found in the study are largely independent of any disproportionate weighting of intercorrelated characters. Second, an interest in estimating the phylogenetic relationships among the herons led us to select characters whose states could be matched with those of the other Ciconiiformes and for which the primitive character states could be determined. We were able to find apparently similar skeletal character states in the skeletons of herons and of other Ciconiiformes and thereby to estimate the primitive character states. We were unable to find as many corresponding character states in the other orders of birds that were examined (Anseriformes, Falconiformes-including Cathartidae, Gruiformes, and Pelicaniformes).

In contrast our initial inspection of the display feathers and plumage patterns used by Bock (1956) as the main characters in his heron revision showed us that we could not match the character states of the herons with those of the other Ciconiiformes, so these were not useful in estimating the early evolutionary branching pattern of the herons, although they were useful in comparing certain closely related species. Plumage is probably of limited value in reconstructing estimates of remote evolutionary history because it is so often associated with species recognition signals and sexual selection and so has diverged rapidly among even closely related species. Conspicuous plumage differences among closely related species of ducks, manakins, and the birds of paradise and bower birds have caused systematists to argue for the use of other morphological features and of behavioral characters in estimating their evolutionary relationships (Bock, 1963; D. W. Snow, 1975). Herons display the feathers in courtship (e.g. Meyerriecks, 1960,1962a), when male-male threats and female-male mate selection occur. We note that several different species groups of herons have long, white crest feathers-some tiger herons, some day herons, and some night herons-and it appears impossible to support the assertion of uniquely derived homologies in such instances. Although it would have been helpful to include number and size of certain muscles as taxonomic characters as well as functional correlates of the skeletal features that were studied, only very limited data 
were available on heron muscles. Similarly the number of species that have had their display behavior studied in detail is limited and some major groups of herons have not been studied at all. We have used little distributional information in reconstructing estimates of past evolutionary history because herons are powerful flying birds that have long-distance migrations and have dispersed and expanded their ranges hundreds or thousands of miles in the past century in some species, particularly in the Cattle Egret Egretta ibis. These nonskeleton characteristics of herons are discussed later to test various conclusions of heron relationships that are derived from the skeletal data.

\section{METHODS AND MATERIALS}

Skeletons of herons were assembled, and the search for qualitative character differences was begun by comparing a bone of one species, our basic unit of comparison, with the corresponding bone of each of the other species. This process was repeated for each bone. At first the characters reported to vary by Shufeldt (1901) and Cracraft $(1967,1968)$ were examined; later all the bones except the phalanges were compared. Comparisons of bones showed a number of different characters that appeared to vary in a continuous manner from species to species and other characters that varied in a discontinuous manner. The discontinuously varying characters were selected for numerical taxonomic analysis in our comparison. In instances where species were intermediate in a skeletal character between two distinct character states, the characters either were assigned intermediate states or were assigned to one of the two original states according to their distinctiveness. We disregarded variation in lengths or proportions of different bones (e.g. relative length of the humerus to the synsacrum) because (a) bone lengths and their ratios vary in a continuous, not a discontinuous, manner, and (b) lengths and ratios are often correlated with body size (Schnell, 1970), hence are not good independent indicators of ancestral affinities of the species. After the study was completed we found that Adams (1956) had made a study of most of the species of herons and had described ratios of bones in detail. Adams also used several qualitative character states, and he based his systematic conclusions about relationships on these differences rather than on the ratio data. Nine of the 11 characters described by Adams as varying in a discontinuous, qualitative manner we also had independently so described, and this agreement between studies supports the validity of the distinctiveness of the character states.

Where available, several specimens of a species were examined to check the skeletal characters so that we could avoid characters with considerable intraspecific variation due to age, sex, or other factors 
and characters with variation due to differences in specimen preparation (e.g. maceration $v s$. beetle-cleaned specimens).

The emphasis in the present study on estimating the phylogenetic relationships led us to search particularly for character states that were shared by a number of species rather than for character states unique to a single species or two. If we had attempted to evaluate the distinctiveness of each species we would have included a more detailed description of each unique combination of character states of species such as Cochlearius cochlearius, where shapes of the quadrate, palatines, pterygoids, and several other bones of the skull as well as the broad axis were correlated with the specialized, broad bill of this species.

Complete skeletons were not available for several species of herons. For some of these we used incomplete (e.g. trunk) skeletons. For others we partially dissected the head of a study skin by wetting the skin in water and cutting a flap in the skin to reveal the lacrimal-ectethmoid-orbital region. Several characters were visible in these incomplete specimens.

Fossil herons were not examined in the study. The fossil history of herons has been traced back to the Eocene (Brodkorb, 1963). At least 20 fossil species in 12 genera have been described, including 10 extinct genera and two recent genera (Ardea and Nycticorax) (Brodkorb, 1963; Brunet, 1970; Moseley and Feduccia, 1975). In addition, several recent species have been identified in Pleistocene and prehistoric sites, all of them records within the present ranges of these species except for a reported identification (humerus) of Egretta intermedia from Madagascar (Andrews, 1897; Brodkorb, 1963). Identification of fossils is generally based on comparison of one bone or part of a bone with the corresponding elements of neospecies. None of the pre-Pleistocene fossil herons is known from more than a single bone. The incomplete nature of the fossil specimens identified as herons prevented our including these in the quantitative comparison of the skeletons of the living species of herons. We may note that fossils attributed to the modern genus Ardea are known from the Upper Miocene and to Nycticorax from the Lower Pliocene.

Anatomical names follow mainly the terms of Howard (1929), Newton (1896), Bock (1963), and Bock and McEvey (1969), although in a few instances we have applied descriptive names of our own.

\section{THE SKELETAL CHARACTERS OF HERONS}

In the following section we discuss the variation in the skeleton of herons mainly in those characters that vary in a discontinuous manner. Examples of the character states are illustrated, as are several other skeletal features that vary continuously. The character states 
used in comparing the herons are described and arranged below under the bone on which they occur. Numbers $(0,1$, etc.) listed after each character refer to the different character states recognized. The numbers used here are arbitrary and do not imply primitive or derived conditions. Later analysis of the characters determined the likely derivation of the character states.

\section{Skull}

The skulls and components of the cranial morphology of representative herons are illustrated in Figures 1-10. Most herons have a long bill; this varies in shape from the slender needle-like bill of Agamia agami through spears of the large Ardea day herons and the deeper bills of Nycticorax nycticorax to the rather broad bill of Nyctanassa violacea. The most distinctive one is the Boat-billed Heron Cochlearius cochlearius, which has a broad scoop-like bill with shallow grooves on the ventral surface. Except for Cochlearius the shape of the bill varies but slightly from one heron species to another, and only one pair of character states was recognized.

CHARACTER 1: Bill shape. 0- slender and narrow (Figs. 1,2, 3A-B, 9A-E). 1- deep and broad (Figs. 3D, 9F).

The shape of the palatines varies considerably in herons. Three distinct characters were recognized. The breadth of the palatines is generally related to bill width in the herons but this is remarkably distinctive only in Cochlearius. The shape of the posterior portion of the palatines varied in the relative length of the lateral and medial projections (the transpalatine process and the mediopalatine process, respectively, of Bock, 1963), and in the emargination of the posterior palatine margin between them. This shape was generally very similar in closely related herons, e.g. in members of a single superspecies, but varied considerably within a group of related genera (Figs. 9, 10). Another variation noted in the palatines of herons is the amount of fusion of the posterior part of the ventromedial shelf, and this was

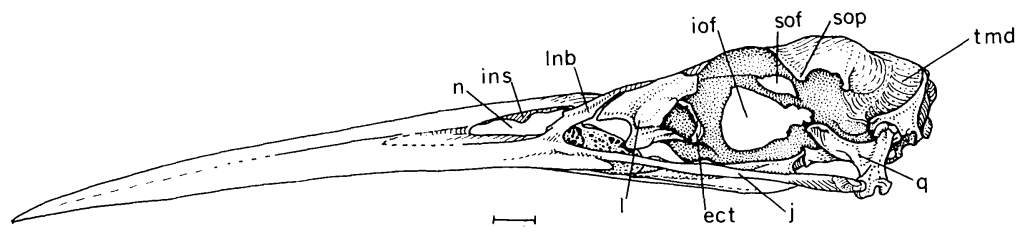

Fig. 1. Skull of Ardea herodias, lateral view. Symbols: ect-ectethmoid, lateral (main) projection; ins-internasal septum (incomplete); iof-interorbital foramen; $j$-jugal; l-lacrimal; lnb-lateral nasal bar; $n$-nostril; q-quadrate; sofsupraorbital foramen; sop-supraorbital process; tmd-temporal muscle depression. The scale line is $10 \mathrm{~mm}$. 

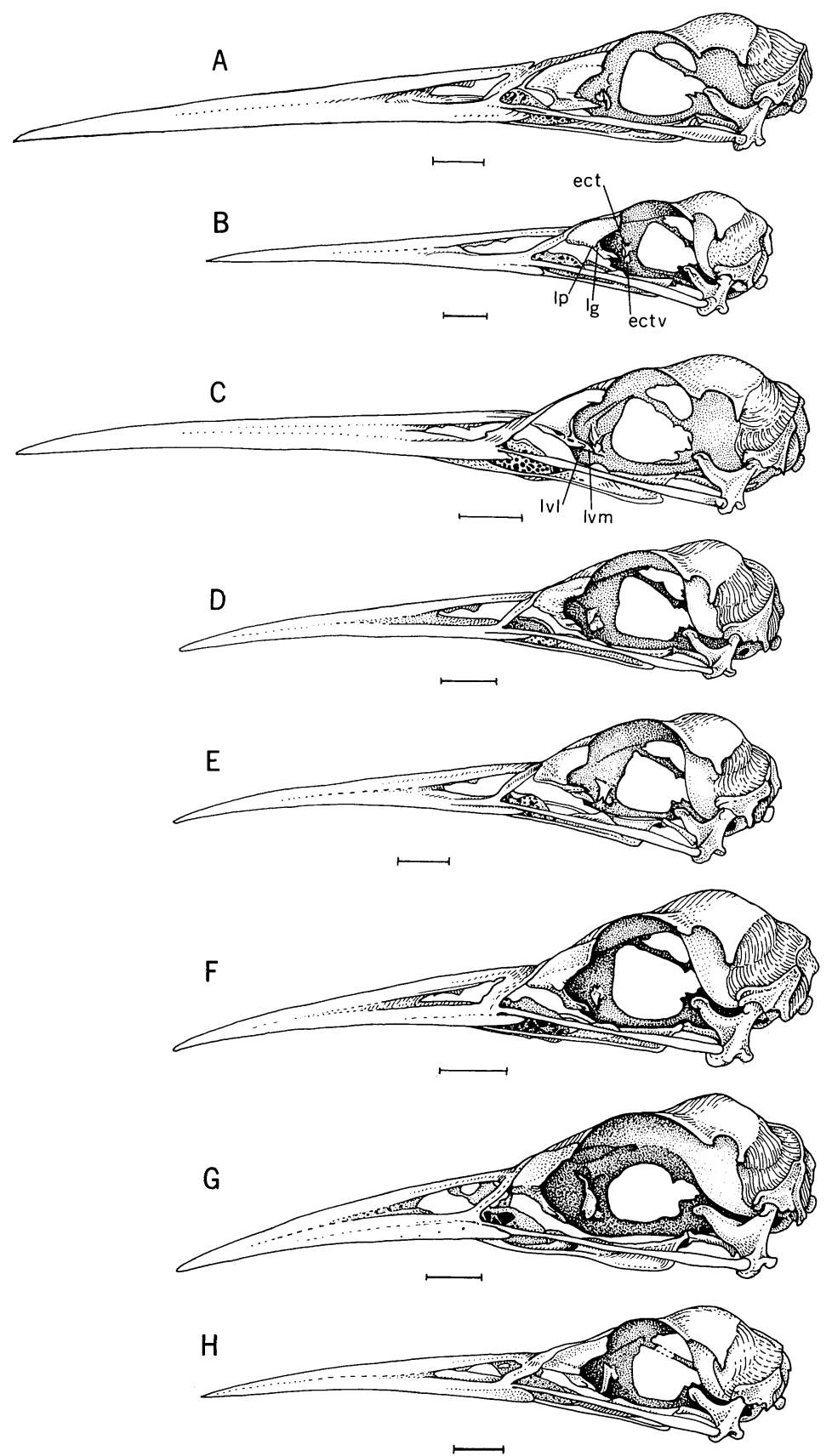

Fig. 2. Lateral view of the skull of eight species of Ardeinae. A.) Ardea alba; B.) Egretta garzetta; C.) E. thula; D.) E. caerulea; E.) E. novaehollandiae; F.) E. ibis; G.) Syrigma sibilatrix; H.) Ardea ralloides. Symbols: ectectethmoid, lateral projection; ectv-ventral ectethmoid tubercle; lg-lateral groove of lacrimal; lp-lacrimal projection dorsal to groove; lvl-ventrolateral projection of lacrimal; lvm-ventromedial projection of lacrimal. The scale lines are $10 \mathrm{~mm}$. 

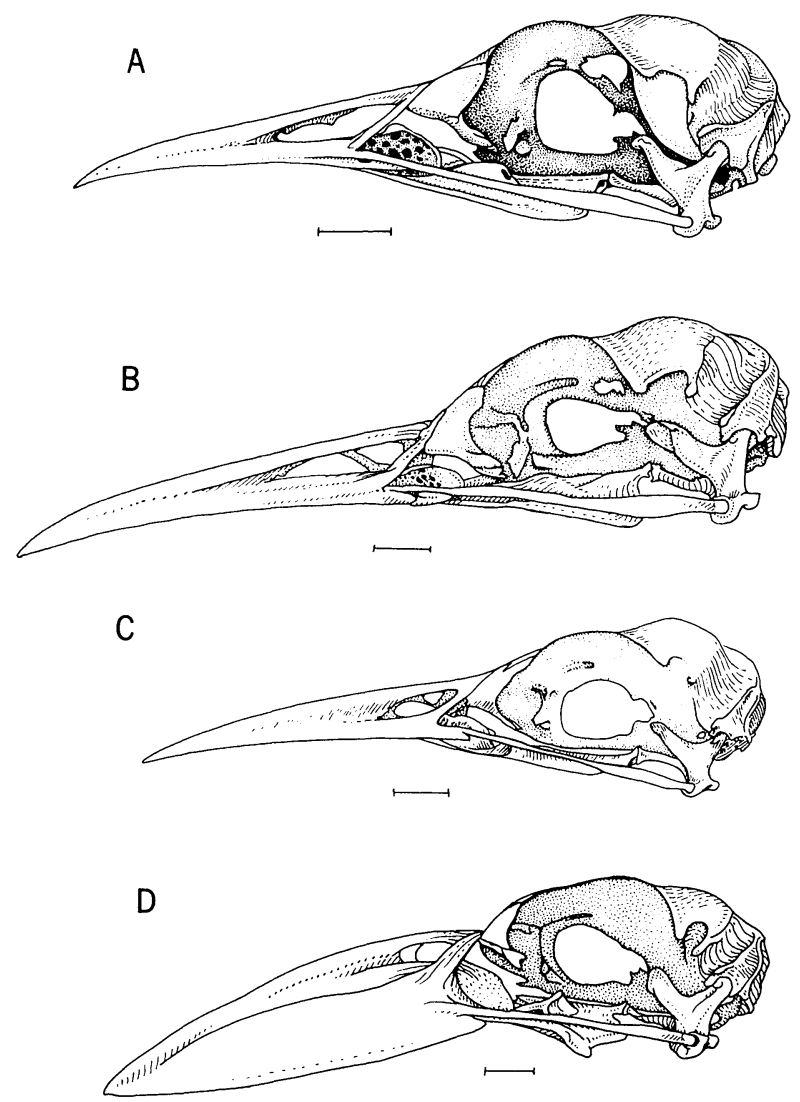

Fig. 3. Lateral view of the skull of four night herons. A.) Nycticorax melanolophus; B.) Nycticorax nycticorax; C.) Nyctanassa violacea; D.) Cochlearius cochlearius. The scales are $10 \mathrm{~mm}$.

originally coded, but as this fusion was variable within some species it was excluded from later analysis.

CHARACTER 2. Palatine shape. 0- narrow (Fig. 9A-E). 1-broad (Fig. 9F).

CHARACTER 3. Emargination of posterior palatine. 0- notched or U-shaped (Fig. 9A). 1-slightly concave but concavity not extending anterior to lateral process of palatine (Fig. 9A). 2- straight, nearly perpendicular to long axis of skull. 3-straight, forms acute angle with long axis of skull (Fig. 9F).

CHARACTER 4. Lateral process of palatine. 0-lateral process extends further posteriorly than medioventral process. 1-lateral process extends no further posteriorly than medioventral process.

Some variation was found in the shape of the quadrate but this was extreme only in Cochlearius and appeared to be a highly derived character state in that genus. The position of a small pneumatic 


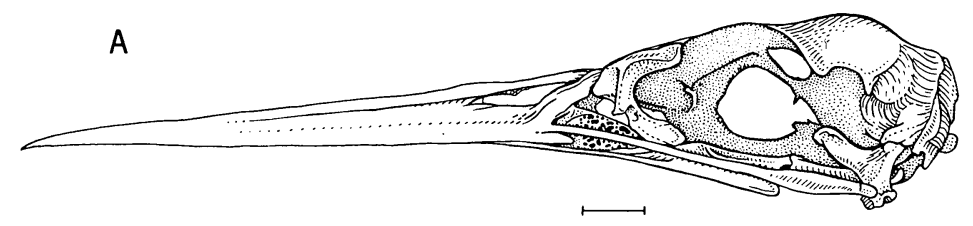

B
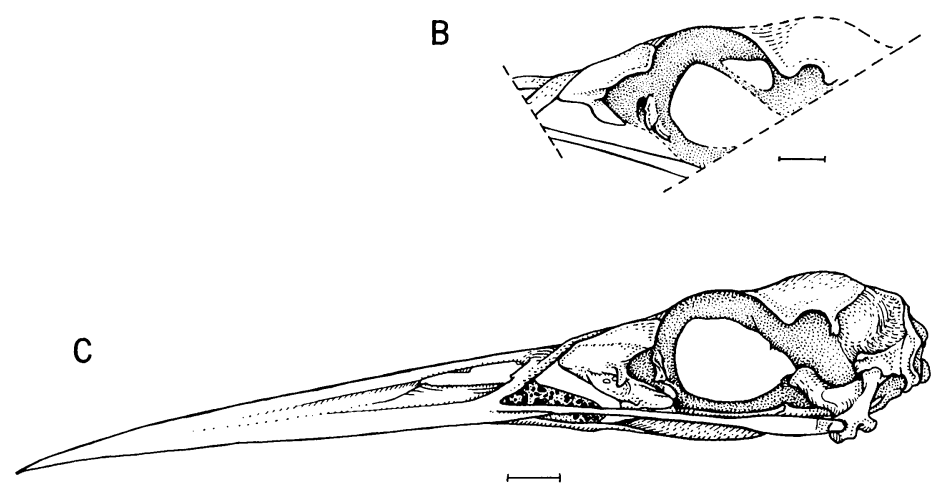

Fig. 4. Lateral view of the skull of three tiger herons. A.) Tigriornis leucolophus; B.) Zonerodius heliosylus (partial specimen only); C.) Tigrisoma mexicanum. The scale lines are $10 \mathrm{~mm}$.

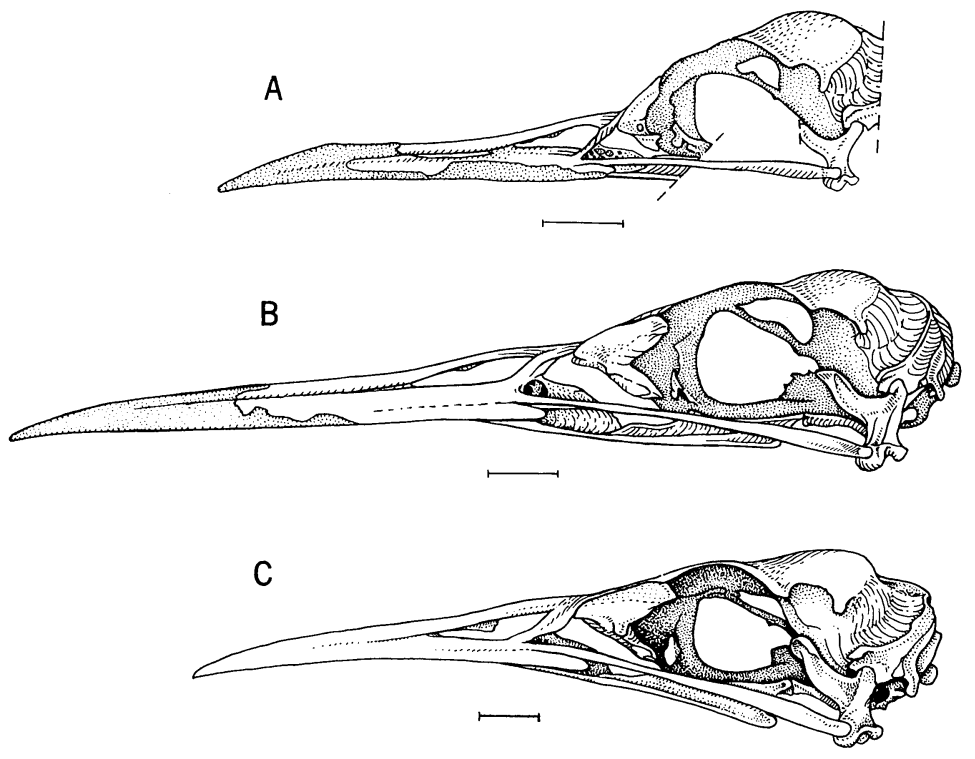

Fig. 5. Lateral view of the skull of three bitterns. A.) Zebrilus undulatus; B.) Botaurus lentiginosus; C.) Botaurus poiciloptilus. The scale lines are $10 \mathrm{~mm}$. 
A
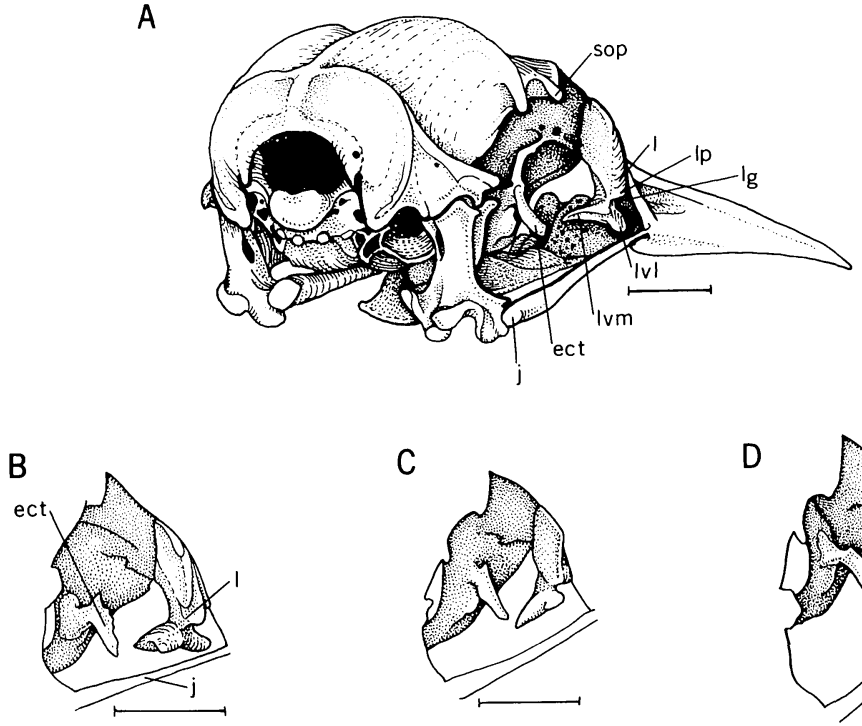

C

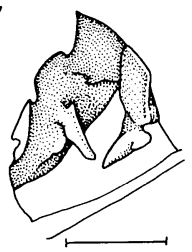

D

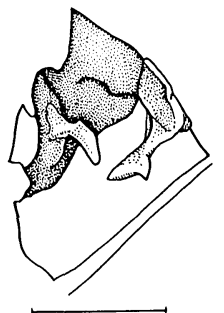

$\mathrm{E}$

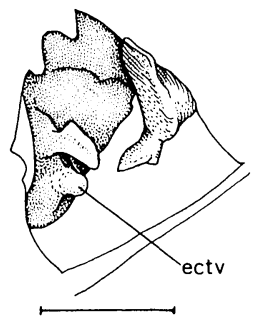

$\mathrm{F}$

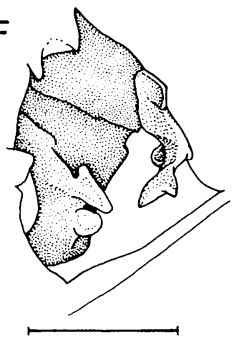

G

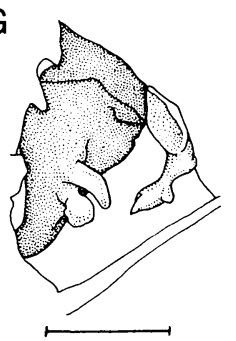

H

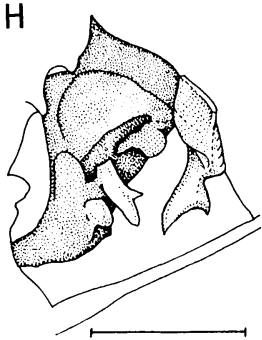

Fig. 6. Oblique view $\left(20^{\circ}\right.$ from posterior) of the skull of several day herons showing variation in the ectethmoid-lacrimal complex. The cut-away view exposes the anterior orbital region viewed from behind. A.) Ardea herodias; B.) A. alba; C.) Ardeola ralloides; D.) Egretta ibis; E.) E. garzetta; F.) E. thula; G.) E. caerulea; H.) E. novaehollandiae. Symbols: j-jugal; sop-supraorbital process; ect-ectethmoid lateral (main) projection; ectv-ventral ectethmoid tubercle; 1-lacrimal; lg-lateral groove of lacrimal; lp-lacrimal projection dorsal to groove; lvm-ventromedial projection of lacrimal; lvl-ventrolateral projection of lacrimal. Scale lines $=10 \mathrm{~mm}$ relative only to the lacrimal.

foramen in the quadrate varied, particularly among the night herons, but was impossible to code because many species had the hole in an intermediate position.

The shape of the interorbital foramen varied from species to species within several groups. The main feature differentiating shape in the interorbital foramen was the curvature of the anterior margin. CHARACTER 5. Interorbital foramen. 0- anteriormost projection of foramen near ventral surface (Fig. 1). 1-anteriormost projection 
near equator of foramen (Fig. 5B, C). 2-anteriormost projection near dorsal surface (Fig. 3A-C). 3-same as in 2, but foramen small (Fig. 2G).

CHARACTER 6. Supraorbital (or intraorbital) foramen. 0- large (Fig. 1). 1- small (Fig. 3B). 2- absent (Fig. 3C).

The bones located anterior to the eye in the skull varied in several ways, such as flexibility and stoutness of nasal hinge, that appeared to be uncodable because of intermediate species and variation within a single species, perhaps because of differences in age or in specimen preparation. An example is the nasal septum, a character used to separate Ardea from Egretta species by Adams (1956). The bones in the lacrimal and ectethmoid complex were different in several groups and appeared to separate several species or groups of species from each other; five characters were found to be distinctive in this area. The lacrimals were noted by Cracraft (1968) to vary, though we found some discrepancies between his descriptions and the series of specimens available to us. Adams (1956) remarked on the variation in heron ectethmoids, and Bock (1956) suggested that the larger species may have large ectethmoids, though we found no such tendency in our survey.

CHARACTER 7. Size of lacrimal. 0- small, extends less than halfway from roof of skull to jugal (Fig. 3D). 1-medium, extends more than halfway to jugal (Fig. 1A). 2- large, extends to jugal and articulates with it; jugal grooved to accommodate lateral process of lacrimal (Fig. 4A).

CHARACTER 8. Ventral projection of lacrimal. 0- none, lacrimal simply lobate ventrally. 1 - slight ridge projects laterally from end of ventral projection (Fig. 6A, B). 2- bifurcate with subequal ventromedial and ventrolateral projections (Figs. 6D, 7A). 3bifurcate with lateral projections greatly enlarged, in some species articulating with jugal (Fig. 8D, E).

CHARACTER 9. Lateral groove of lacrimal. 0- no lateral projection overhanging groove on lateral aspect of lacrimal (Figs. 6D, E, F, $\mathrm{H}, 8 \mathrm{~A}-\mathrm{C}$ ). 1- small lateral process dorsal to groove (Fig. 6A, B). 2- prominent lateral process dorsal to groove (Fig. 8D).

CHARACTER 10. Lateral ectethmoid process. 0-absent (Fig. 7D). 1 - present (Fig. 6A). Note: size and shape varied considerably as described by Adams (1956). We note here that the size and shape are similar among many species that appear to be closely related (e.g. at the superspecies level).

CHARACTER 11. Rounded or pointed tubercle ventral to main lateral ectethmoid. 0-absent (Fig. 6B, D, 7A, C). 1-small tubercle (Fig. 6A, C). 2- large tubercle (Fig. 6F, G, 7B).

CHARACTER 12. Ridge below main lateral ectethmoid (may be homolog of character 11). 0- absent (Fig. 6A, B, D, 7B, 8A). 1- present (Fig. 7C, 8B). 
A
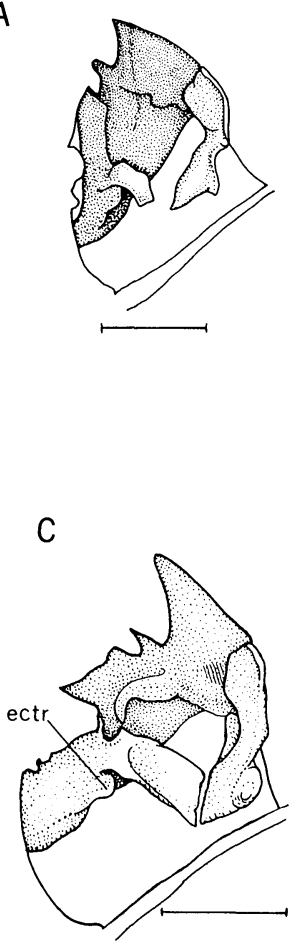

B
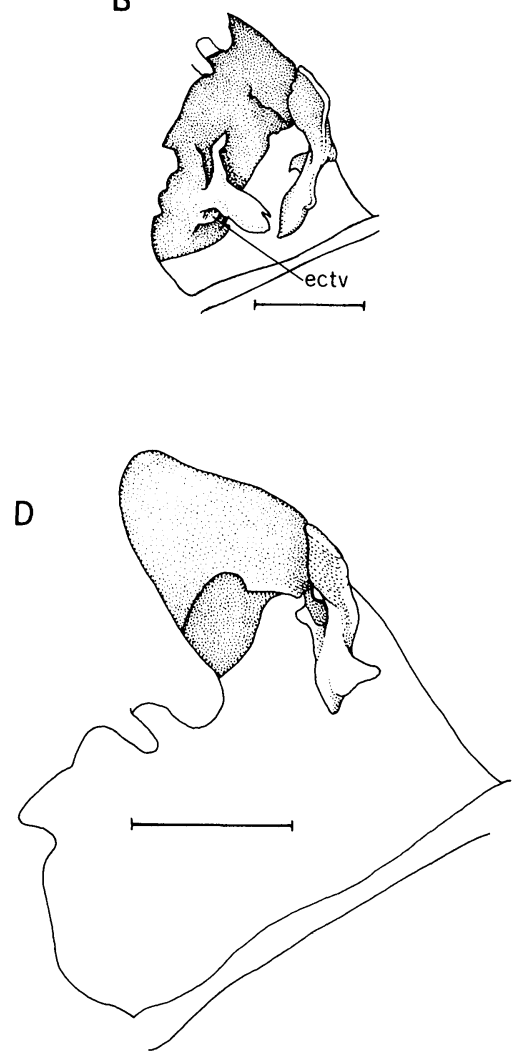

Fig. 7. Oblique view $\left(20^{\circ}\right.$ from posterior) of the lacrimal-ectethmoid region of four night herons. A.) Nycticorax melanolophus; B.) Nyctanassa violacea; C.) Nycticorax nycticorax; D.) Cochlearius cochlearius. Symbols: ectr-ventral ectethmoid ridge; ectv-ventral ectethmoid tubercle. Scale line $=10 \mathrm{~mm}$. relative only to the lacrimal.

Herons vary considerably in the depth of the temporal muscle depression, and an attempt was made to code variation in terms of the prominence of the ridge on the dorsal midline when the depression approached each other from the two sides. However, we found considerable variation within single species (e.g. Ardea herodias) and we were reluctant to code the variation for species when we had only a single specimen.

The ridges around the foramen magnum varied somewhat, but the only strongly differentiating character we found associated with the braincase was the presence of pronounced ventrolateral flanges at the lateroposterior edge of the basitemporal plate. Preliminary dissection by R. I. Orenstein of the head of a specimen of Nycticorax nycticorax indicates that the flange is also a site of attachment of a bicipital band of fibrous connective tissue attaching to the medial 
A

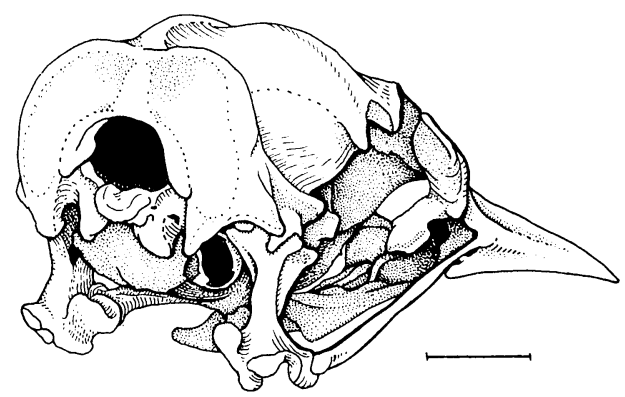

B

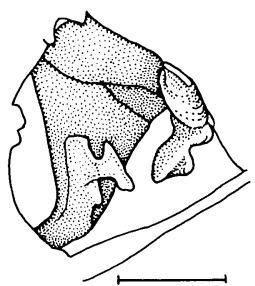

C

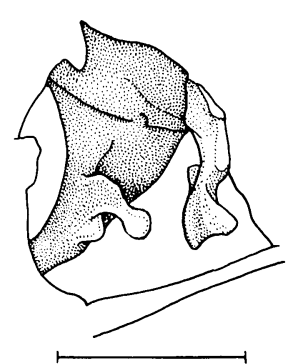

D

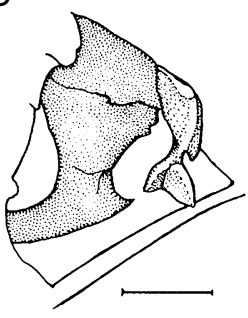

$E$

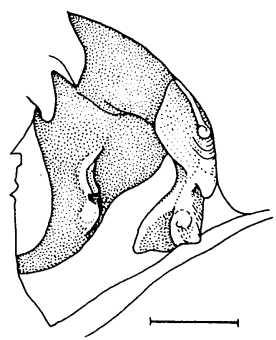

Fig. 8. Oblique view $\left(20^{\circ}\right.$ from posterior $)$ of the lacrimal-ectethmoid complex of several tiger herons and bitterns. A.) Botaurus poiciloptilus; B.) Botaurus lentiginosus; C.) Zebrilus undulatus; D.) Tigriornis leucolophus;

E.) Tigrisoma mexicanum. Scale line $=10 \mathrm{~mm}$. relative only to the lacrimal.

posterior edge of the mandible. The structure appears to correspond to the "medial brace" of Bock (1960), who described its prominence in certain night herons. Unlike Bock, we find its variation unrelated to bill width among the species of night herons; it is prominent in Cochlearius, but it is as prominent in the slender-billed N. melanolophus as in $N$. nycticorax, where it is more pronounced than in the broader-billed Nyctanassa violacea. It is poorly developed in all herons other than the night herons, in spite of the variation among bill shape in this group. We regard the character as potentially useful as an indicator of phylogeny because its form varies discontinuously and because there is no obvious correlation of the ridge development with simple bill morphology.

CHARACTER 13. Basitemporal ridge. 0-prominent (Fig. 10B). 1 - absent to small (Fig. 10A).

\section{Vertebrae}

The cervical vertebrae of herons vary in a distinctive manner more obviously than do the other vertebrae. Examples are shown in 

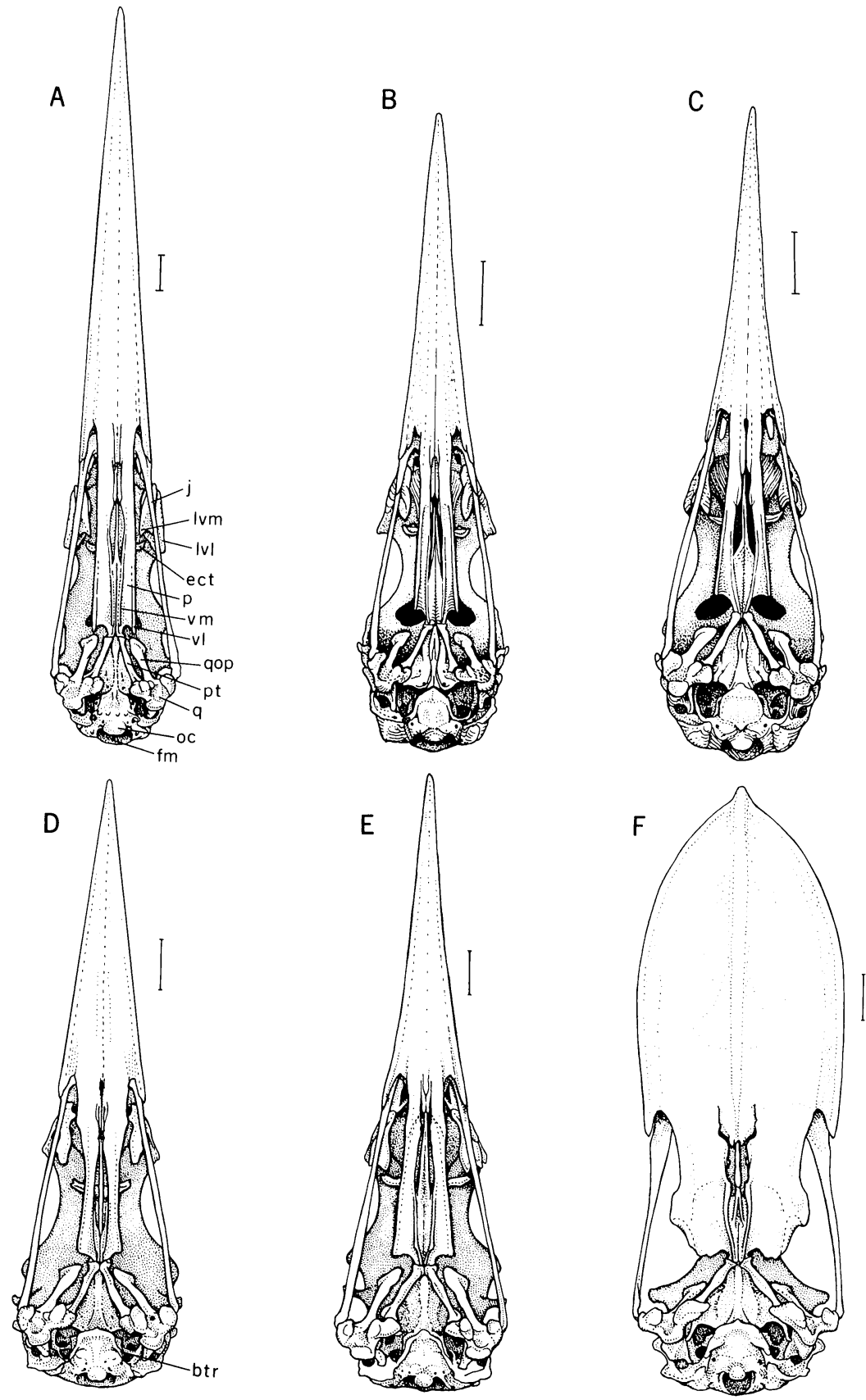

Fig. 9. Ventral views of the skulls of herons. A.) Ardea herodias; B.) Ardeola striata virescens; C.) Syrigma sibilatrix; D.) Nyctanassa violacea; E.) Nycticorax nycticorax; F.) Cochlearius cochlearius. Symbols: btrbasitemporal ridge; ect-ectethmoid, lateral process; fm-foramen magnum; $\mathrm{j}$-jugal; lvl-ventrolateral projection of lacrimal; lvm-ventromedial projection of lacrimal; oc-occipital condyle; $\mathrm{p}$-palatine; vm-medial posterior process of palatine; vl-lateral posterior process of palatine; pt-pterygoid; q-quadrate; qoporbital process of quadrate. Scale lines are $10 \mathrm{~mm}$. 
A

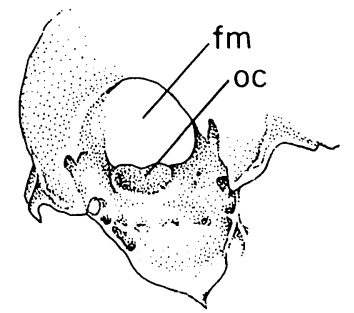

B

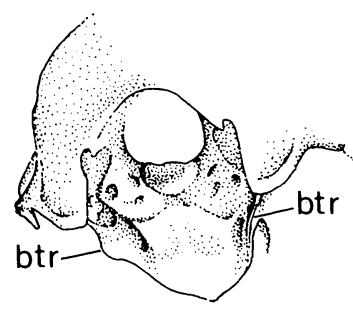

Fig. 10. Lateral basitemporal ridge, oblique view of right ventral posterior aspect of skull. A.) Ardea herodias; B.) Nycticorax nycticorax. Symbols: btrbasitemporal ridge; fm-foramen magnum; oc-occipital condyle. The scale line is $10 \mathrm{~mm}$.

Figures 11, 12 and 13. The cervical vertebrae are long and slender and the articular facets differ among the species, resulting in different minimal angles of flexion between corresponding vertebrae in different herons. The kink of heron necks is due to this morphological specialization for a spearing mechanism (Král, 1965). We were reluctant to seek large numbers of characters in this complex inasmuch as they would probably be functionally interrelated and also highly specialized for the feeding ecology of each species, and most of the characters, such as articular angles, we found to vary in a continuous manner across the species of herons.

The shape of the axis varies considerably among herons (Figs. $11,12)$, though not in all of the details illustrated by Humphrey and Parkes (1963), whose specimen of Syrigma was apparently broken. The axis was usually similar in form among closely related species.

CHARACTER 14. Axis. 0-narrow, postzygapophyses separated by notch (Figs. 11-12A, B). 1-intermediate, postzygapophyses separated by notch (Figs. 11-12D, E, F). 2-broad, postzygapophyses separated by broad arc behind (Figs. 11-12H, I, J).

The posteriormost cervical vertebra with a lateral vertebral canal formed by an ossified strut joining the transverse process (hyperpophysis) and the ventrolateral hypopophysis is either vertebra 16 or 17 in the herons. Often this same vertebra was the most posterior vertebra with an unfused neural spine (V- or Y-shaped, not I-shaped as in the thoracic vertebrae) and the most posterior one with no articulating elongated bicipital rib. Two of these characteristics were used, and in coding the character we found variation between the left and right sides of specimens of Egretta ibis and E. caerulea.

CHARACTER 15. Cervical vertebra, number of posteriormost with lateral vertebral canal. In some species (Egretta caerulea, E. sacra, E. ibis, Syrigma sibilatrix) the canal is incompletely formed by the partial ossification of the lateral strut with the 

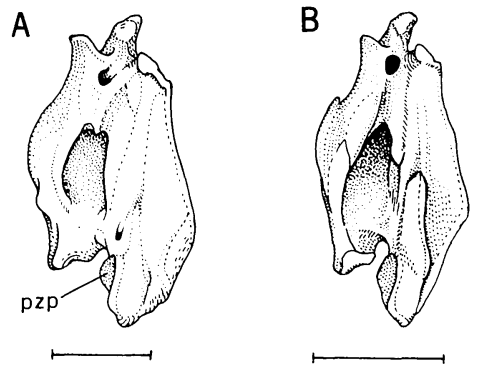

C

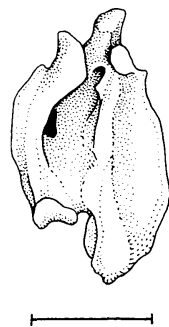

D

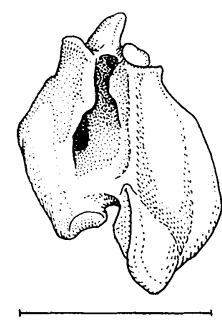

$\mathrm{E}$

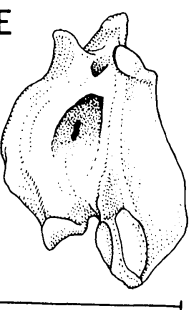

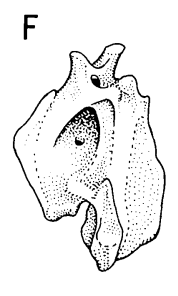
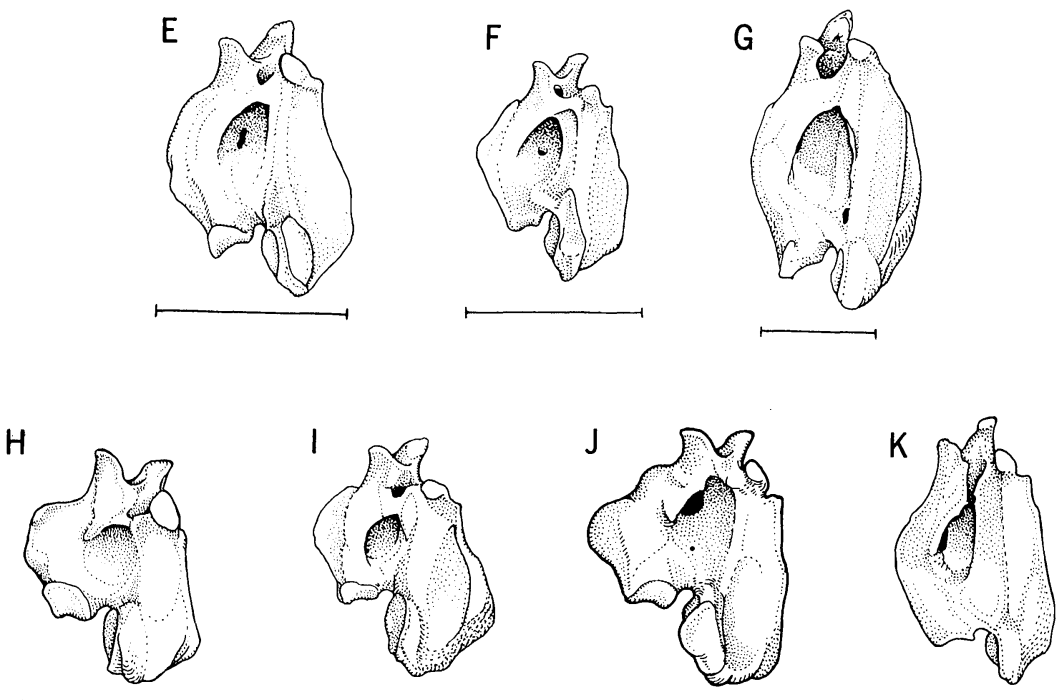

Fig. 11. Axis vertebra, lateral view. A.) Ardea herodias; B.) Ardea alba; C.) Egretta rufescens; D.) Pilherodius pileatus; E.) Syrigma sibilatrix; F.) Egretta ibis; G.) Tigrisoma mexicanum; H.) Nyctanassa violacea; I.) Nycticorax nycticorax; J.) Cochlearius cochlearius; K.) Botaurus lentiginosus. Symbols: pzp-postzygapophyses. The scale lines are $10 \mathrm{~mm}$.

lateral and ventral sites of attachment of the vertebra, but the strut differs from the bicipital rib by lacking a ventral process. The character state of these species was coded as having a lateral vertebral canal. 0- vertebra 16 (Fig. 13B, D) 1-vertebra 17 (Fig. $13 \mathrm{~A}, \mathrm{C})$.

CHARACTER 16. Cervical vertebra, number of posteriormost with no facets for bicipital rib. 0-vertebra 16 (Fig. 13B). 1-vertebra 17 (Fig. 13A, C, D).

\section{Pectoral Assemblage}

Aspects of the pectoral assemblage of herons are shown in Figures 14-18. The sternum appears to be more consistent among the 

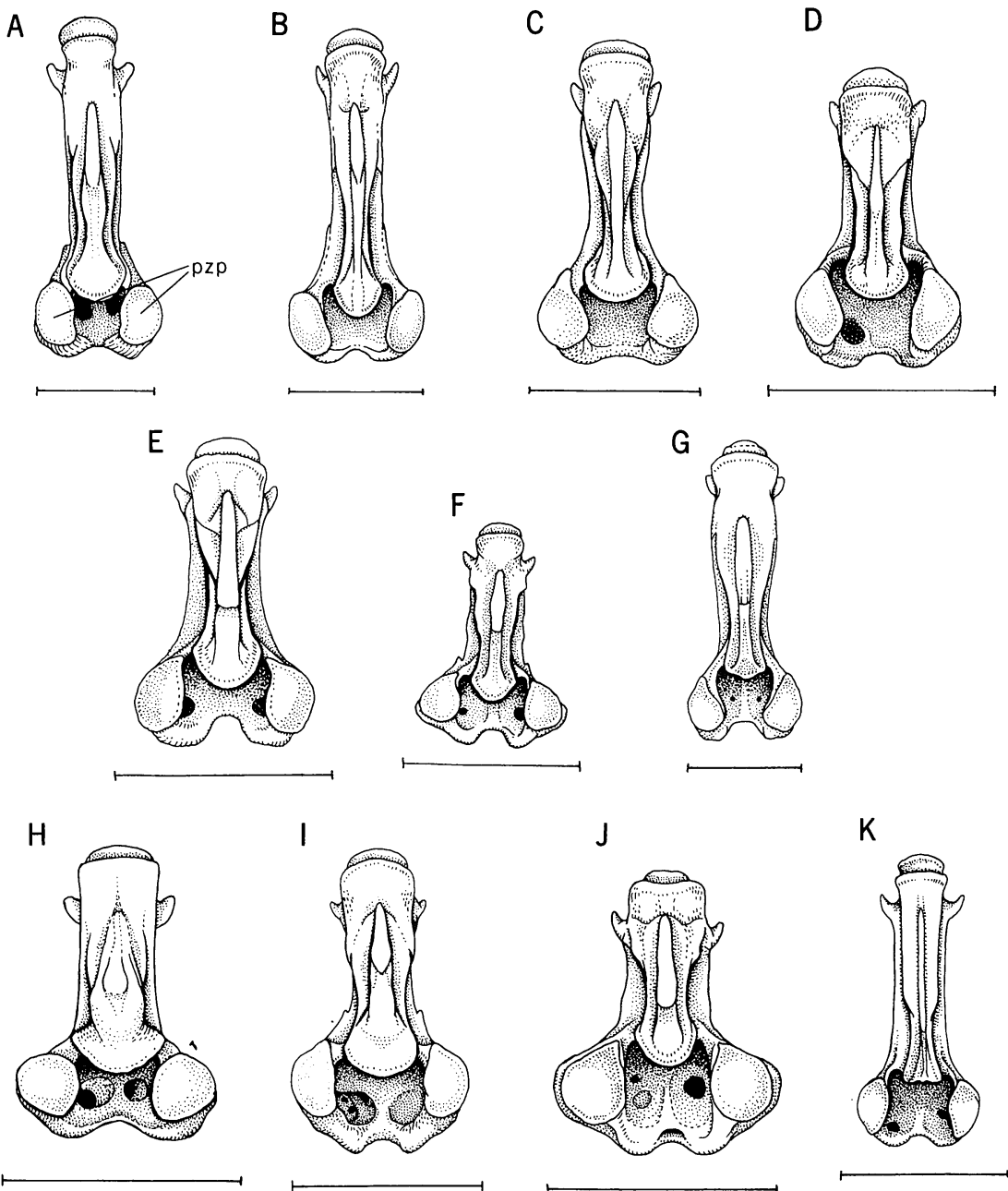

Fig. 12. Axis vertebra, ventral view. A.) Ardea herodias; B.) Ardea alba; C.) Egretta rufescens; D.) Pilherodius pileatus; E.) Syrigma sibilatrix; F.) Egretta ibis; G.) Tigrisoma mexicanum; H.) Nyctanassa violacea; I.) Nycticorax nycticorax; J.) Cochlearius cochlearius; K.) Botaurus lentiginosus. Symbols: pzppostzygapophyses. The scale lines are $10 \mathrm{~mm}$.

species of herons than in some other families of birds such as the shorebirds (Figs. 14, 15). The African Tiger Heron Tigriornis leucolophus has a deeply notched sternum, unlike the sternum of any other heron species examined (a skeleton of the New Guinea Tiger Heron Zonerodius heliosylus was not available). It also has a suggestion of a second pair of notches medial to the deep lateral pair, though the specimen may have been immature and hence incompletely ossified in this region. No variation was found in the overlapping coracoidial sulci, and all herons had the left sulcus crossing dorsal to the right 
A

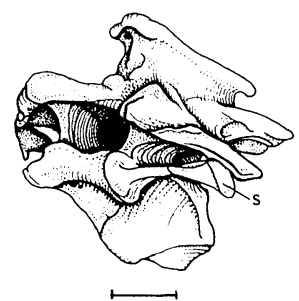

B

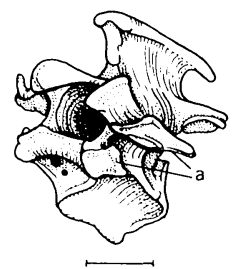

C

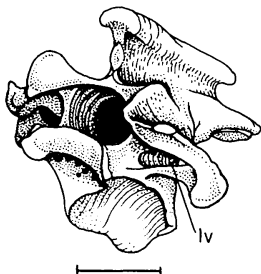

D

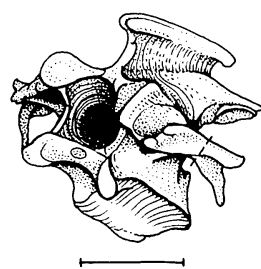

Fig. 13. Variation in cervical vertebra 17. The view is oblique from the anterioventrolateral. Note the persistence of the lateral canal in Ardea and Pilherodius and its absence in Nycticorax and Syrigma. Also note the articular surfaces for the heads of the free cervical rib attachment in Nycticorax. A.) Ardea herodias; B.) Nycticorax nycticorax; C.) Pilherodius pileatus; D.) Syrigma sibilatrix. Symbols: a-articular surfaces; lv-lateral vertebral canal; $\mathrm{s}-$ ossified strut. The scale lines are $10 \mathrm{~mm}$.

sulcus. Variation such as that noted for some fossil herons (Ligon, 1965) in the shape of the lip of the sulcus or the depth of the sulcus was barely perceptible, and the sternum of most species was intermediate in shape. The shape and depth of the keel did not vary in a discontinuous manner. The sternocoracoidial process varied in shape. The ventral manubrium varied in length and in the shape (pointed, flat, rounded), but shapes varied among individuals of some species and we were unable to code the manubrial shape in a consistent manner.

CHARACTER 17. Depth of sternal notches. 0-shallow, sternum emarginate for less than half the lateral distance across the posterior lateral processes (Figs. 14 and 15A, B, C, E, F, G). 1-deep, nearly as extensive as the distance across the posterior lateral processes (Figs. 14D, 15D).

CHARACTER 18. Ventral manubrial process. 0-short (Figs. 14F, 15F). 1-intermediate (Figs. 14 and 15A, C, D, E, G). 2-long (Figs. 14B, 15B).

CHARACTER 19. Stemocoracoidial process of sternum. 0-angle of process directed upwards or back, with anterior slope at least as long as posterior slope (Fig. 14A). 1-angle directed forwards, with anterior slope shorter than posterior slope (Fig. 14B-G).

The coracoid of herons has been described as slender and tapering in Botaurus and thick and rounded in other herons (Ligon, 1965), though in our material this character difference did not appear distinct. As Ligon (1965) and Adams (1956) pointed out, the sternal facet of the coracoid is located somewhat higher on the shaft in the bitterns than in the other herons. The position of the facet was somewhat intermediate in the tiger herons but was more similar to that of the day herons than to that of the bitterns. 
A

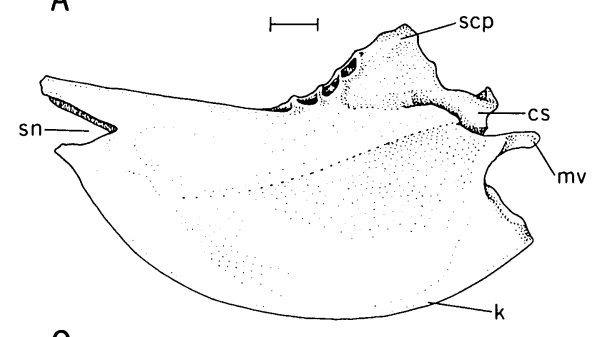

$\mathrm{C}$

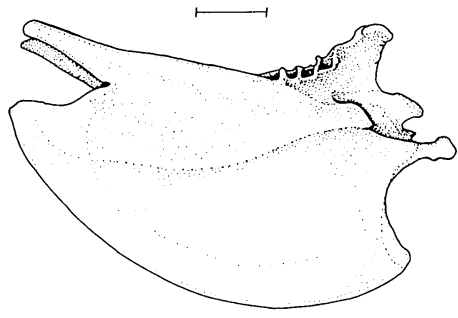

$\mathrm{E}$

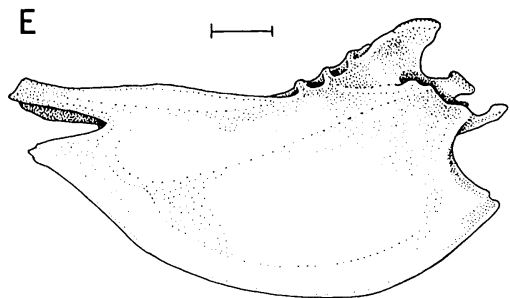

B

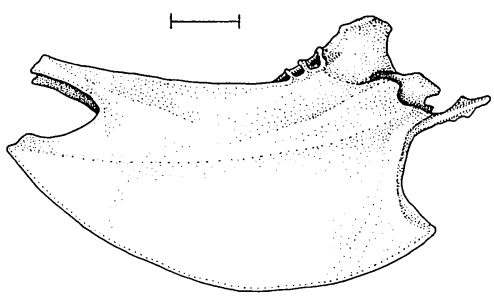

D
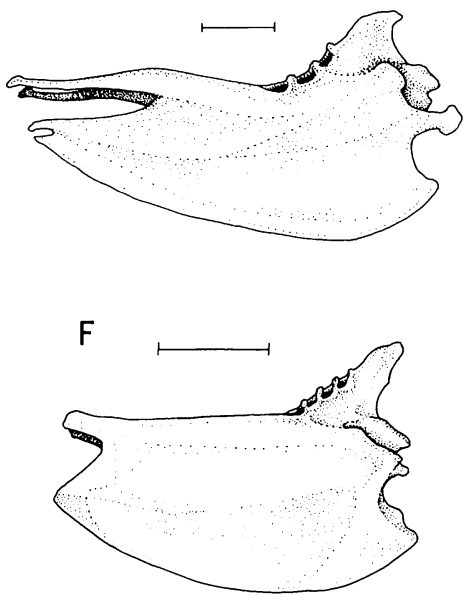

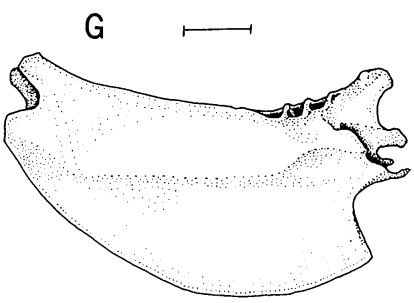

Fig. 14. Sternum, lateral view. A.) Ardea herodias; B.) Agamia agami; C.) Nycticorax nycticorax; D.) Tigriornis leucolophus; E.) Tigrisoma mexicanum; F.) Zebrilus undulatus; G.) Botaurus lentiginosus. Symbols: cs-coracoidal sulcus; $\mathrm{k}$-keel; $\mathrm{mv}$-ventral manubrium; scp-sternocoracoidal process; $\mathrm{sn}-$ sternal notch. The scale lines are $10 \mathrm{~mm}$.

CHARACTER 20. Coracoid, posterior sternal facet. 0- subterminal, low on shaft (Fig. 16A). 1- higher on shaft (Fig. 16B, C).

The furculum varies in the length and shape of the internal and external spines among the herons. We found some variation within single species (Ardea herodias, Ardeola striata virescens) in the length and amount of bifurcation of the external spine and some variation and occasional breakage of the internal spine. Coding variations of this character among the small Ixobrychus species may include some 


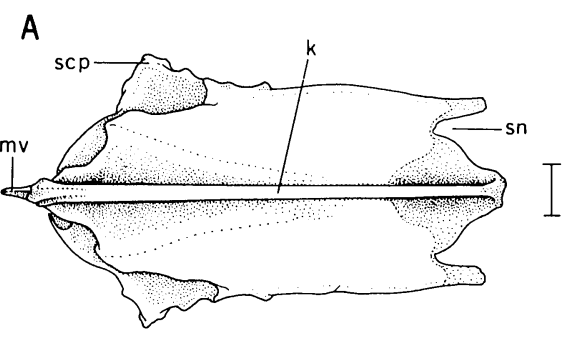

\section{B}
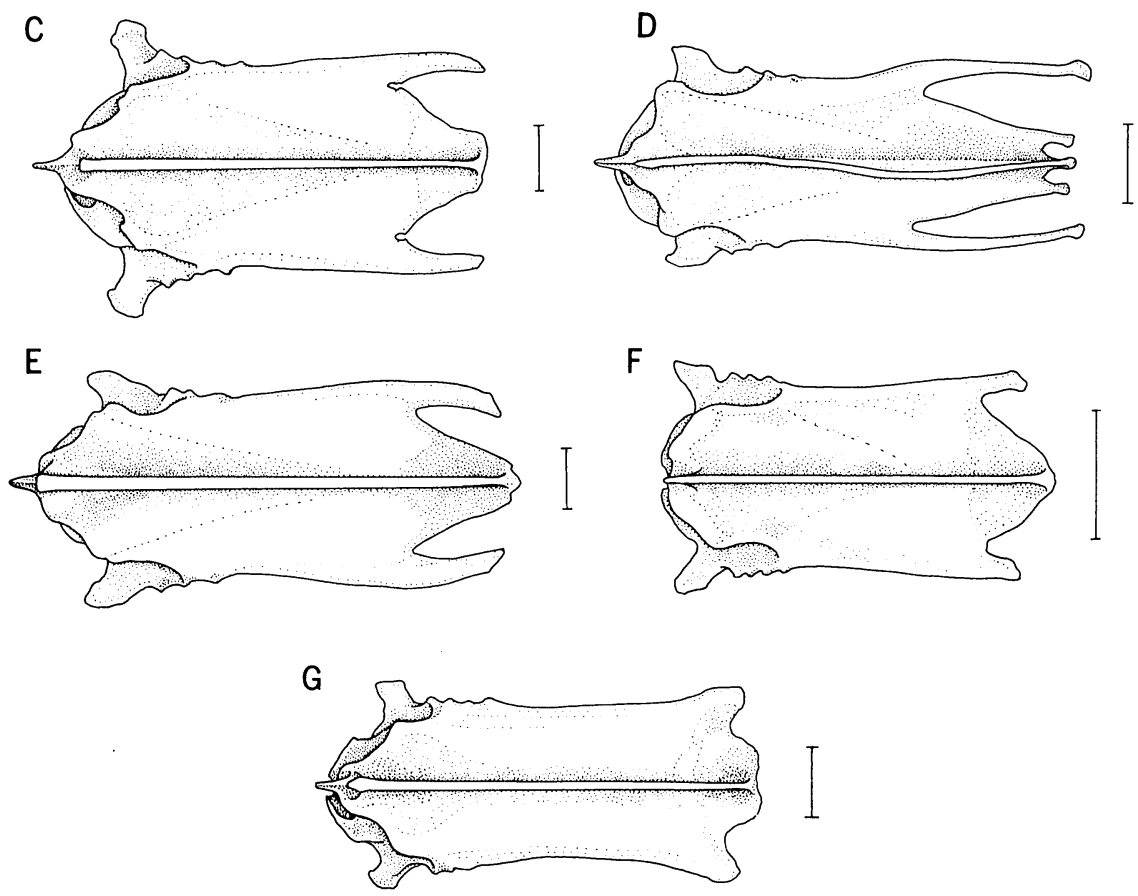

Fig. 15. Sternum, ventral view. A.) Ardea herodias; B.) Agamia agami; C.) Nycticorax nycticorax; D.) Tigriornis leucolophus; E.) Tigrisoma mexicanum; F.) Zebrilus undulatus; G.) Botaurus lentiginosus. Symbols: k-keel; mv-ventral manubrium; scp-sternocoracoidal process; sn-sternal notch. The scale lines are $10 \mathrm{~mm}$.

errors due to breakage of the spines. Details of the shapes of the spines were generally very similar among closely related species but differed considerably among some of the egrets, the bitterns, and some other groups (Fig. 17).

CHARACTER 21. Furculum, external spine (posterior furcular process). 0-absent (Fig. 17L-O). 1-present, moderate length, not distinctly bifurcate (Fig. 17A, B). 2-long, not distinctly bifurcate (Fig. 17G). 3- present, bifurcate (Fig. 17E, R).

CHARACTER 22. Furculum, internal spine (anterior furcular process). 0- absent or inconspicuous (Fig. 17A, H, J, N, O, P, S). 

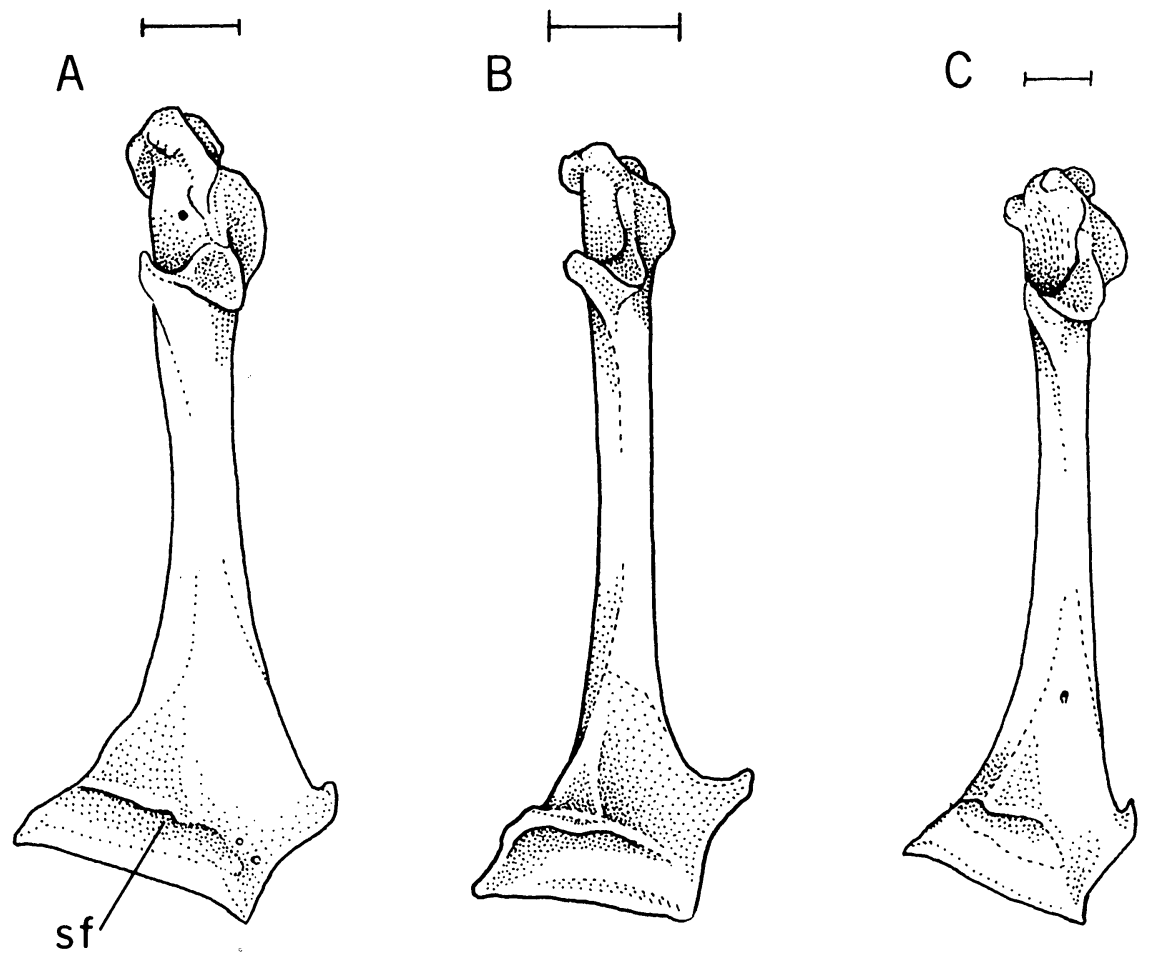

Fig. 16. Coracoid, dorsal view. Note the variation in the position on the shaft of the posterior sternal facet. A.) Ardea herodias; B.) Zebrilus undulatus; C.) Botaurus lentiginosus. Symbols: $s f=$ posterior sternal facet. The scale lines are $5 \mathrm{~mm}$.

1- short (Fig. 17C, E, I, K-M, Q, R). 2-long (Fig. 17B, D). 3- very long (Fig. $17 \mathrm{~F}, \mathrm{G}$ ).

In the wing, distinct character state variation was found in the humerus, including the shape and height of the deltoid process, in the occurrence and extent of the pneumatic fossa around the pneumatic foramen, and in the extent of the ligamental furrow. Adams (1956) noted variation also in the carpometacarpus but we were unable to discern distinct character state differences in this element.

CHARACTER 23. Humerus, shape of deltoid crest. 0-relatively angulated, especially on palmar surface (Fig. 18A-D, F-I). 1relatively rounded or curved (Fig. $18 \mathrm{E}, \mathrm{J}$ ).

CHARACTER 24. Humerus, relative height of deltoid crest. 0projects well above proximal shaft of humerus (Fig. 18A, B, C, F, G, I). 1- stands in low relief (Fig. 18C, E, H, J).

CHARACTER 25. Humerus, pneumatic fossa. 0- none, pneumatic foramen opening nearly flush with circumference of shaft (Fig. 

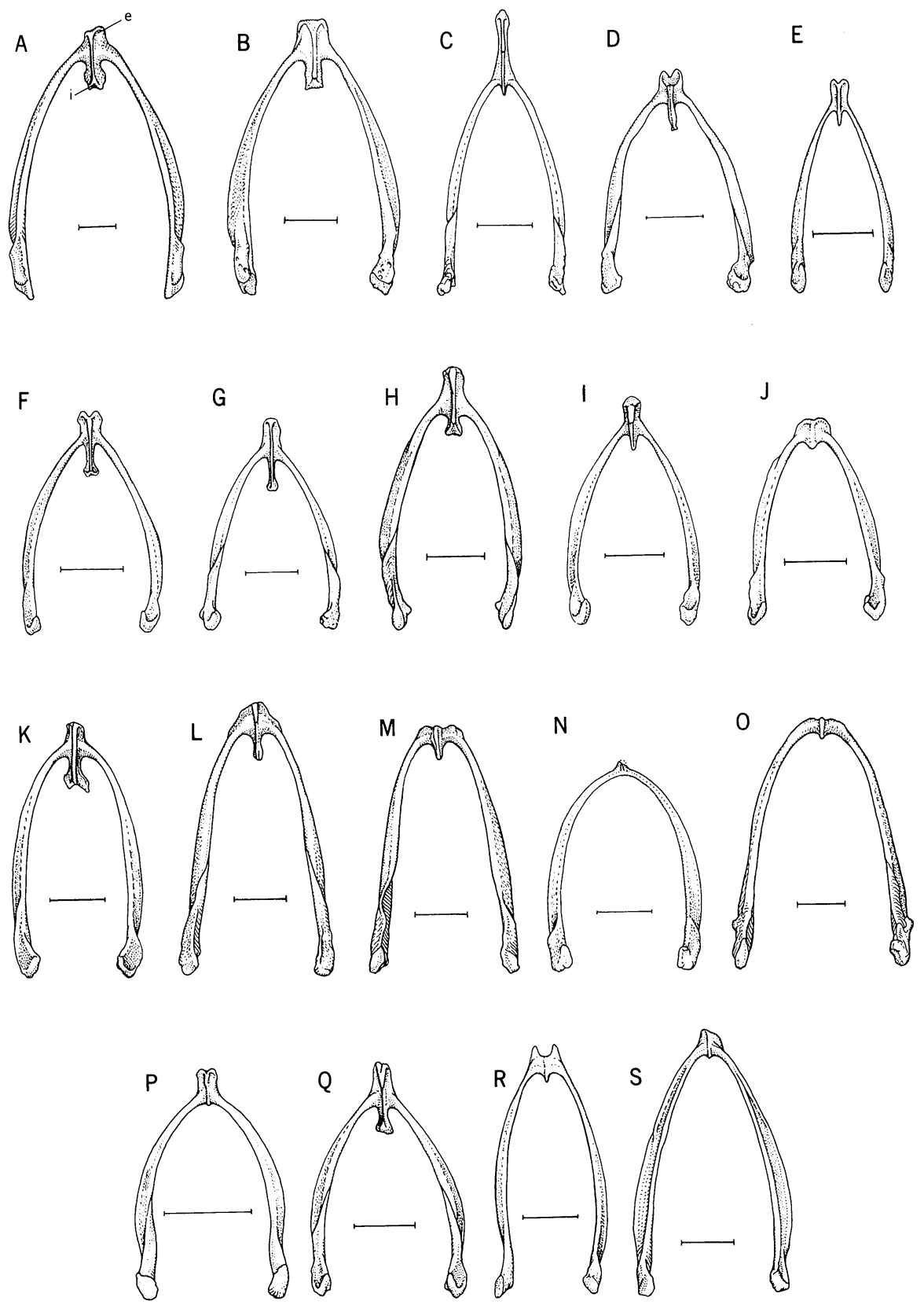

Fig. 17. Furculum, ventral view. A.) Ardea herodias; B.) Ardea alba; C.) Agamia agami; D.) Pilherodius pileatus; E.) Ardeola ralloides; F.) Egretta thula; G.) Egretta novaehollandiae; H.) Egretta rufescens; I.) Egretta ibis; J.) Syrigma sibilatrix; K.) Nyctanassa violacea; L.) Nycticorax nycticorax; M.) Cochlearius cochlearius; N.) Tigriornis leucolophus; O.) Tigrisoma mexicanum; P.) Zebrilus undulatus; Q.) Ixobrychus sturmii; R.) Botaurus lentiginosus; S.) Botaurus poiciloptilus. Symbols: e-external spine; i-internal spine. The scale lines are $10 \mathrm{~mm}$. 

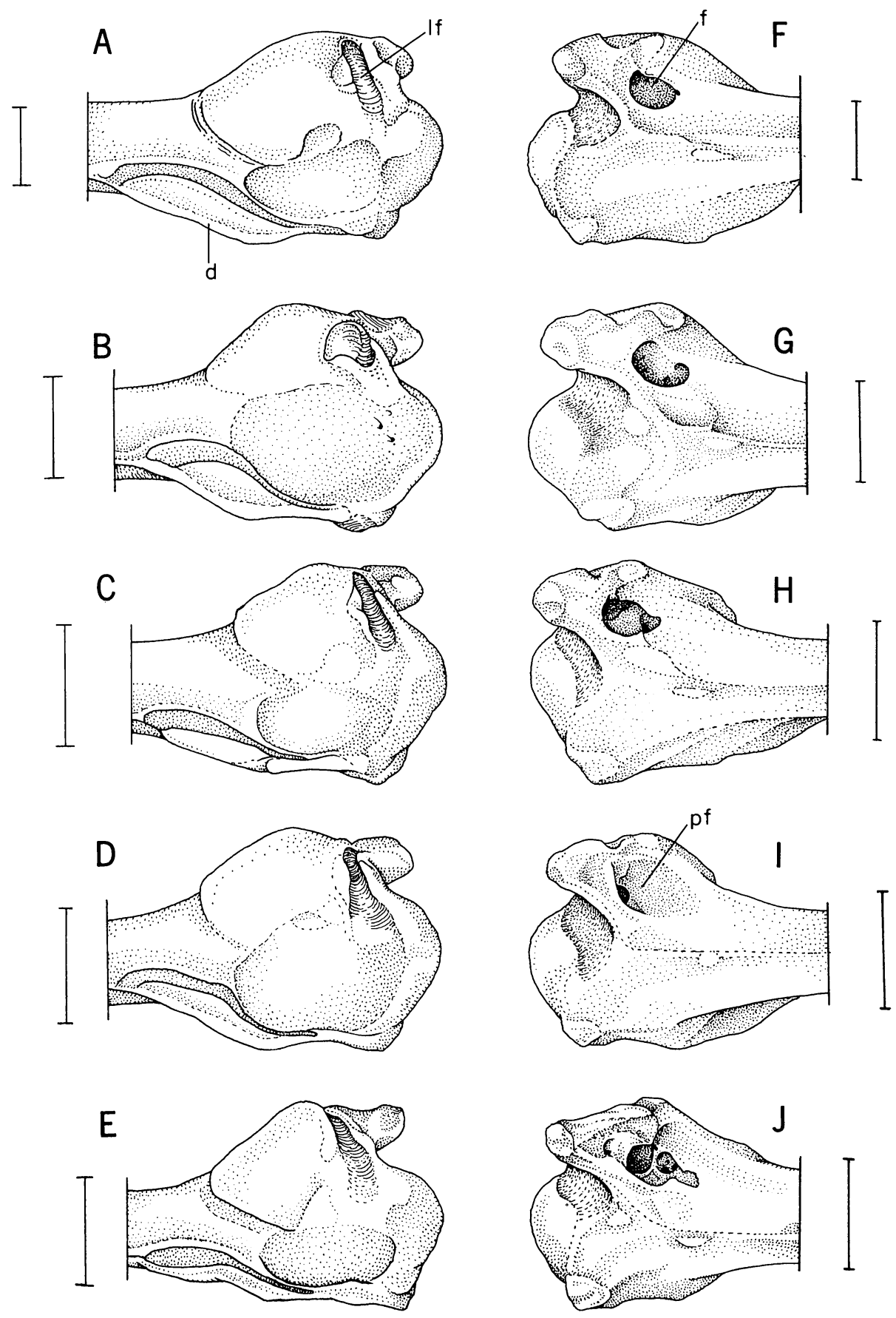

Fig. 18. Variation of the head of the humerus. A-E = palmar view, F-J = aconal view. $\mathrm{A}, \mathrm{F}=$ Ardea herodias; $\mathrm{B}, \mathrm{G}=$ Tigrisoma mexicanum; $\mathrm{C}, \mathrm{H}=$ Nycticorax nycticorax; $\mathrm{D}, \mathrm{I}=$ Cochlearius cochlearius $; \mathrm{E}, \mathrm{J}=$ Botaurus lentiginosus . Symbols: d-deltoid crest; f-pneumatic foramen; lf-ligamental furrow; pfpneumatic fossa. The scale lines are $10 \mathrm{~mm}$. 
$18 \mathrm{~F}, \mathrm{H}, \mathrm{J})$. 1-foramen lies in small fossa. 2-foramen lies in large fossa (only in Cochlearius) (Fig. 18I).

CHARACTER 26. Humerus, ligamental furrow. 0-deeply recessed proximal to the bicipital surface of the humerus, and extends far to palmar surface (Fig. 18A, C-E). 1- shallow furrow, extends a shorter distance (Fig. 18B).

Pelvic Assemblage

Details of the variation of the synsacrum and their tarsometatarsus, the skeletal elements in which we found significant differences among species, are shown in Figures 19-23. The synsacrum is a complex bone with several varying components in the herons. Character states were found that defined some major groups of genera such as the bitterns and the tiger herons, and other character states that separated species into species groups within a genus (Ardea, Botaurus). Variation also was found in the posterior ischial shelf and in the fusion of the posterior sacral vertebrae with the synsacrum, but no consistent differences were discovered between the extremes of shapes and degrees of fusion.

CHARACTER 27. Synsacrum, iliac crest dorsal to acetabulum. 0dorsal ridge of iliac crest is rounded (Fig. 20A-C, G). 1-dorsal ridge of iliac crest is angulated (Fig. 20D-F, H-L).

CHARACTER 28. Synsacrum, posterior iliac crest. 0- lateral shelf relatively undeveloped posterior to acetabulum, especially on posterior half of ilium (Fig. 19-20A-K). 1-lateral projection of crest prominent and extends posteriorly well beyond level of ischiopubic fenestra (Botaurus pinnatus, not illustrated). 2- very prominent lateral crest, developed more laterally than in 1 (Fig. 19-20L).

CHARACTER 29. Synsacrum, fusion of parapophyses of synsacral thoracic and lumbar vertebrae with anterior portion of ilium anterior to pectineal region and forming recesses or foramina with it. 0- 5 pair of fused parapophyses (vertebrae 24-28) (Fig. 21A, B, D). 1- 6 pair (vertebrae 24-29) (Fig. 21C).

CHARACTER 30. Synsacrum, iliac recess (renal cavity), as viewed from ventral surface of synsacrum, posterior projection of recess forms cavity in iliac region. 0-prominent, posterior margin of renal cavity is recessed medially out of sight in caudal depressions (Fig. 21A-C). 1-renal depression is shallow and laterally recessed in posterior portion of synsacrum (Fig. 21D).

CHARACTER 31. Synsacrum, ischiopubic symphysis. 0-an anterior ischiopubic symphysis bridges the ischium and pubis behind the obturator foramen (Fig. 22J-L). 1-anterior ischiopubic symphysis absent (Fig. 22A-I). 

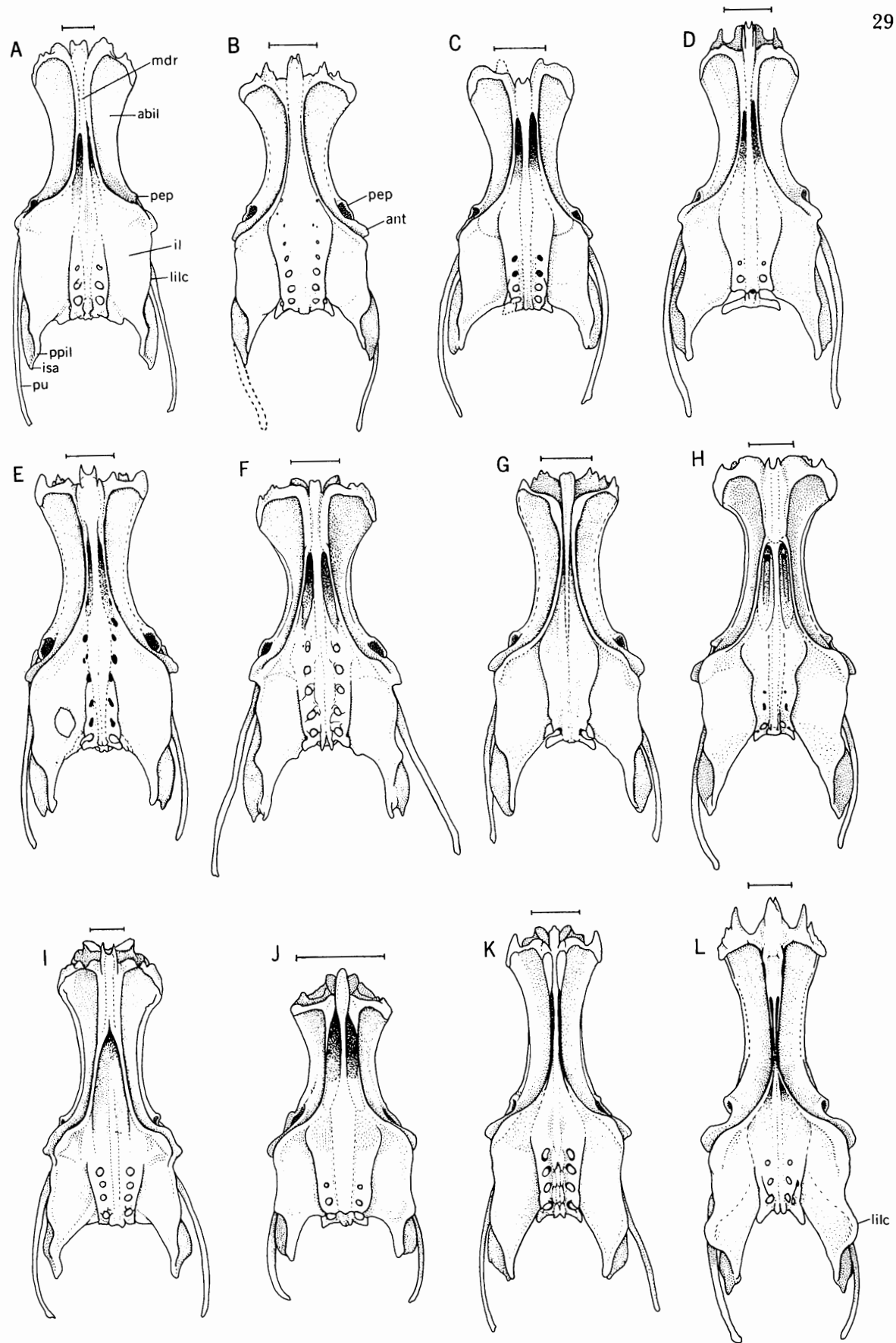

Fig. 19. Synsacrum, dorsal view. A.) Ardea herodias; B.) Egretta novaehollandiae; C.) Syrigma sibilatrix; D.) Nyctanassa violacea; E.) Nycticorax nycticorax; F.) Cochlearius cochlearius; G.) Tigriornis leucolophus; H.) Tigrisoma lineatum; I.) Tigrisoma mexicanum; J.) Zebrilus undulatus; K.) Botaurus lentiginosus; L.) Botaurus poiciloptilus. Symbols: abil-anterior blade of ilium; antantitrochanter; il-ilium; isa-ischial angle; lilc-lateral margin of iliac crest; mdr-median dorsal ridge; pep-pectineal process; ppil-posterior projection of ilium; pu-pubis. The scale lines are $10 \mathrm{~mm}$. 

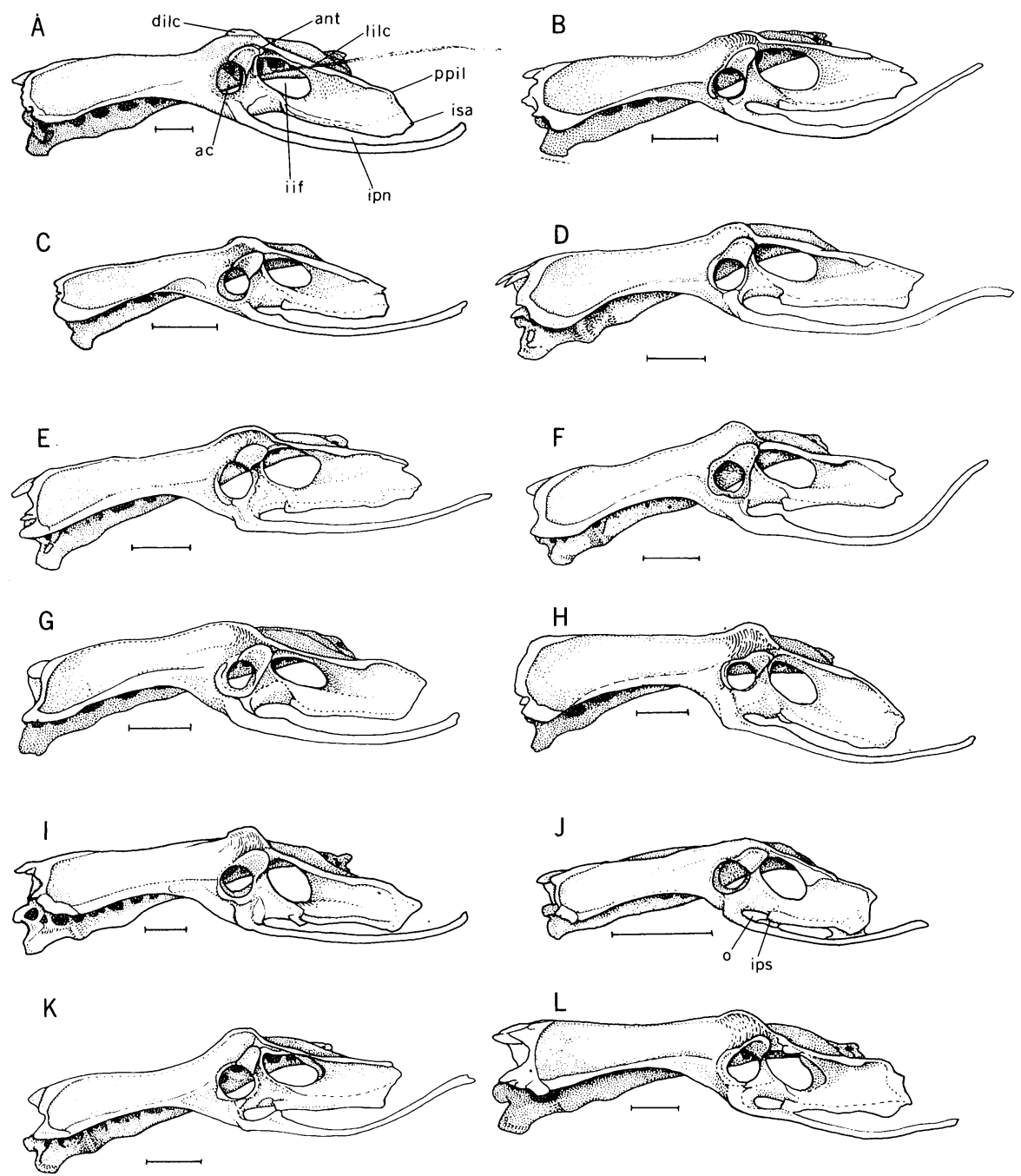

Fig. 20. Synsacrum, lateral view. A.) Ardea herodias; B.) Egretta novaehollandiae; C.) Syrigma sibilatrix; D.) Nyctanassa violacea; E.) Nycticorax nycticorax; F.) Cochlearius cochlearius (flexion of pubis is an artifact); G.) Tigriornis leucolophus; H.) Tigrisoma lineatum; I.) Tigrisoma mexicanum; J.) Zebrilus undulatus; K.) Botaurus lentiginosus; L.) Botaurus poiciloptilus. Symbols: acacetabulum; ant-antitrochanter; dilc-dorsal projection of iliac crest; iif-ilioischiatic fenestra; ipn-ischio-pubic notch; ips-ischiopubic symphysis; isa-ischial angle; lilc-lateral margin of iliac crest; o-obturator foramen; ppil-posterior projection of ilium. The scale lines are $10 \mathrm{~mm}$.

No consistent differences were found among herons in the femur or tibiotarsus, but some variations were noted in the tarsometatarsus. The degree of fusion among the ridges of the hypotarsus in forming hypotarsal grooves and canals varied considerably and was especially prominent in Botaurus lentiginosus (though not in the other Botaurus 

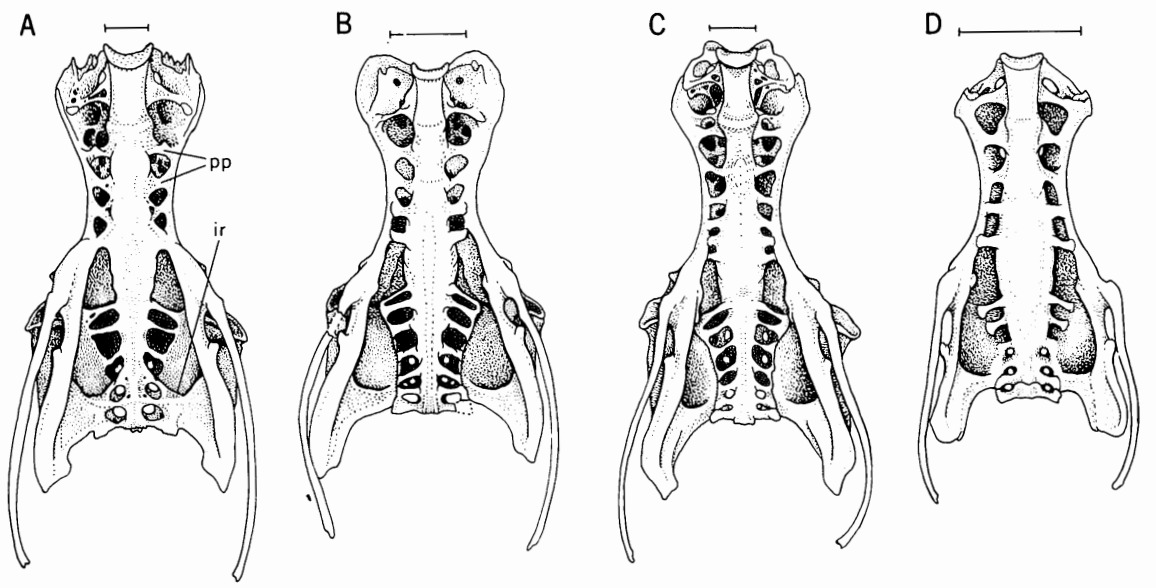

Fig. 21. Synsacrum, ventral view. A.) Ardea herodias; B.) Syrigma sibilatrix; C.) Tigrisoma mexicanum; D.) Zebrilus undulatus. Symbols: ir-iliac recess; pp-parapophyses. The scale lines are $10 \mathrm{~mm}$.

A
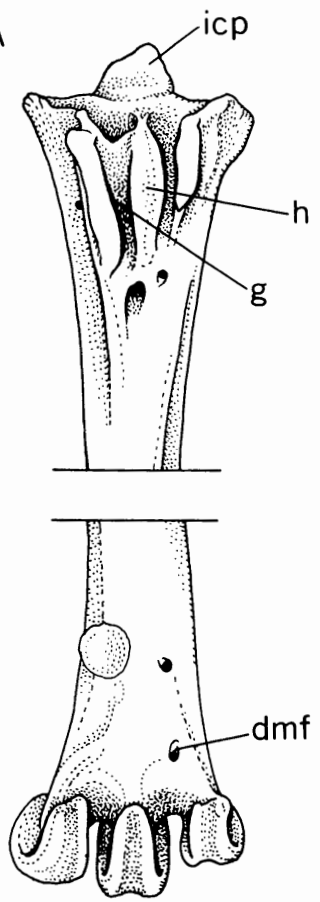

B
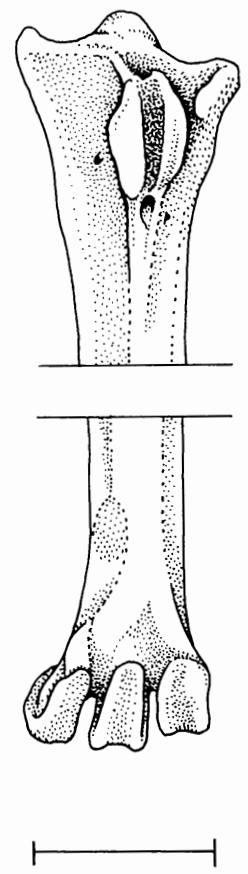

C
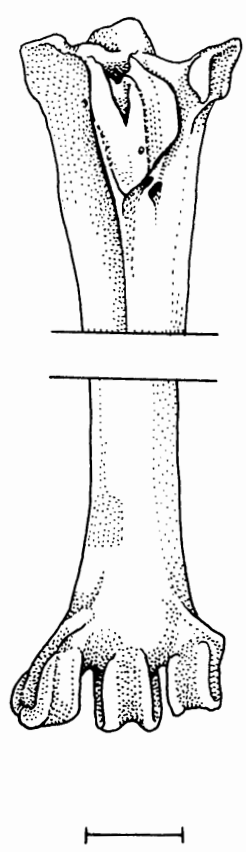

Fig. 22. Variation in the tarsometatarsus, posterior view. A.) Ardea herodias; B.) Zebrilus undulatus; C.) Botaurus lentiginosus. Symbols: dmf-distal metatarsal foramen; $\mathrm{g}$-hypotarsal groove; $\mathrm{h}$-hypotarsus; icp-intercotylar prominence. The scale lines are $10 \mathrm{~mm}$. 
species), in the Tigrisoma tiger bitterns, and in the Reddish Egret Egretta rufescens, in which most specimens showed two or three canals (Fig. 23). The degree of prominence of the ridges also varied between species with the same degree of canal formation, and the ridges were consistently higher and more fused in Ardeola striata and rufiventris than in the pond herons. Some variation occurred in this character within a single species, and all degrees of fusion were indicated among the herons generally, so we did not include the variation of this character in the quantitative analysis. The shape of the intercotylar prominence varied in a subtle yet consistent manner, as suggested by Cracraft (1967), and the large bitterns varied from the other herons in lacking a distal metatarsal foramen penetrating the tarsometatarsal shaft.

CHARACTER 32. Tarsometatarsus, intercotylar prominence. 0articular surface is rounded (Fig. 22C). 1-articular surface is slightly angulated (Fig. 22A).

CHARACTER 33. Tarsometatarsus, distal metatarsal foramen. 0penetrates through shaft (Fig. 22A). 1-absent (Fig. 22B, G). Table 2.

A summary of skeletal character states in the herons is given in

\section{ESTIMATING THE PRIMITIVE CHARACTER STATES}

The uncertainty of estimating the character states of the ancestor of any group has led many numerical taxonomists to despair of using quantitative analytical techniques to uncover likely evolutionary relationships, and much work has avoided an evolutionary interpretation by using simple phenetic methods that describe similarity among living forms but that make no assumptions about evolution (Sneath

A
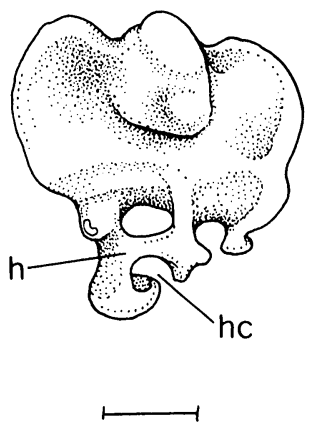

$\mathrm{B}$
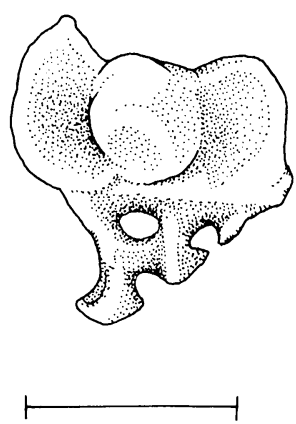

C
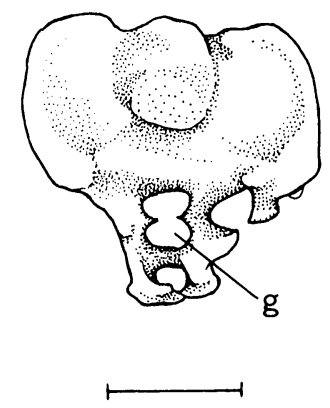

Fig. 23. Variation in the hypotarsus, view of proximal end of tarsometatarsus. A.) Ardea herodias; B.) Zebrilus undulatus; C.) Botaurus lentiginosus. Symbols: g-hypotarsal groove; h-hypotarsus; he-hypotarsal canal. The scale lines are $5 \mathrm{~mm}$. 
and Sokal, 1973: 53-60). However, it is of interest to know to what degree the phenetic similarities among species may be due to their evolutionary history of branching and differentiating, and to what degree the similarities may result from convergence or from independent derivation of character states. In principle, it is possible to estimate the character states of the ancestor of a recent group, that is, the primitive state of each character, and to differentiate these from the derived states of the descendants. Kluge and Farris (1969) have suggested three criteria to use in estimating primitive character states-(1) a character state that is present in many of the most closely related groups (the "out-groups") is likely to be primitive, (2) a character state that is widespread within the group of interest (the "in-group") is likely to be primitive, and (3) a character state whose distribution among the in-group taxa covaries with other "known" primitive character states is likely to be primitive. Other criteria have been suggested, for example, characters that are not correlated with obvious ecological variables and characters with low intrataxon variance, and Kluge and Farris (1969) and Hymen and Rabb (1972) suggest that each of these several criteria may be summed for any character, the ones drawing the most scores for "primitiveness" being the characters of most certain reliability.

The primitive conditions of the characters in the present study were estimated by applying (1), the out-group criterion of Kluge and Farris (1969).

Table 3 lists the out-group non-heron ciconiiform species considered in the estimation of the hypothetical heron ancestor, which we call "primardea." The character states of these species were used in two ways. First, character states that were the same among some herons and among the majority of out-group units examined were regarded as primitive within the herons. For example, the posterior iliac crest lacks a conspicuous lateral projection in the non-heron Ciconiiformes. In the herons some species lack a pronounced lateral crest and others have it; the character state agreeing with that of the out-groups is considered primitive in the herons. Second, character states that were not identical in herons and among the out-groups but that were expressed in an extreme state in the majority of out-group units could sometimes reasonably be regarded as primitive when they were intermediate in some herons between the state of the out-groups and the state of the other herons. This assumes an evolutionary change of character state from, e.g., 0 in the out-groups to 1 in the primitive herons, and then from 1 to 2 in more derived herons. For example, among the non-heron Ciconiiformes the sternal facet of the coracoid is subterminal in position, in the day herons it is positioned somewhat higher, and in the bitterns considerably higher, on the shaft. Thus the day herons have a relatively primitive position of the sternal facet of the coracoid among the herons. Use of the out-group criterion for determining primitiveness assumes nothing about re- 


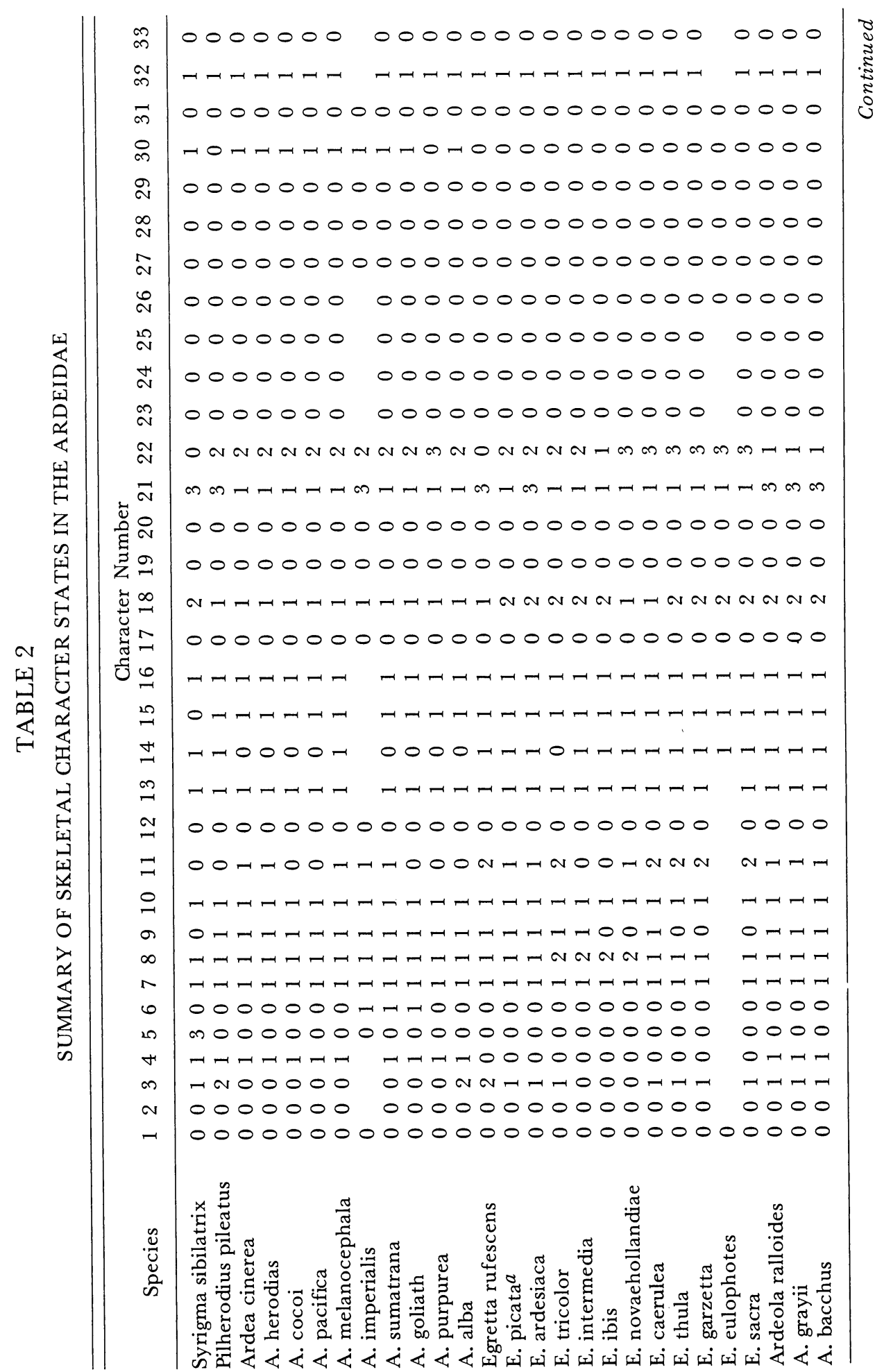




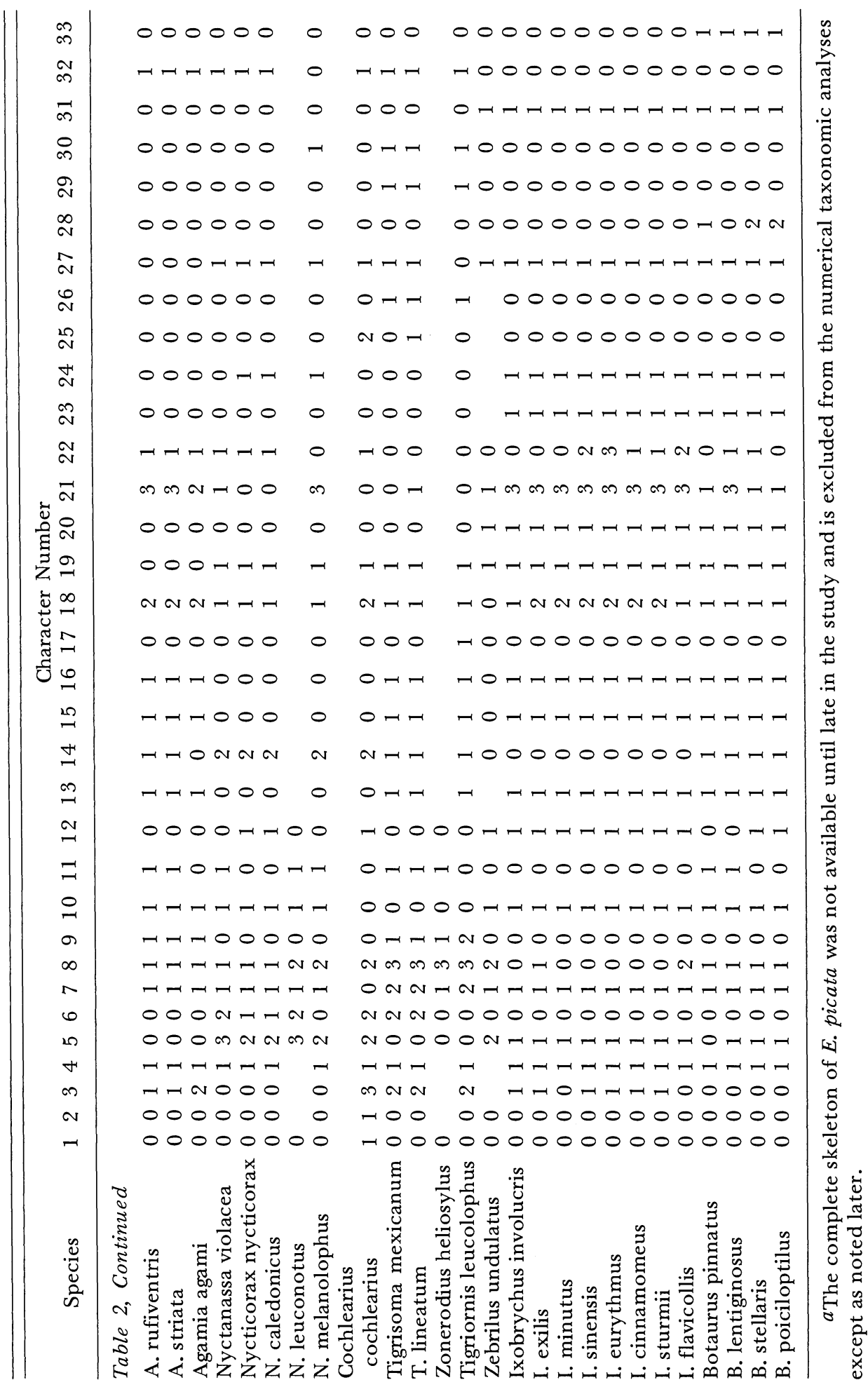




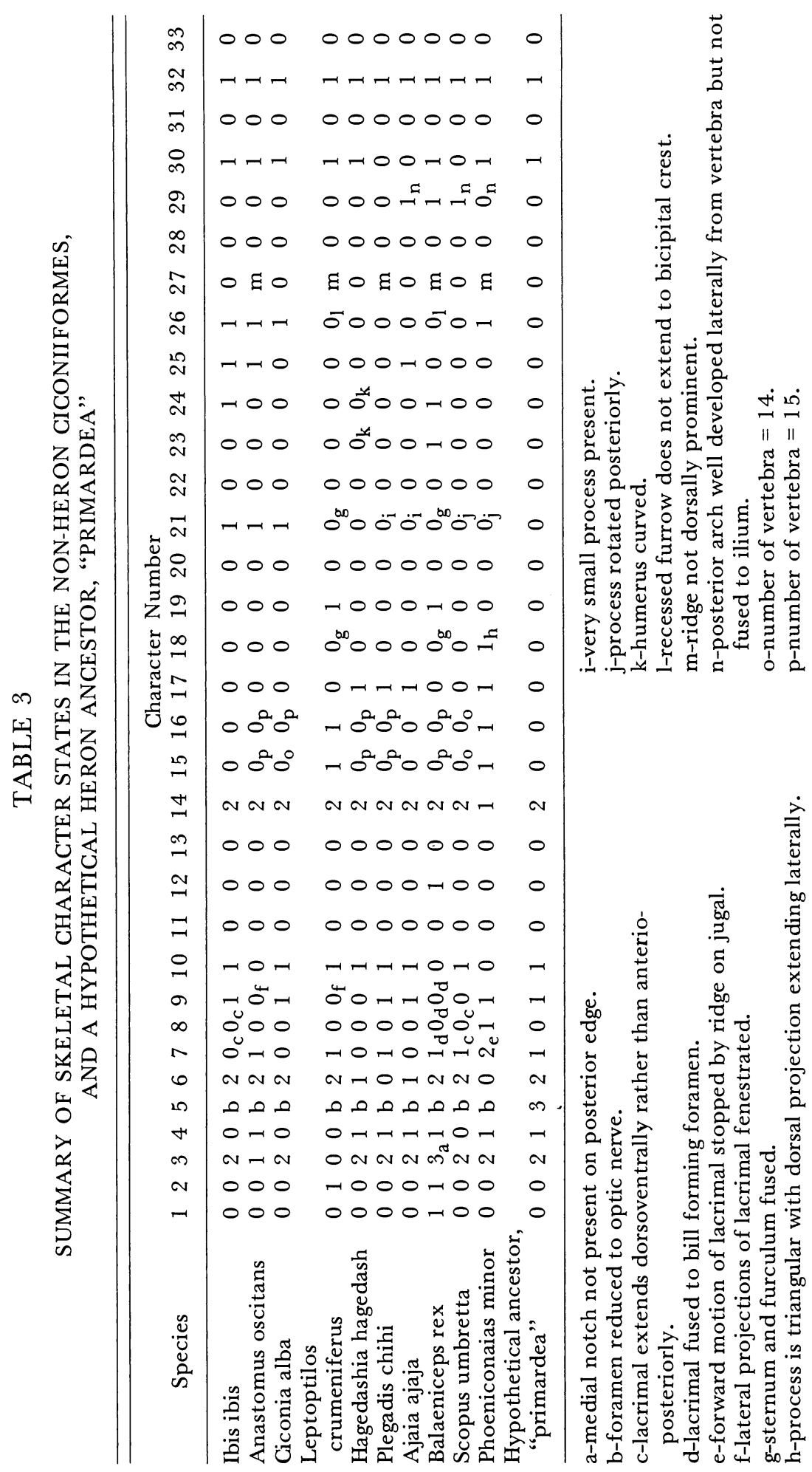


versals of character states among the in-groups, and indeed several reversals of character states are indicated in the results of the study.

Several characters could not be assigned primitive and derived conditions of their states by the out-group criterion because corresponding states could not be found amorig the out-group taxa. These were eliminated from further quantitative analysis, though some were useful in particular comparisons.

The reconstruction of our "primardea" by the out-group criterion relies heavily on our choice of the out-group taxa for comparison. Fortunately there appears to be general agreement among avian systematists that the living birds most closely related to the herons are the storks (Ciconiidae), ibises and spoonbills (Threskiornithidae), hammerhead (Scopus), and whale-headed stork or shoe-bill (Balaeniceps), and probably also the flamingos (Phoenicopteridae). The anatomical and biochemical evidence for the common relationships among all of these birds in a single order Ciconiiformes has been summarized most recently by Sibley and Ahlquist (1972). Selection of a constellation of out-group taxa for anatomical comparison was made to include most of the morphological extremes and we have included no more than one species in any of the genera recognized by Sibley and Ahlquist (1972). Although more species and genera are recognized among the Threskiornithidae than among the Ciconiidae, we compared only 3 of the former and 4 of the latter, as genera appear to be taxonomically over-split and as many species are allopatric in the Threskiornithidae. Only one flamingo was included because of the possibility that flamingos are less closely related to the other Ciconiiformes than are the herons (Sibley and Ahlquist, 1972; Storer, 1971).

In Table 3 are indicated the character states of the species in the out-groups examined. Several characters were represented by nonheron-like states in these other Ciconiiformes. The "primardea" or hypothetical common ancestor of the herons is the hypothetical aggregate of the states found for each character in a simple majority of the sample of species in the out-group. Any "weighting" of characters was due to selection of the out-group species. "Primardea" was then used as the "ancestor" in the phyletic and cladistic numerical taxonomic analyses.

\section{METHODS OF NUMERICAL TAXONOMY AND PHYLOGENETIC ESTIMATION}

The numerical phenetic and phylogenetic techniques applied to herons in this study are described by Sneath and Sokal (1973), Farris (1970), Kluge and Farris (1969), Estabrook (1972), and Estabrook et al. (1975). The multivariate computer routines used are all available through The University of Michigan MIDAS computational package, 
except for the Prim Network and Wagner Tree programs which were written by J. S. Farris and the cladistic compatibility programs developed by G. F. Estabrook and K. Fiala.

Computations were run on all species for which complete character sets were available; additional computations on a reduced set of 26 characters for all of these species and also Zebrilus undulatus were made on those characters available from the incomplete skeleton of Zebrilus. For the numerical calculations the character states were coded as if all the character states were topologically linear; the error resulting from this is apparent only in character 5 (cf. Fig. 36) and evidently did not distort the results, as no estimate of relationships showed species having character 5 state 0 to be closely associated with species having character 5 state 1 (cf. Fig. 36). Multistate characters were coded so that the total range of variation of each character was equivalent in all programs.

Preliminary analyses of phenetic similarity among heron species were made using the Prim Network program to obtain a shortest spanning nondirectional tree (Farris, 1970; Sneath and Sokal, 1973: pp. 254-255). Next, principal components values were computed from the correlation matrix as described in Cooley and Lohnes (1971: p. 105) by the PRINCOM subroutine of MIDAS to summarize the phenetic variation. The ordination values of the herons along the first four principal components were displayed in two-dimensional scatter diagrams. The results were compared with minimum-distance analyses of the PC 1-4 eigenvectors as a control for two-dimensional distortion. The other phenetic analysis used in the study was a clustering technique (CLUSTER of MIDAS). Phenograms were computed by unweighted paired-group analysis of a distance matrix, using both (a) simple matching coefficients and (b) product-moment correlation coefficients (Sneath and Sokal, 1973: 121-137); the means and variances of the variables were standardized in these analyses.

The estimates of phylogenetic relationships made use of the set of character states constructed for the hypothetical ancestor. The Wagner Tree algorithm constructs a most parsimonious directed tree by constructing hypothetical intermediates to minimize total length. The resulting branching pattern estimates the cladistic history and patristic relationships of the OTUs. As described by Kluge and Farris (1969), Farris (1970), and Sneath and Sokal (1973, pp. 341-342), the algorithm reconstructs a phylogenetic tree by a series of steps involving (a) selection of a set of character states for the hypothetical ancestor, as described in the previous section in creating "primardea", (b) determination of the species with the most similar set of character states to the ancestor, and (c) connecting this species to the ancestor, the distance being proportional to the minimum number of changes in the character state involved, (d) determination of the next species that differs least from the ancestor, (e) connec- 
tion of this species to the existing network in such a way that the number of evolutionary changes is minimal (usually by attaching the species to an HTU (hypothetical taxonomic unit) on the network, but occasionally in practice by attaching the species to an existing species), and (f) repetition of steps (d) and (e) in sequence until all species are placed.

The other estimation of evolution, using the program COMPTREE developed by K. Fiala from an earlier program of G. F. Estabrook, reconstructs a plausible cladistic history. The cladistic systematics of Hennig (1966) assumes that only the occurrence of a common derived character state can be used to determine membership of a monophyletically evolved group of organisms. Wilson (1965) and LeQuesne (1969) were among the first to suggest methods for determining uniquely derived character states. Estabrook (1972) discussed some problems involved in estimating phylogenetic history and he indicates (p. 449) that the best estimate is one based on sets of characters that are "compatible." Two characters are said to be compatible if there is a phylogenetic tree on which both characters can be logically true.

For example, consider two characters such as no. 13 (basitemporal ridge) and 31 (ischiopubic symphysis). The ancestor "primardea" is coded 13(0) and 31(0), several species of day herons are coded $13(1)$ and $31(0)$, the night herons are coded $13(0)$ and $31(0)$, and the bitterns are 13(0) and 31(1). No herons were 13(1) and 31(1). If any had been, characters 13 and 31 would not be considered compatible, for there is no phylogenetic tree on which 13(1) and 31(1) could have evolved by a unique pathway since $13(0) 31(1)$ or $13(1) 31(0)$ would be possible, but not both, without a character state reversal or a multiple origin of a derived character state. From these data alone, it would have been impossible to determine which was the true immediate ancestral condition of a species with character suite 13(1) and 31(1). This pair of characters would then have been regarded as incompatible. In the real example given, the two characters indeed are compatible, as there is no logical contradiction and only a single estimate of cladistic history is compatible with the distribution of character states among species.

Another example of character compatibility is in characters 31 (ischiopubic symphysis) and 33 (distal tarsometatarsal foramen). "Primardea" and most of the herons are coded 31(0) 33(0), Ixobrychus bitterns are $31(1) 33(0)$, and Botaurus bitterns are $31(1)$ $33(1)$. No herons were found to be $31(0) 33(1)$. The combinations of characters among all herons can be summarized by a single tree $[31(0) 33(0) \rightarrow 31(1) 33(0) \rightarrow 31(1) 33(1)]$, indicating a single pathway of evolutionary changes in character-state sets.

With an increase in the number of characters and the combinations of characters found among all heron species, however, only a small proportion of characters are compatible across the entire set of 
character states and species. The largest suite of compatible characters is taken as the best available estimate of evolutionary history in the group, though as with the other estimates of similarity and phylogeny, no statistical significance can be placed on the results. The method is in fact an application of mathematical set theory, as compatible characters are those values of a P-Q matrix whose Cartesian products form a tree partial order. It does not imply that the evolution of character states is always irreversible and unique, only that such apparently compatible characters are useful in estimating cladistic relationships. Further details of applying mathematical set theory to evolutionary biology are discussed in LeQuesne (1969), Estabrook (1972), and Estabrook et al. (1975).

\section{RESULTS OF ANALYSIS OF PHENETIC VARIATION AMONG THE HERONS}

Results of the similarities among the species of herons with complete skeletal data estimated by the shortest phenetic distance between species are summarized in Figure 24. The minimally connected graph shows four main groups of herons to be recognizable from the longest phenetic distances in the graph linking any of the species. The four groups are (1) day herons, including Ardea, Egretta, Ardeola, Agamia, Pilherodius, and Syrigma, (2) the night herons Nycticorax nycticorax and N. melanolophus, Nyctanassa violacea, and Cochlearius cochlearius, (3) the tiger herons Tigrisoma and Tigriornis, (4) bitterns of the genera Ixobrychus and Botaurus. Note that all members of the Egretta group are separated from the larger Ardea, including $A$. alba, and that Syrigma is phenetically distinct. Cochlearius is phenetically distinct but closest to the night herons.

A similar analysis of 26 characters available for the incomplete specimen of Zebrilus undulatus together with the same reduced set of characters for the other heron species gives the graph in Figure 25. Zebrilus is intermediate between the night herons and the bitterns, though closer to the bitterns. The other differences between Figures 24 and 25 result from the smaller set of characters used in Figure 25, which was a test of the position of Zebrilus.

Principal components analysis of the heron skeletal characters gave similar results. Scatter diagrams ordinating the herons by their position on the first two principal components (PC) from the analysis of 33 skeletal characters indicate the same four groups as the minimally connected graph algorithm-the day herons, the night herons, the tiger herons, and the bitterns. Figure 26 shows the distinctiveness of Cochlearius which is nearly equidistant along PC1 and 2 from night herons and tiger herons. A two dimensional graph of heron positions on PG 1 and 3 (not illustrated, but see Table 4) locates Cochlearius close to the night herons and well separated from 


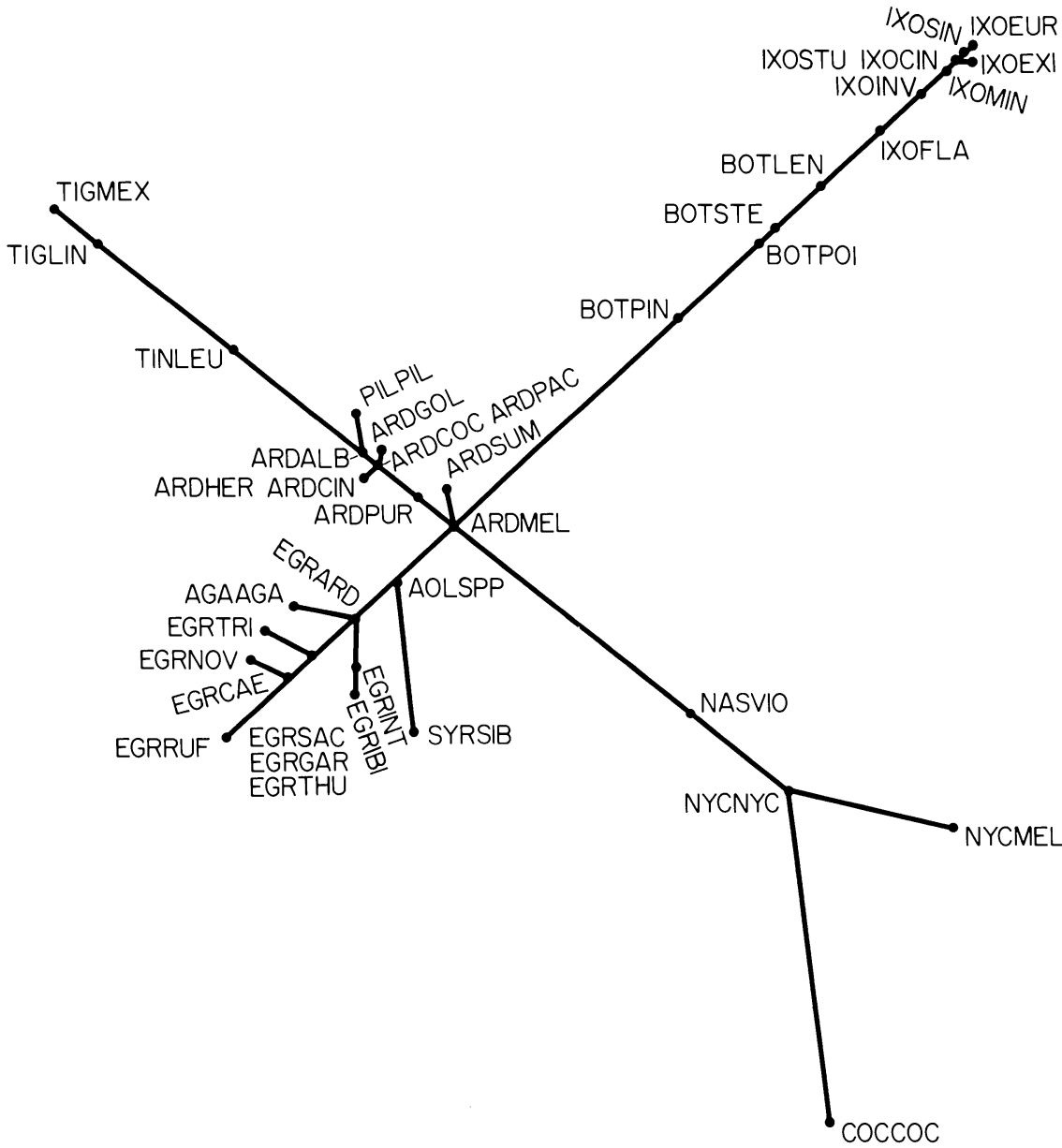

Fig. 24. Prim Network or phenetic minimally connected graph of Ardeidae using 33 skeletal characters. Abbreviations for this and the following figures are the first three letters of the genus and the first three letters of the species. AGAAGA $=$ Agamia agami; AOLSPP $=$ Ardeola species; $\cdot$ AOLBAC $=$ Ardeola bacchus; AOLGRA $=A$. grayii $;$ AOLRUF $=A$. rufiventris $;$ AOLSTR=A. striata; $\mathrm{ARDALB}=A r d e a$ alba $; \mathrm{ARDCIN}=A$. cinerea $; \mathrm{ARDCOC}=A$. coco $i$ ARDGOL $=$ $A$. goliath $; \mathrm{ARDHER}=A$. herodias $; \mathrm{ARDMEL}=A$. melanocephala $; \mathrm{ARDPAC}=A$. pacifica; $\mathrm{ARDPUR}=A$. purpurea $; \mathrm{ARDSUM}=A$. sumatrana; $\mathrm{BOTLEN}=$ Botaurus lentiginosus; BOTPIN $=B$. pinnatus; $\mathrm{BOTPOI}=B$. poiciloptilus; $\mathrm{BOTSTE}=B$. stellaris; $\mathrm{COCCOC}=$ Cochlearius cochlearius; $\mathrm{EGRARD}=$ Egretta ardesiaca $;$ $\mathrm{EGRCAE}=E$. caerulea $; \mathrm{EGRGAR}=E$. garzetta; $\mathrm{EGRINT}=$ E. intermedia $;$ $\mathrm{EGRIBI}=E$. ibis; $\mathrm{EGRNOV}=E$. novaehollandiae $; \mathrm{EGRPIC}=E$. picata $; \mathrm{EGRRUF}=$ E. rufescens; $\mathrm{EGRSAC}=E$. sacra; $\mathrm{EGRTHU}=E$. thula; $\mathrm{EGRTRI}=$ E. tricolor; IXOCIN = Ixobrychus cinnamoneus; IXOEUR $=I$. eurhythmus; IXOEXI = I. exilis; IXOFLA = I. flavicollis; IXOINV=I. involucris; IXOMIN=I. minimus; IXOSIN=I. sinensis; IXOSTU $=I$. sturm $\ddot{i} ; \mathrm{NASVIO}=N y$ ctanassa violacea $; \quad \mathrm{NYCCAL}=N y c t i$ corax caledonicus; $\mathrm{NYCMEL}=N$. melanolophus; $\mathrm{NYCNYC}=N$. nycticorax; PILPIL = Pilherodius pileatus; $\mathrm{SYRSIB}=$ Syrigma sibilatrix $;$ TIGLIN $=$ Tigrisoma lineatum; TIGMEX = T. mexicanum; TINLEU= Tigriornis leucolophus; $\mathrm{ZEBUND=}$ Zebrilus undulatus. For later figures, ANCESTOR= "primardea;" $\mathrm{ARD}(\mathrm{SPP})=$ Ardea species; $\mathrm{BOT}(\mathrm{SPP})=$ Botaurus species; $\mathrm{EGR}(\mathrm{SPP})=$ Egretta species; $\mathrm{IXO}(\mathrm{SPP})=$ Ixobrychus species. 


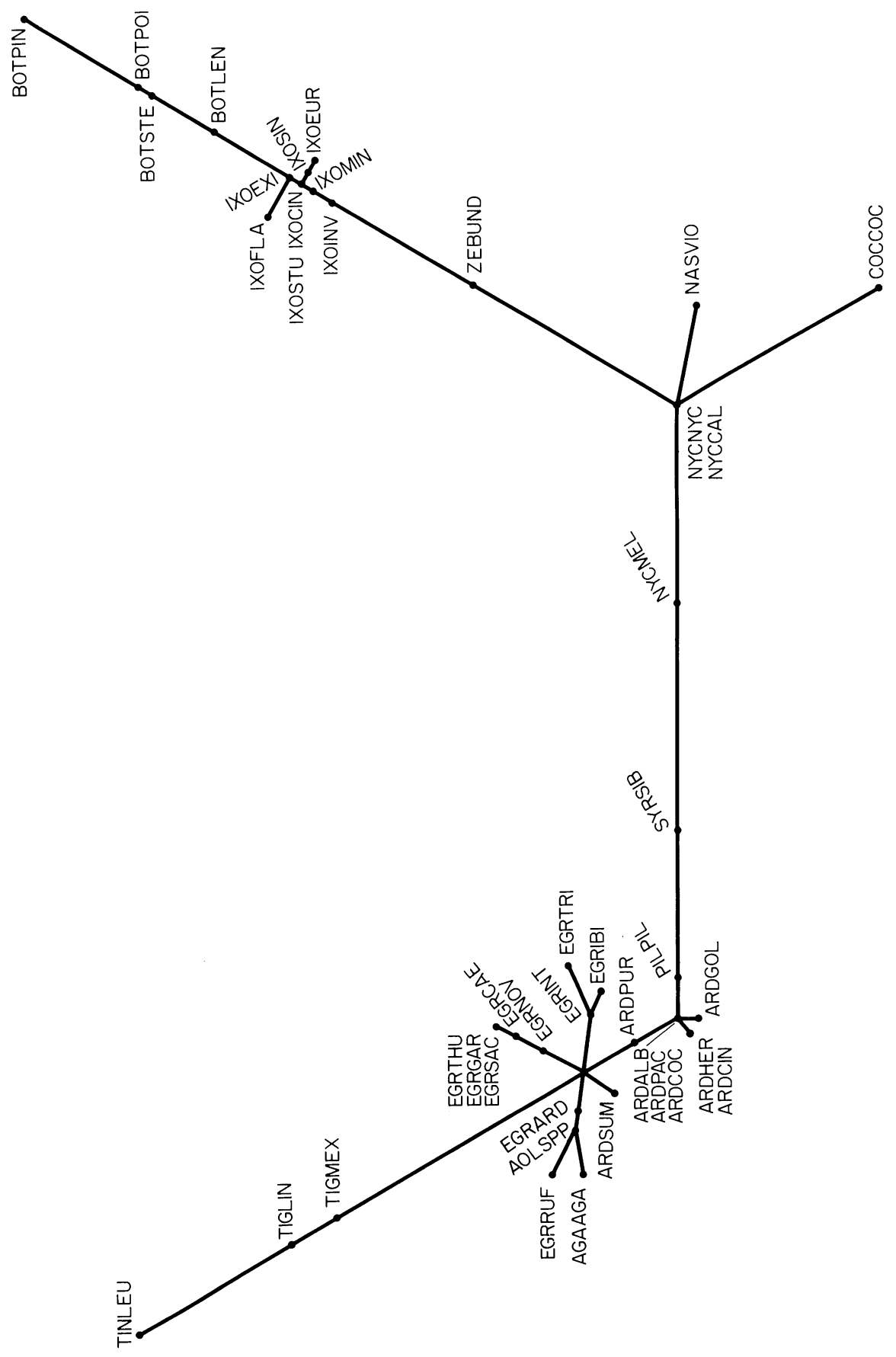


the tiger herons. Ordination on PC 2 and 3 together (not illustrated) as well as ordination on PC 4 showed a distinct separation between the large bitterns Botaurus and the small bitterns Ixobrychus.

A minimally connected graph was constructed to compare the overall similarity among the herons as described by the principal components ordination values. Each species is connected to the similar species, with the similarities determined by computing similarity

TABLE 4

EIGENVECTORS OF PRINCIPAL COMPONENTS ORDINATION OF 33 CHARACTERS OF HERON SPECIES

\begin{tabular}{|c|c|c|c|c|c|}
\hline \multirow{2}{*}{$\begin{array}{l}\text { Character } \\
\text { Number }\end{array}$} & \multirow{2}{*}{$\begin{array}{c}\text { Character } \\
\text { Name }\end{array}$} & \multicolumn{4}{|c|}{ Eigenvectors } \\
\hline & & PC I & II & III & IV \\
\hline 1 & Skull: bill shape & -.004 & .247 & -.159 & .365 \\
\hline 2 & palatine shape & -.004 & .247 & -.159 & .365 \\
\hline 3 & palatine emargination & .096 & .109 & .082 & .382 \\
\hline 4 & palatine lateral process & -.134 & .114 & .111 & -.083 \\
\hline 5 & interorbital foramen & -.188 & .205 & -.144 & -.151 \\
\hline 6 & supraorbital foramen & .043 & .300 & .022 & -.029 \\
\hline 7 & lacrimal size & .091 & .020 & .391 & -.183 \\
\hline 8 & lacrimal ventral projection & .171 & .189 & .170 & -.039 \\
\hline 9 & lacrimal lateral groove & .236 & -.040 & .162 & .010 \\
\hline 10 & ectethmoid & -.089 & -.276 & -.240 & -.188 \\
\hline 11 & ectethmoid tubercle & .169 & -.081 & -.055 & .018 \\
\hline 12 & ectethmoid ridge & -.292 & .070 & .007 & .107 \\
\hline 13 & basitemporal ridge & .051 & -.286 & .213 & .208 \\
\hline 14 & Vertebrae: axis shape & .034 & .234 & -.125 & -.195 \\
\hline 15 & lateral canal & .045 & -.272 & .219 & .212 \\
\hline 16 & rib facets & .051 & .286 & .213 & .208 \\
\hline 17 & Sternum: notch & .073 & .082 & .247 & -.022 \\
\hline 18 & manubrial length & -.008 & -.080 & -.122 & .317 \\
\hline 19 & sternocoracoidal process & -.248 & .197 & .158 & -.029 \\
\hline 20 & Coracoid: sternal facet & -.303 & -.073 & .124 & .115 \\
\hline 21 & Furculum: external spine & -.132 & -.162 & -.016 & .127 \\
\hline 22 & internal spine & .096 & -.160 & -.171 & .071 \\
\hline 23 & Humerus: deltoid crest shape & -.303 & -.073 & .124 & .115 \\
\hline 24 & deltoid crest height & -.313 & .014 & .051 & -.078 \\
\hline 25 & pneumatic fossa & .020 & .274 & -.060 & .349 \\
\hline 26 & ligamental furrow & .105 & .169 & .367 & -.001 \\
\hline 27 & Synsacrum: iliac crest shape & -.271 & .175 & .086 & -.023 \\
\hline 28 & posterior iliac crest & -.143 & -.012 & .086 & -.085 \\
\hline 29 & parapophyses fusion & .105 & .169 & .367 & -.001 \\
\hline 30 & iliac recess & .106 & .132 & .042 & .014 \\
\hline 31 & ischiopubic symphysis & -.303 & -.073 & .124 & .115 \\
\hline 32 & Tarsometatarsus: intercotylar prominence & .305 & .045 & -.102 & -.049 \\
\hline \multirow[t]{3}{*}{33} & metatarsal foramen & -.157 & -.015 & .084 & -.072 \\
\hline & Component & 9.08 & 6.95 & 4.89 & 2.79 \\
\hline & Total cumulative variance & $27.5 \%$ & $48.6 \%$ & $63.4 \% 7$ & $71.8 \%$ \\
\hline
\end{tabular}




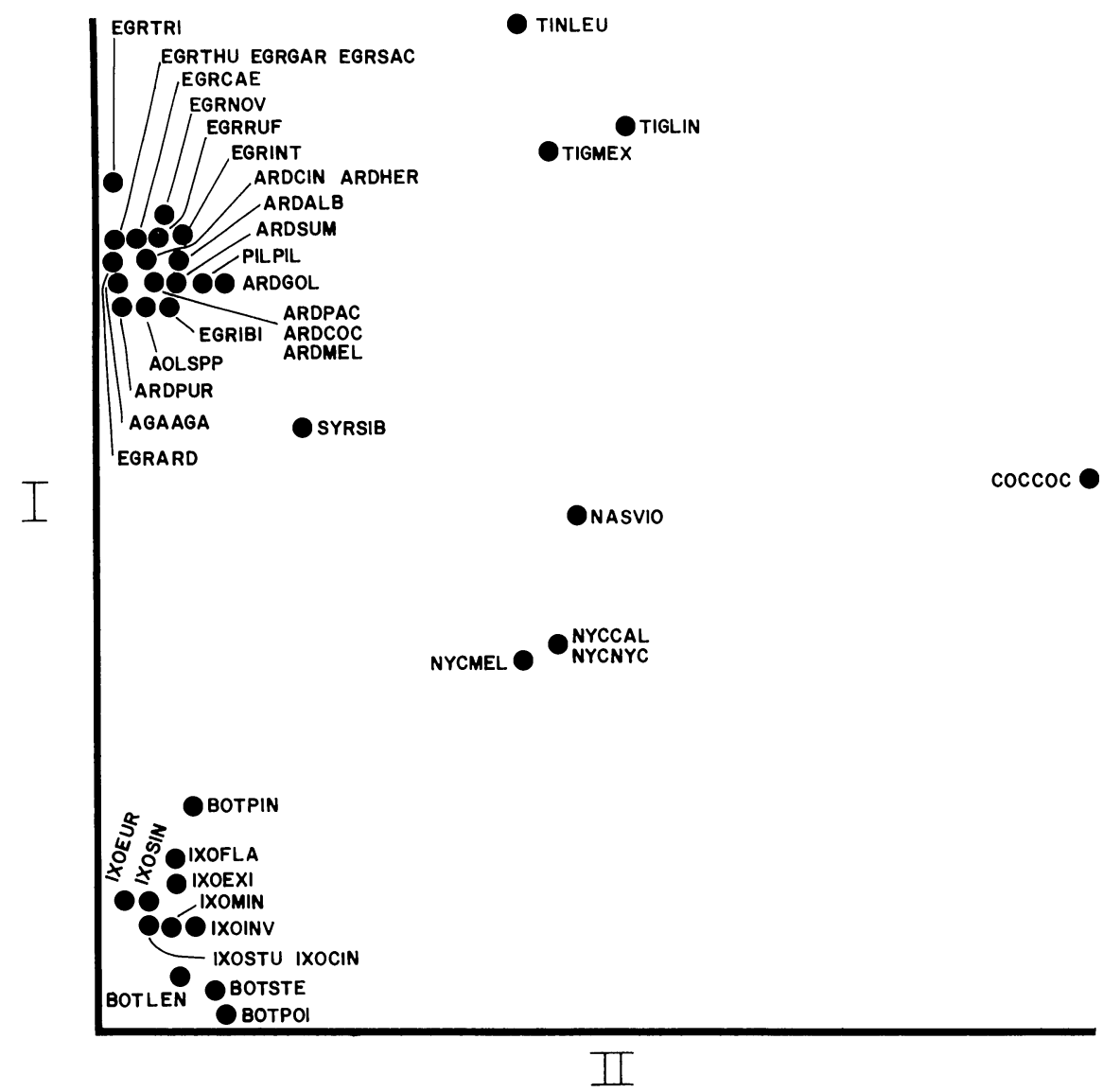

Fig. 26. Principal components analysis of Ardeidae.

values among species from the character eigenvectors on PC 1-4 of Table 4. The technique of deriving a minimally connected graph of species from their character eigenvectors is useful for clarifying phenetic relations when these may have been distorted by graphic representation of the principal components values in restricted two dimensional space (Sneath and Sokal, 1973: 255-257); we have separated the two graphs for clarity. Figure 27 shows the same general phenetic relationships among species that were evident in the two dimensional graph in Figure 26, with the species of day herons, night herons, tiger herons, and bitterns each being more similar to each other than to a member of another group. Syrigma is more similar to the day herons than to the night herons. The egrets do not form a distinct cluster or branch, though they are closer to each other than to the larger Ardea species.

The close association of day herons in Figures 26 and 27 was resolved somewhat by principal components analysis restricted to 


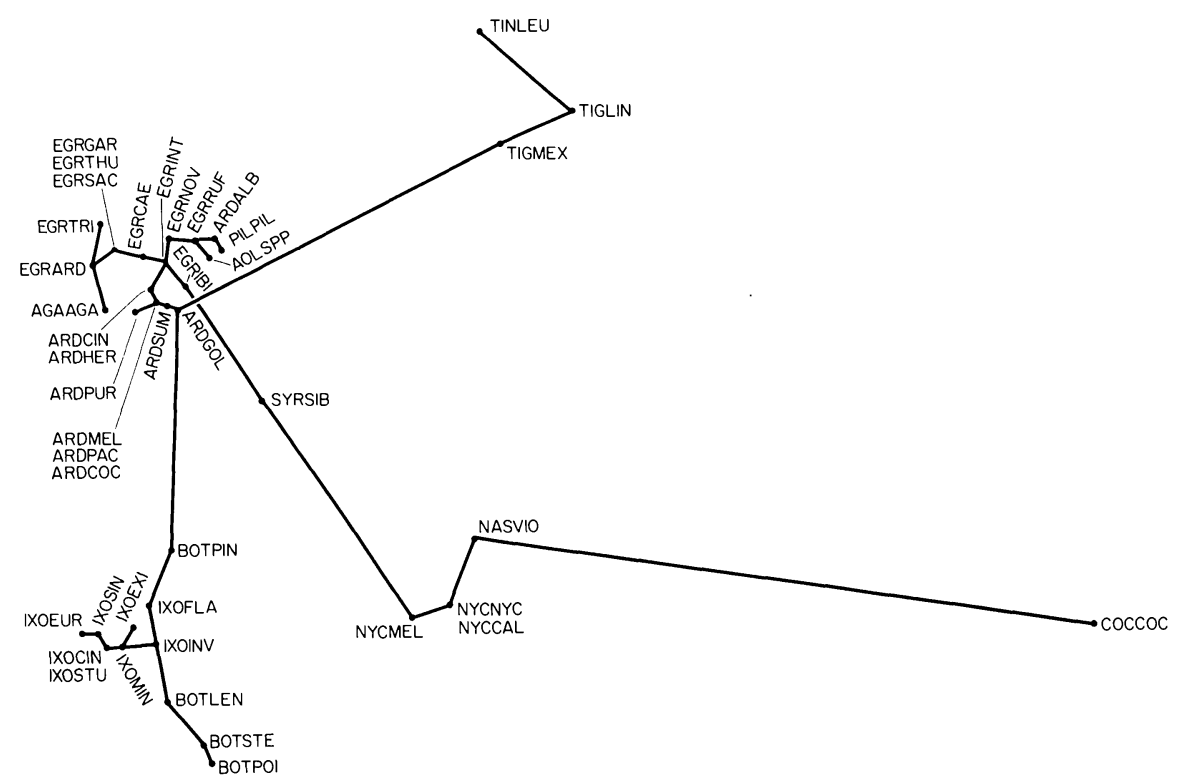

Fig. 27. Minimally connected graph of Ardeidae. Lines connecting the species are constructed from a Prim Network analysis of the eigenvectors of principal components 1-4 from Table 4.

those 23 species (Table 5, Fig. 28). Syrigma is strongly separated from the other day herons. The large Ardea (including alba) species do not overlap the egrets Egretta. The egrets, Ardeola, and Agamia do not appear to be very distinct from each other, and Ardeola and Agamia are most similar to each other. Pilherodius is not clearly distinct from this complex. A minimally connected graph illustrated in Figure 29 was constructed from the eigenvectors of PC 1-4 from Table 5 to control for two-dimensional distortion of the phenetic relationships in Figure 28. The results agree closely with the phenetic similarities shown in the two-dimensional graph of principal components ordination of the herons. Each species of Egretta (including rufescens) has as its most closely associated species another egret, and each Ardea is most closely associated with another Ardea species.

Principal components analysis of the 26 characters available in the specimen of Zebrilus gave the results summarized in Table 6 and Figure 30. The same constellation of species occurs with only slight distortion caused by the smaller set of characters and by the inclusion of either or both of these two additional forms, though in the reduced character set Syrigma is equally similar to Egretta ibis and Nycticorax nycticorax. Zebrilus is phenetically intermediate between the night herons and the bitterns in PC 1 and 2 but is clearly associated with the bitterns alone in PC 1 and 3 and also in PC 2 and 3 (not illustrated but see Table 6). The hypothetically 


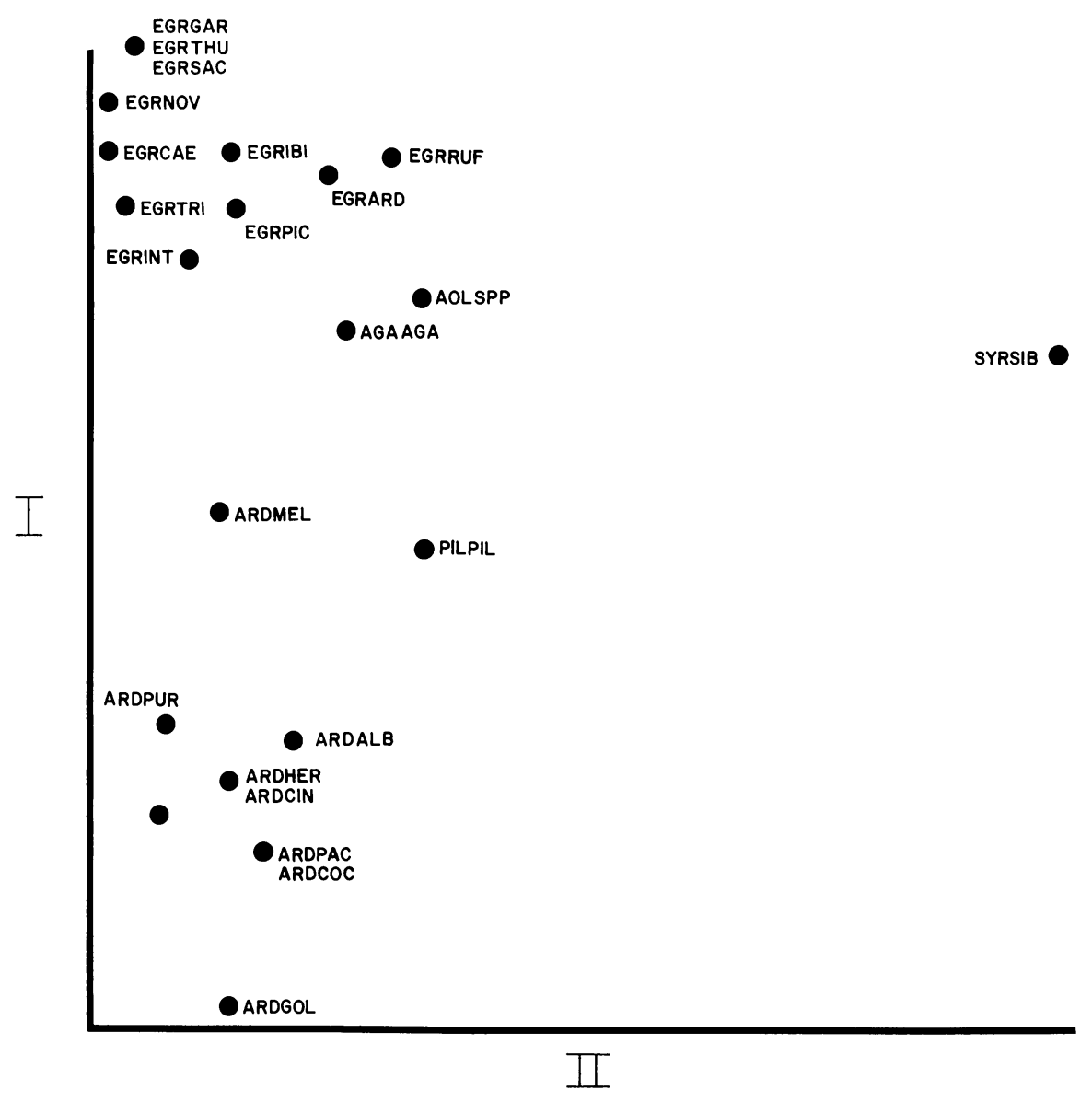

Fig. 28. Principal components analysis of the day herons Ardeinae.

reconstructed heron ancestor "primardea" is phenetically intermediate between the tiger herons, the day herons, and the night herons, and is most different from the bitterns, in PC 1 and 2 (Fig. 30) intermediate between night and day herons in PC 1 and 3 , and associated with the night herons in PC 2 and 3. A minimally connected graph constructed by Prim Network analysis of the eigenvectors of Table 6 and illustrated as Figure 31 estimates the phenetic resemblance of Zebrilus to be closest to the bitterns, as did the two-dimensional graphic ordination of herons on PC 1 and 3 and also on PC 2 and 3.

The hypothetical ancestor "primardea" is more similar to the night herons than to any of the other living species of herons in several analyses: in Fig. 26, in the minimal connected network of the principal components values of the complete set of characters (where it is slightly closer to Nyctanassa than to Syrigma), in the minimal connected net- 


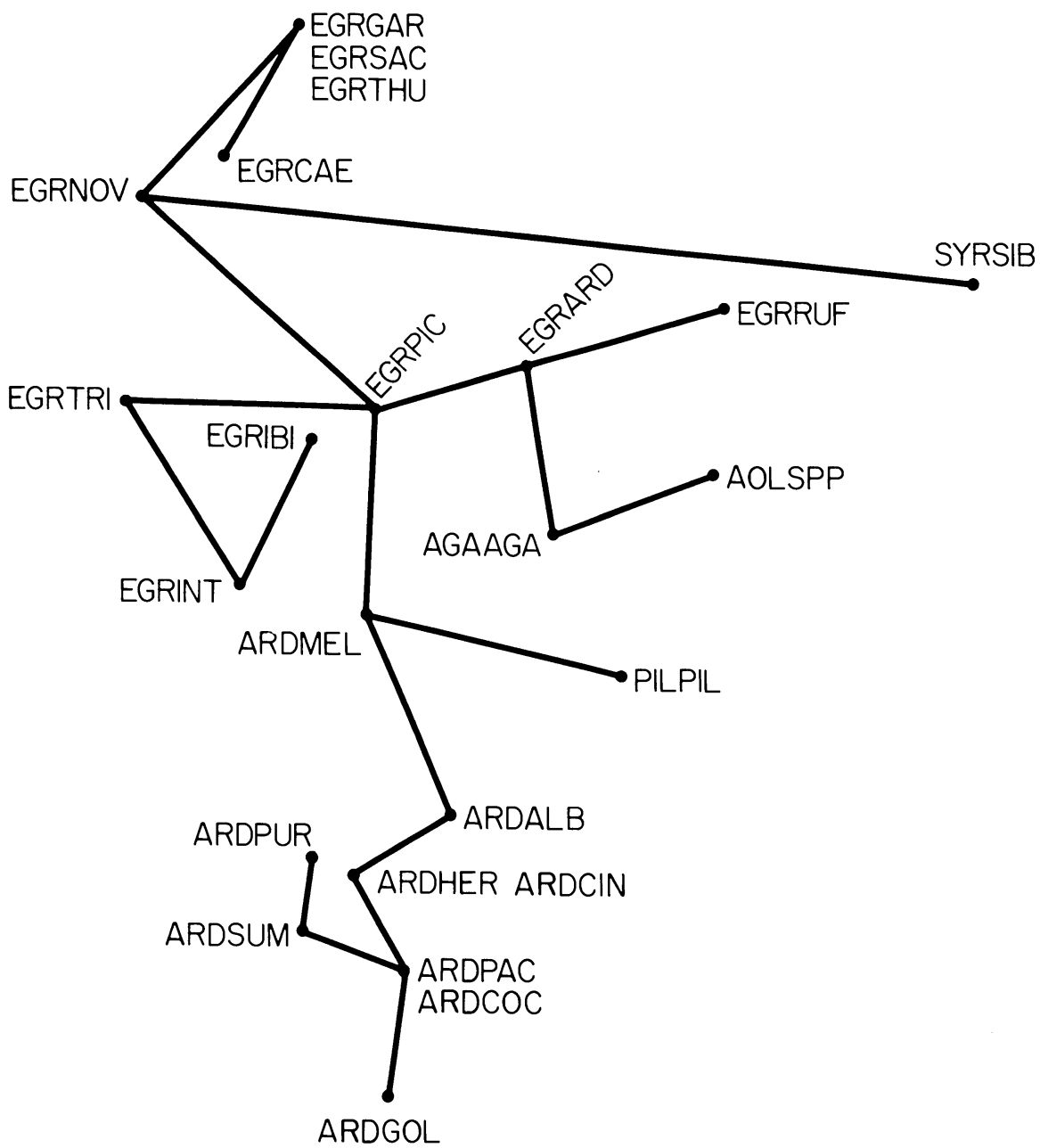

Fig. 29. Minimally connected graph of the species of day herons Ardeinae, derived from a Prim Network analysis of eigenvectors of principal components 1-4 from Table 5 .

work of the character states themselves (as in Fig. 24), and in the correlation coefficient phenogram (where it appears between Cochlearius and the other night herons). In the simple matching coefficient phenogram, "primardea" is closest to Syrigma, which is distantly associated with other day herons. According to the reconstruction of a primitive heron based mainly on the skeletal characters of other kinds of Ciconiiformes, the primitive herons may have looked something like one of these day herons or night herons.

Examination of the eigenstructure in Tables 4-6 allows an estimation of the degree to which the principal component ordination 
TABLE 5

EIGENVECTORS OF PRINCIPAL COMPONENTS ORDINATION OF 13 CHARACTERS OF DAY HERONS ARDEINAE

\begin{tabular}{clrrrr}
\hline \multirow{2}{*}{$\begin{array}{c}\text { Character } \\
\text { Number }\end{array}$} & \multicolumn{2}{l}{ Character } & \multicolumn{4}{c}{ Eigenvectors } \\
& Name & PC I & II & III & IV \\
\hline 3 & Skull: palatine emargination & .267 & .129 & .189 & .300 \\
4 & palatine lateral process & -.394 & .232 & .168 & .096 \\
5 & interorbital foramen & .019 & .460 & -.405 & .044 \\
6 & supraorbital foramen & -.259 & -.083 & -.046 & -.024 \\
8 & lacrimal ventral projection & .168 & -.164 & -.248 & -.652 \\
9 & lacrimal lateral groove & -.294 & .029 & .515 & -.243 \\
11 & ectethmoid tubercle & .317 & -.189 & .073 & .431 \\
14 & Vertebrae: axis shape & .422 & .138 & .059 & .081 \\
15 & $\quad$ lateral canal & -.019 & -.460 & .405 & -.044 \\
18 & Sternum: manubrial length & .368 & .151 & .064 & -.319 \\
21 & Furculum: external spine & .143 & .416 & .410 & .040 \\
22 & internal spine & -.015 & -.440 & -.247 & .296 \\
30 & Synsacrum: iliac recess & -.395 & .166 & -.196 & .170 \\
& & & & & \\
& Component & 3.47 & 3.06 & 1.89 & 1.17 \\
& Total cumulative variance & $26.7 \%$ & $50.2 \%$ & $64.7 \%$ & $73.7 \%$
\end{tabular}

values of the herons may be heavily weighted on any single functionally adapted set of characters. If the high values were associated mainly with the bill mechanism, the pectoral assemblage, or the vertebrae, one might question the use of the characters as approximations of a representative set of characters that reflect different and independent functional complexes and a large number of genetic differences associated with them. In Table 4 the sequence of characters (from the greatest) associated with PC 1 was: humerus (deltoid crest height), tarsometatarsus (intercotylar prominence), synsacrum (ischiopubic symphysis), coracoid (sternal facet), and humerus (deltoid crest shape). Eigenvectors with high loading for PC 2 were found for skull (supraorbital foramen, basitemporal ridge, ectethmoid), humerus (pneumatic fossa), and vertebra (lateral canal). Values affecting PC 3 were in the skull (lacrimal size) and humerus (ligamental furrow) and synsacrum (anterior parapophysial fusion). Note that most eigenvectors with high loading are associated with postcranial characters and so are unlikely to be related to adaptations directly involving the feeding mechanism, and also that each principal component is affected nearly equally by several characters from different parts of the body. The value and anatomical distribution of characters with eigenvectors of high loading give some support to the hypothesis that the characters used to describe variation may be appropriately representative of the overall differences among the heron species (the non-specificity hypothesis, Sneath and Sokal, 1973: 97-103). Eigenvector analysis of the other two principal 
TABLE 6

EIGENVECTORS OF PRINCIPAL COMPONENTS ORDINATION OF 26 CHARACTERS OF HERONS INCLUDING ZEBRILUS AND "PRIMARDEA"

\begin{tabular}{ccrrrr}
\hline \multirow{2}{*}{$\begin{array}{c}\text { Character } \\
\text { Number }\end{array}$} & Character & \multicolumn{4}{c}{ Eigenvectors } \\
& Name & PC I & II & III & IV \\
\hline 1 & Skull: bill shape & -.039 & .237 & -.199 & .482 \\
2 & palatine shape & -.039 & .237 & -.199 & .482 \\
5 & interorbital foramen & -.221 & .231 & -.172 & -.229 \\
6 & supraorbital foramen & .021 & .344 & -.018 & -.025 \\
7 & lacrimal size & .104 & .054 & .450 & -.180 \\
8 & lacrimal ventral projection & .142 & .216 & .219 & .102 \\
9 & lacrimal lateral groove & .280 & .008 & .163 & -.006 \\
10 & ectethmoid & -.067 & -.301 & -.259 & -.312 \\
11 & ectethmoid tubercle & .195 & -.087 & -.046 & .036 \\
12 & ectethmoid ridge & -.341 & .020 & .011 & .123 \\
14 & Vertebrae: axis shape & .025 & .271 & -.135 & -.143 \\
15 & lateral canal & .093 & -.312 & .235 & .244 \\
16 & rib facets & .099 & -.319 & .220 & .222 \\
17 & Sternum: notch & .078 & .113 & .293 & .053 \\
18 & manubrial length & .019 & .161 & -.099 & .385 \\
19 & sternocoracoidal process & -.301 & .167 & .190 & .051 \\
20 & Coracoid: sternal facet & -.338 & -.122 & .136 & .064 \\
21 & Furculum: external spine & -.120 & -.238 & -.014 & .067 \\
22 & internal spine & .133 & -.193 & -.172 & .136 \\
27 & Synsacrum: iliac crest shape & -.326 & .135 & .107 & .035 \\
28 & posterior iliac crest & -.159 & -.027 & .115 & -.050 \\
29 & parapophyses fusion & .100 & .203 & .414 & .072 \\
30 & iliac recess & .116 & .182 & .009 & -.013 \\
31 & ischiopubic symphysis & -.338 & -.122 & .136 & .064 \\
32 & Tarsometatarsus: intercotylar prominence & .342 & .093 & -.120 & -.015 \\
33 & metatarsal foramen & -.176 & -.036 & .113 & -.038 \\
& Component & 6.97 & 5.34 & 3.73 & 2.14 \\
& Total cumulative variance & $26.8 \%$ & $47.4 \%$ & $61.7 \%$ & $69.9 \%$ \\
& & & &
\end{tabular}

components analyses gave similar results. The day herons Ardeinae were very much alike in the postcranial characters except for vertebral characteristics of Syrigma, the processes on the sternum and furculum, the iliac recess, and seven cranial characters some of which probably are related to species adaptations for feeding (Table 5). The more important components affecting PC 1, which separated the large Ardea species from the egrets, included the shape of the axis, the iliac recess, the shape of the palatines, and the sternal manubrium. In Table 6 the eigenvectors with the highest loadings were mainly postcranial and largely similar to those of Table 4 . The conclusions drawn about phenetic similarities from the principal components axis appear to be based on a wide array of skeletal characters that are not closely related in the sense of their anatomical function. 


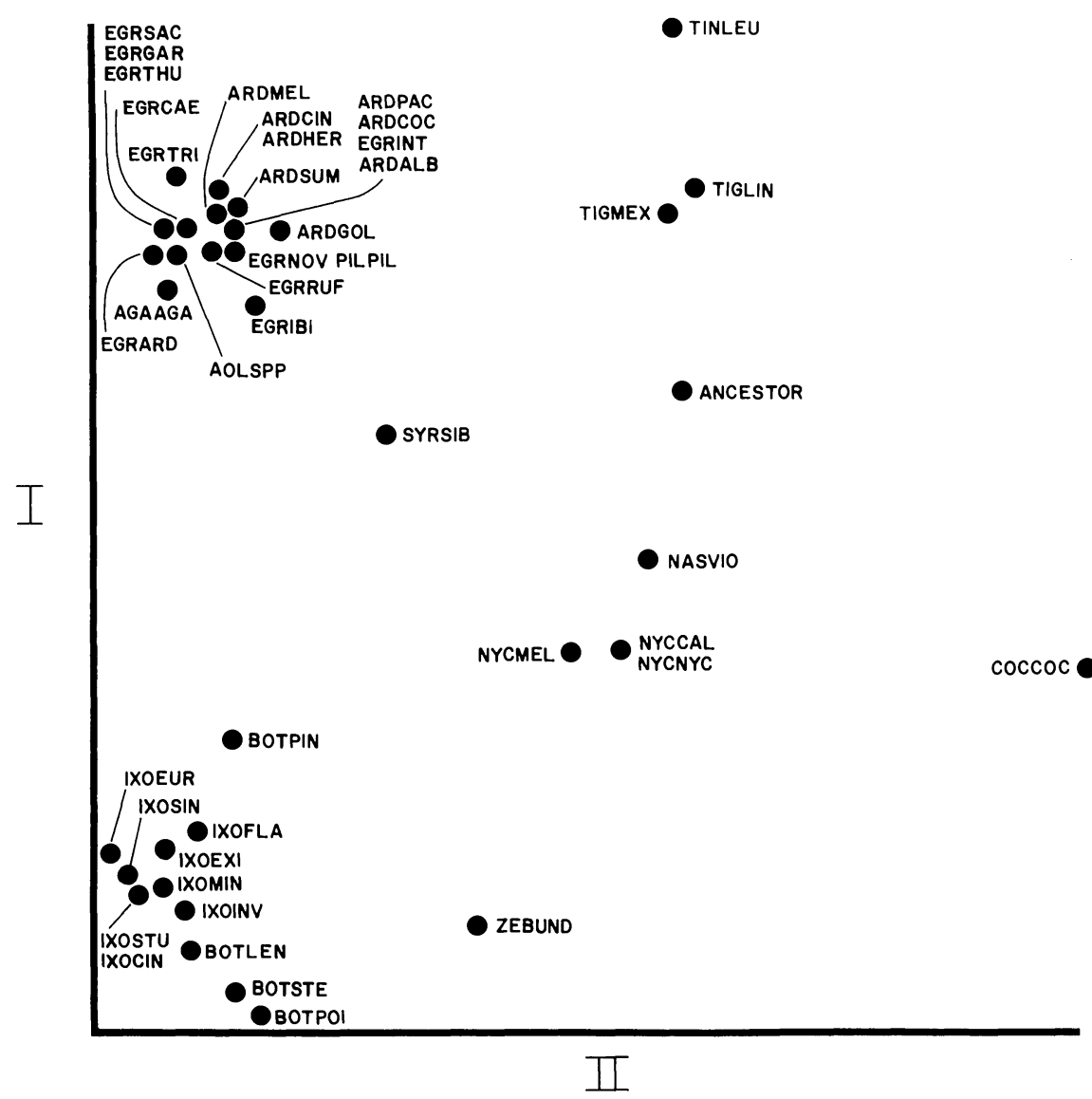

Fig. 30. Principal components analysis of herons including Zebrilus and also a hypothetical ancestor "primardea."

The phenetic similarity associations among heron species were determined for the set of discrete skeletal character states by two routines similar to two used for skeletal measurements of gulls and for character states of ploceine nest structure by Schnell (1970, 1973). Figure 32 summarizes the resemblance among the heron species as determined by simple matching coefficient analysis of the distance matrix (Sneath and Sokal, 1973: 132-133). Four major groups are evident and these correspond to the same sets of species as in the earlier minimally connected graphs and the principal components analyses. Many species associations within these groups are similar to those of the other phenetic analyses, but a few differences are evident; in particular, the bitterns are more closely associated with the night herons than either group is with the day herons. The egrets are more closely associated with each other (and with Agamia and Ardeola) than with the large Ardea species, and the egrets are 


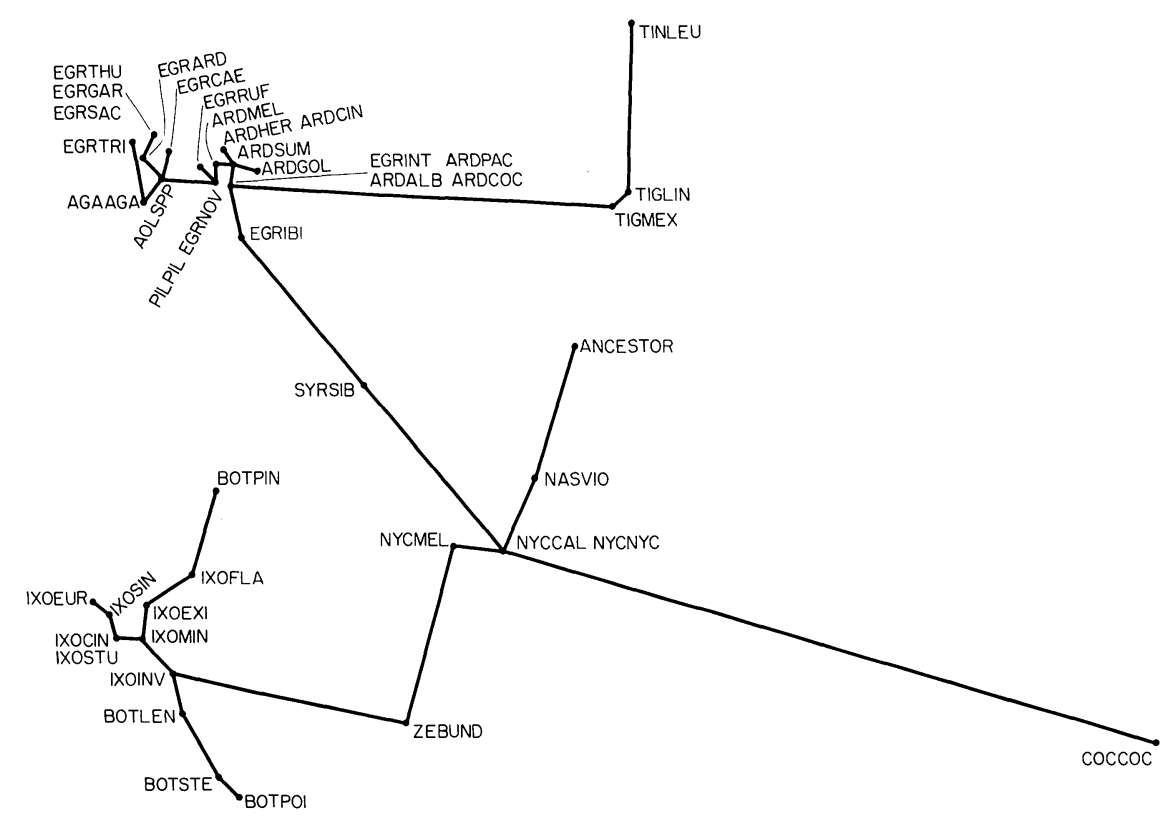

Fig. 31. Minimally connected graph (Prim Network) of the eigenvectors of principal components 1-4 from Table 6 .

less similar to each other than are the large Ardea species. Egretta rufescens is a distinct form. Figure 33 shows the phenetic resemblance of heron species based on Pearson product-moment correlation coefficient analysis (Sneath and Sokal, 1973: 137). The same associations of species are very similar to those in Figure 32, although Syrigma is associated with the night herons rather than with the day herons.

The results of these similarity analyses, together with the other phenetic results allow us to conclude that there are four distinct groups of heron species, and also that certain groups of species generally occur together. Associations among the species within the groups appear to be consistent at several levels, particularly the separation of the Ixobrychus and Botaurus bitterns, Cochlearius and the other night herons, and Syrigma and the other day herons.

\section{ESTIMATING THE EVOLUTIONARY HISTORY OF THE HERONS}

The results of two versions of the Wagner Tree analysis are shown in Figures 34 and 35. Figure 34 summarizes results of this phylogenetic estimate for all species represented by complete skeletal material. Four distinct and different groups are recognizable by the long distances separating the tiger herons, the day herons, the 


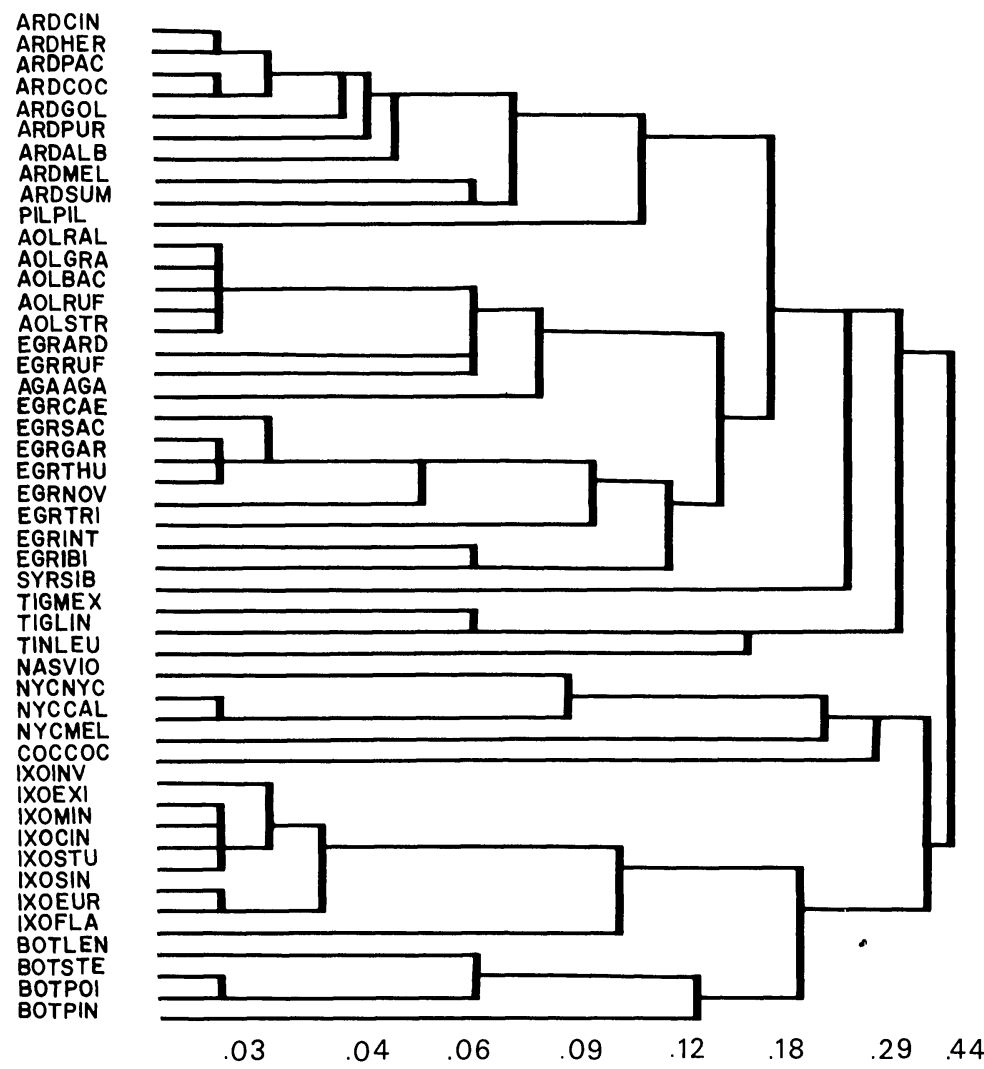

Fig. 32. Association phenogram (simple matching coefficients) of heron species based on character states of 33 skeletal characters. The cophenetic correlation is .938 .

bitterns, and the night herons. Cladistic separation of these four groups is not clearly shown, however, as the day heron-tiger heron branch is pictured as first splitting with Syrigma, the tiger herons are a second-order branch, and the night herons are not cladistically distinct from the bitterns. If phenetic differences are considered together with the cladistic estimate we can recognize a branching pattern that separates tiger herons from day herons as being more important than that separating a single species Syrigma. In the day herons, the egrets, pond herons Ardeola spp., and Agami Heron Agamia are not cladistically distinct from the large Ardea herons. The species recognized as egrets are represented as a monophyletic group, with the possible exception of the species rufescens, which appears to be cladistically distinct. Two groups of egrets are apparent, the "typical" egrets novaehollandiae, caerulea, garzetta, thula, and sacra, and the more diverse assemblage of picata, ardesiaca, tricolor, intermedia, and ibis. 

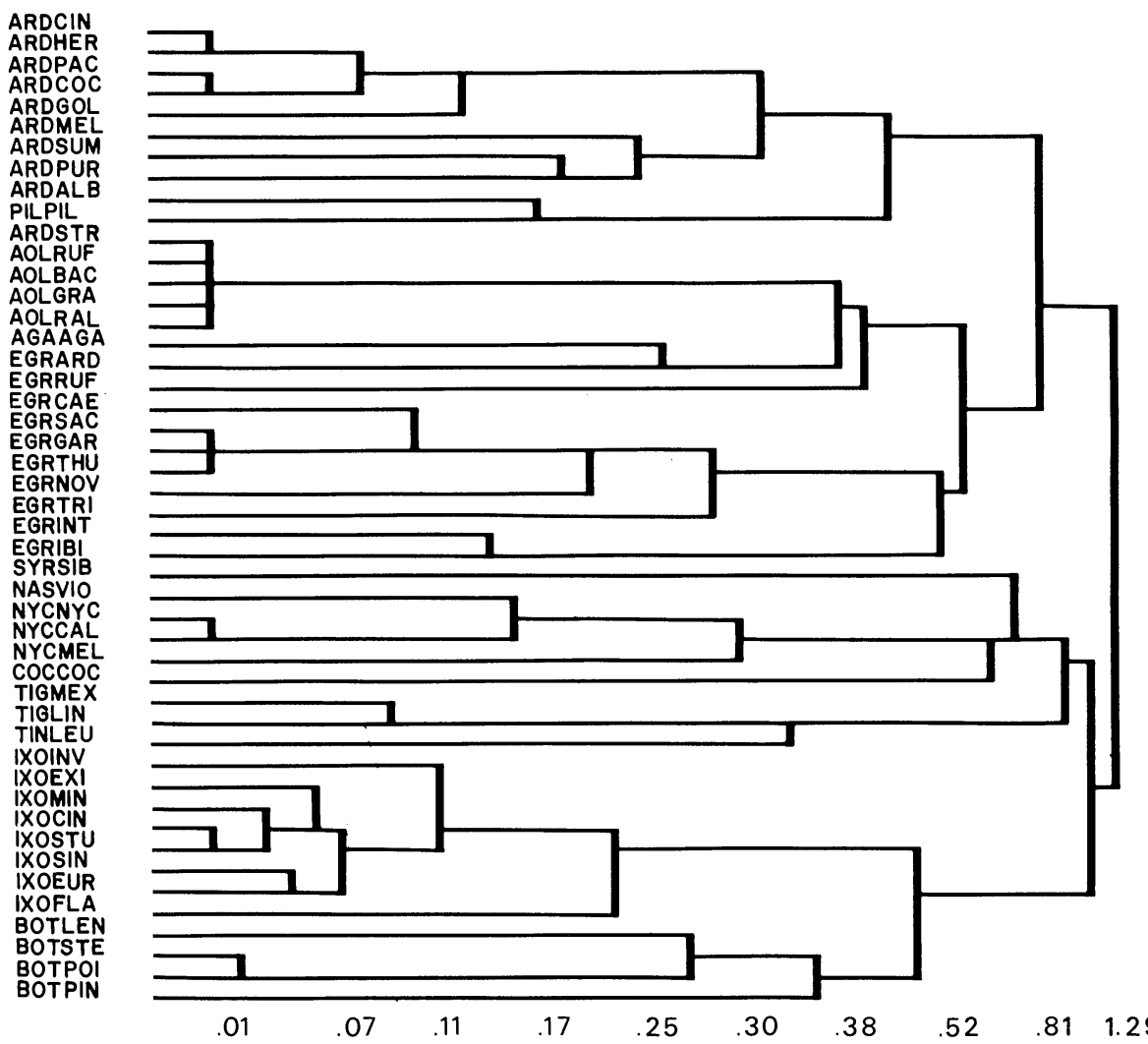

Fig. 33. Correlation phenogram (Pearson product-moment correlation coefficients) of heron species based on character states of 33 skeletal characters. The cophenetic correlation is .929 .

A Wagner Tree analysis was also completed using only the 26 characters that were available for the specimen of Zebrilus (but not including picata). In the results, Zebrilus is clearly associated with the bitterns, as it was in the phenetic routines (Fig. 35), and Botaurus and Ixobrychus each are estimated to be monophyletic groups.

The minimum pathways of differentiation of each character from the states found in "primardea" are summarized in Figure 36. The phylogenetic analysis of the Wagner Tree indicates that many character states may also undergo reversal and independent derivation, as the $c$-values (the "index of constancy" of Kluge and Farris (1969)) suggest that the skeletal characters have undergone on the average more than two reversals or multiple origins of state.

In the cladistic compatibility analyses the largest set of compatible characters included 16 of the original 33 characters. Figure 37A diagrams the cladistic history of the herons as estimated from the compatibility analysis. The diagram indicates four cladistically 


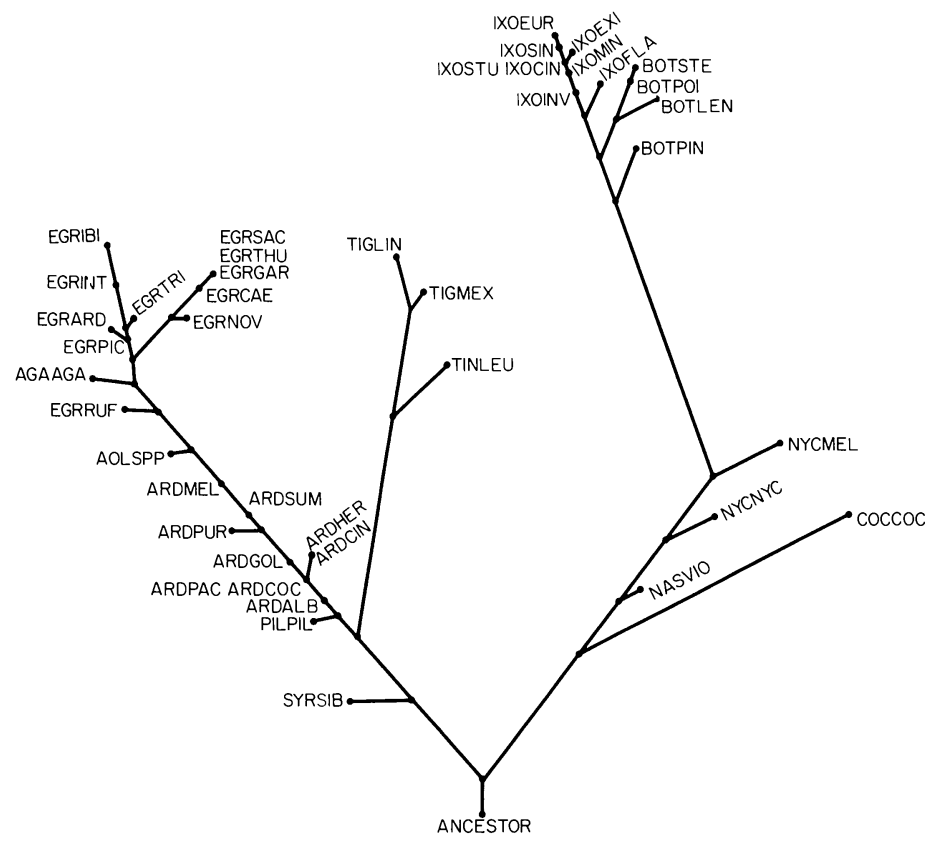

Fig. 34. Estimate of heron phylogeny by the Wagner Tree or directed most parsimonious graph of Ardeidae. Intermediate points indicate position of hypothetical taxonomic units. $c=.438$.

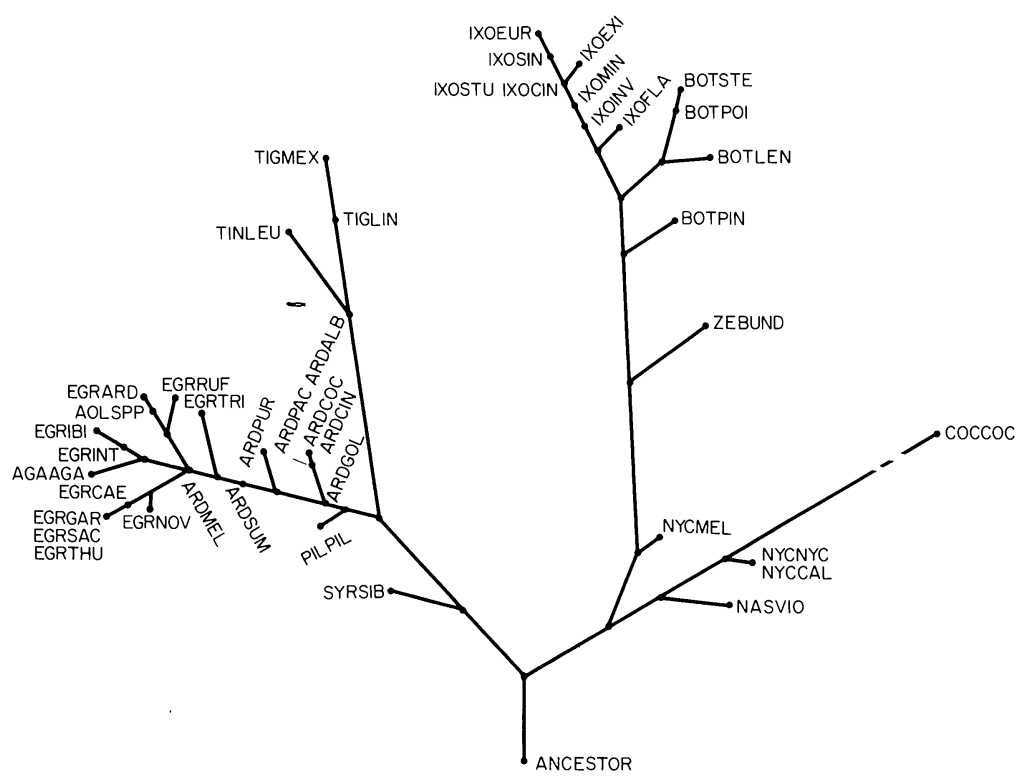

Fig. 35. Estimate of heron phylogeny by the Wagner Tree analysis of the Ardeidae including Zebrilus, using 26 characters. $c=.400$. 
CHARACTER STATE ANCESTORS AND TREES

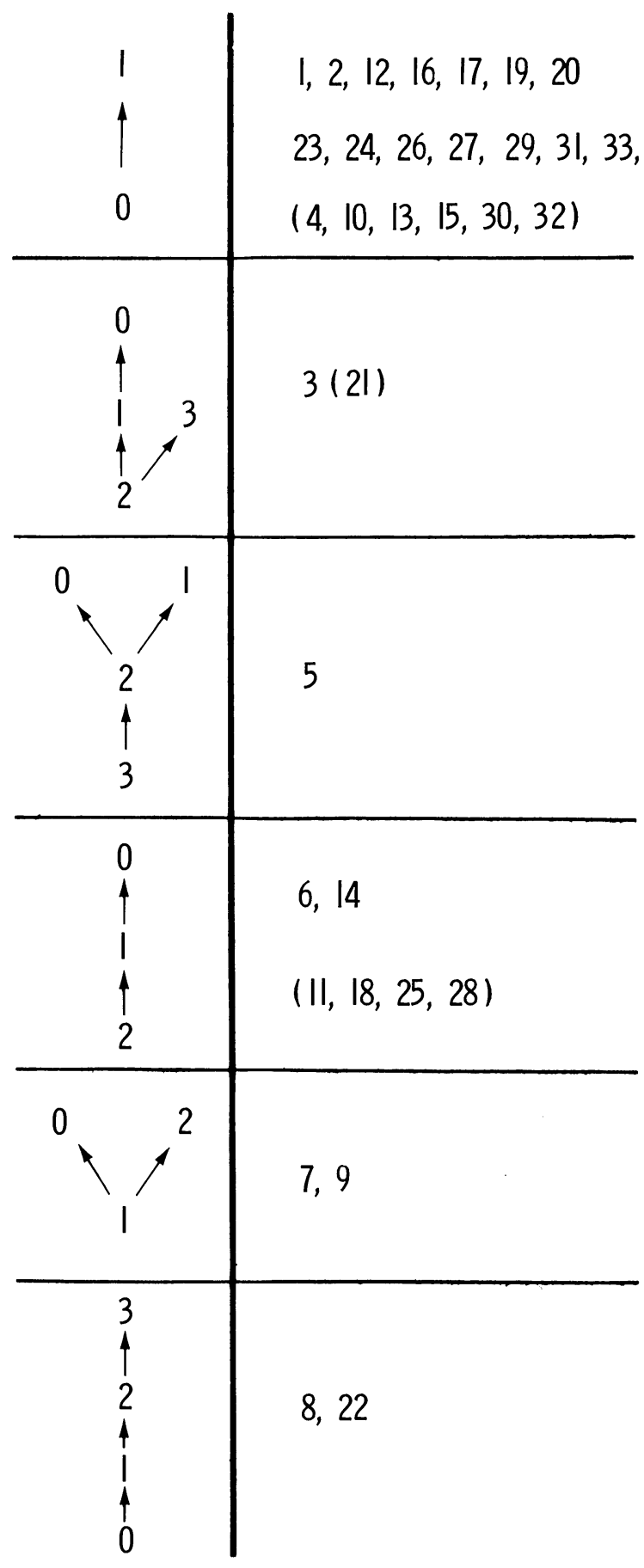

Fig. 36. Proposed evolutionary pathways of initial directions of differentiations of 33 characters used in study. Ancestral character states as found in the hypothetical ancestor "primardea" are connected by arrows to derived character states. Character numbers in parentheses show reverse coding (i.e. Character 4 has the ancestral character state coded 1 and the derived character state coded 0 ). 

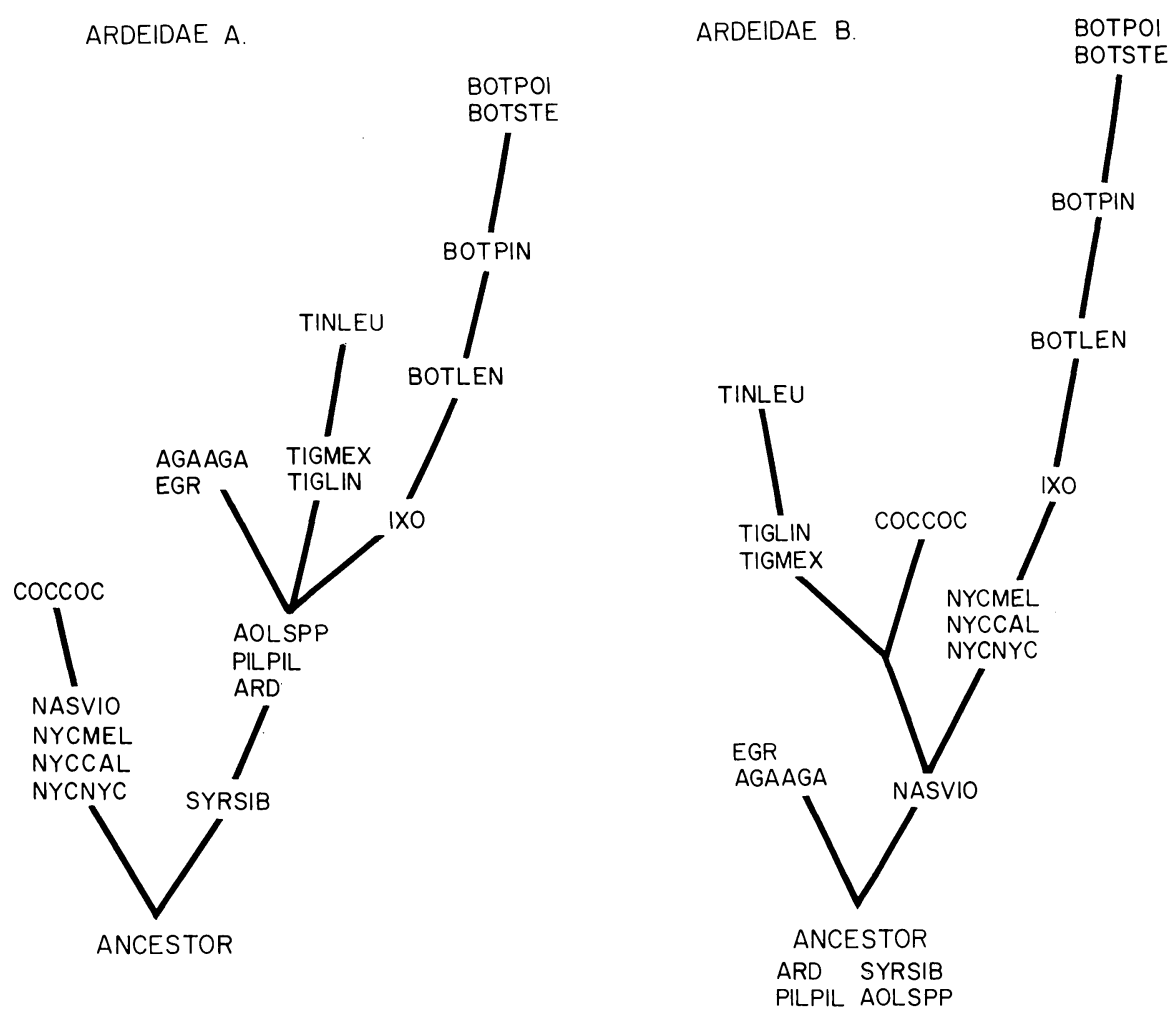

Fig. 37. Diagram of heron phylogeny estimated by the cladistic compatibility algorithm COMPTREE. Diagrams $\mathrm{A}$ and B are based on equally maximal numbers of compatible character suites or cliques. A: characters $1,2,4,7,13$, $15,16,17,20,23,26,28,29,31,32,33$. B: characters $1,2,4,7,10,17,19$, $20,23,24,26,28,29,31,32,33$.

separate groups, the night herons (including Cochlearius), part of the day herons (the egrets and Agami Heron), the tiger herons, and the bitterns. The character differentiating the night heron clade from the "primardea" ancestor is the presence of a high ridge around the lateral aspect of the basitemporal; the character differentiating the other clade is the shape of the axis and (except in Syrigma) the condition of the 17 th vertebra. The cladistic distinctions are made on single character state changes in most instances. A second equally parsimonious diagram, with a slightly different set of 16 characters determined to be compatible in the same original 33 characters, suggests a different cladistic history (Fig. 37B). The day herons are not differentiated from the ancestor "primardea" and the bitterns and tiger herons are figured as independent derivatives of the night herons, with Cochlearius being a derivative of the tiger heron line. We regard Fig. 37A to be the better estimate of cladistic history because it is more closely supported by the other phylogenetic 
estimate and by the phenetic descriptions of similarity, in particular in placing Cochlearius with the night herons.

Cladistic compatibility tests were also made for the four groups of the herons and the results are pictured in Figures 38-41. There were no cladistic divergences estimated in the day herons. Figure 38 shows the two largest sets of compatible characters which give two different estimates of evolutionary history. Figure 38A estimates that the egrets together with Agamia are distinct from the large Ardea species; Figure 38B does not. The cladistic estimate of the night herons also involves two numerically equal trees (Fig. 39A, B), one of which (A) corresponds closely to the phenetic differentiation indicated in the principal components analysis and in Figures 34 and 35 in the Wagner Tree analysis, whereas the other (B) does not correspond with other phylogenetic results or with phenetic estimates of differences so is less likely to be the evolutionarily true cladistic history than is A. Figure 40 shows the cladistic estimate of the largest suite of compatible characters (33) of the tiger herons. The

DAYHERONS A.

EGRTRI EGRINT

EGRNOV EGRIBI

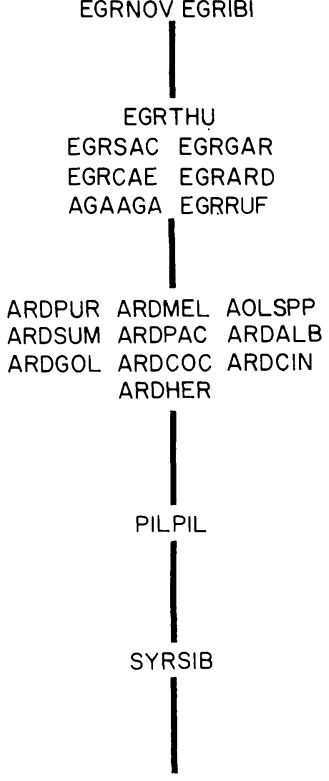

ANCESTOR
DAYHERONS B.

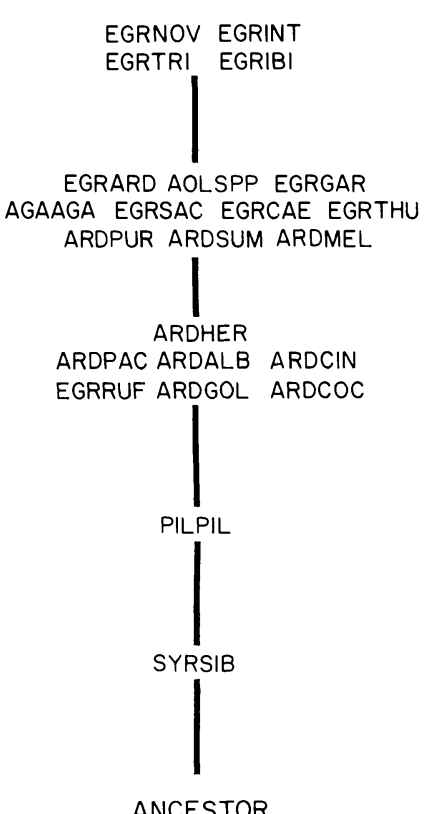

Fig. 38. Diagram of phylogeny within the day herons Ardeinae as estimated by the cladistic compatibility program COMPTREE. Diagrams A and B are based on equally maximal numbers of compatible character suites. A: characters $1,2,5,7,8,10,13,15,16,17,19,20,23,24,25,26,27,28,29$, $30,31,32,33$. B: characters $1,2,4,5,7,8,10,13,15,16,17,19,20,23,24$, $25,26,27,28,29,31,32,35$. 
NIGHT HERONS A

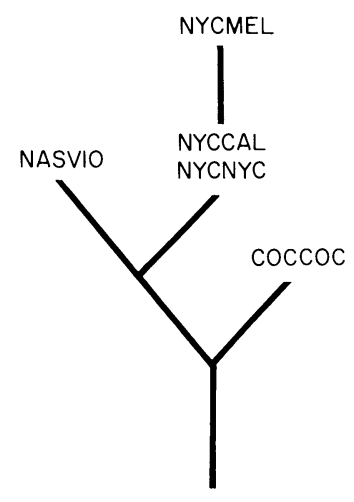

ANCESTOR
NIGHT HERONS B.

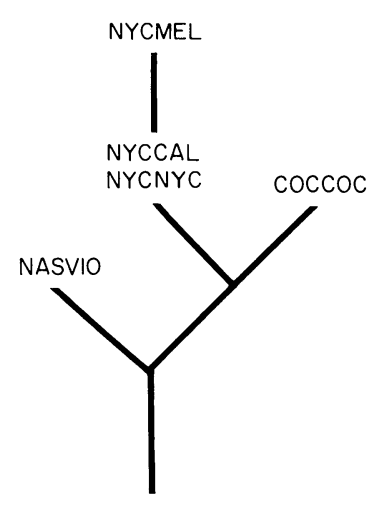

ANCESTOR

Fig. 39. Diagram of phylogeny within the night herons Nycticoracinae as estimated by the cladistic compatibility program COMPTREE. Diagrams A and B are based on equally maximal numbers of compatible character suites. A: characters $1,2,3,4,6,7,9,10,13-29,31-33$. B: characters $1,2,4,5,6,7,9,10$, 13-29, 31-33.

TIGER HERONS

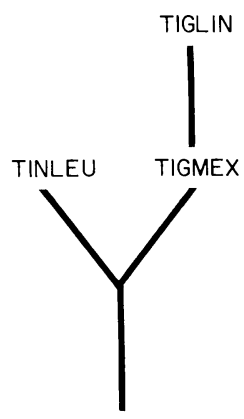

ANCESTOR

Fig. 40. Diagram of phylogeny within the tiger herons Tigrisomatinae as estimated by the cladistic compatibility algorithm COMPTREE. Estimate is based on all 33 characters, with all being compatible.

Old World species Tigriornis leucolophus is cladistically distinct from the New World species Tigrisoma lineatum and T. mexicanum, in agreement with past taxonomy and with geographical distribution. Finally, analysis of the bitterns showed five different maximal sets of compatible characters. The estimate shown in Figure 41 is the only one of the five in which the four large Botaurus bitterns are 


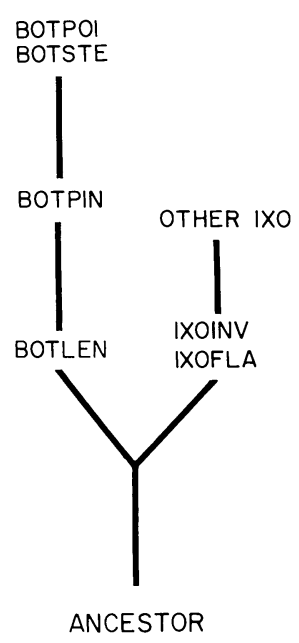

Fig. 41. Diagram of phylogeny within the bitterns Botaurinae as estimated by the cladistic compatibility algorithm COMPTREE. Estimate is based on 26 compatible characters $(1,2,4,6,7,9,10,13-20,23-33)$.

cladistically separated from the smaller Ixobrychus species. We select the results that are supported by other estimates of phylogenetic (Fig. 35) and phenetic (Figs. 24, 25, 26, 27, 28, 30, 31, 32, 33) relationships. A compatibility test was also made of Zebrilus together with all of the heron species (not illustrated), and the Zebrilus character states proved to be on the main trunk (rather than on a side branch) leading to the bitterns, supporting the earlier phenetic and phylogenetic impressions that it is a bittern.

Figure 42 gives an estimation of the probable cladistic history of the evolution of the herons from the "primardea" ancestor. The figure is a composite of Figures 37-41 and adds the resolution of cladistics of each of the four major groups of herons to that of the overall relationships in Figure 37. The branching points of the tiger herons and of the bitterns from the day heron line are transposed to a point below the differentiation of Syrigma and the other day herons because of the closer phenetic association of Syrigma with the day herons (Figs. 24, 26, 29, 30, 32, contra Fig. 33). We note that in estimation of the phylogenetic trees by the Wagner- Kluge- Farris method there is some uncertainty in attaching the branching points of strongly differentiated groups of the species back to their point of separation from the estimated immediate common ancestor, cf. the differences in Figures 34 and 35, and that the cladistic compatibility statements are made on the basis of single characters in this data set. 
COMPOSITE ARDEIDAE

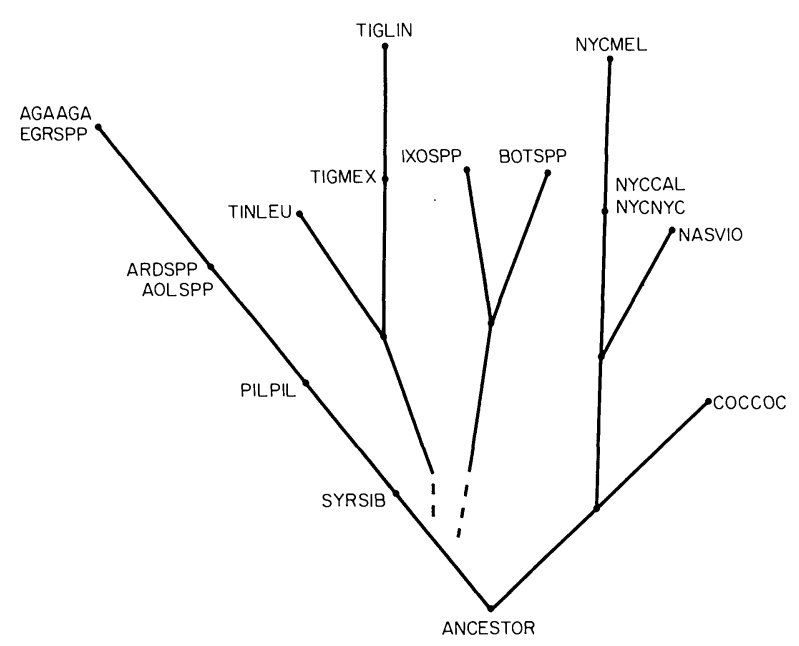

Fig. 42. Diagram of cladistic evolution within the Ardeidae based on a composite of the character compatibility results of Figs. 40-44.

\section{DISCUSSION OF THE NUMERICAL TAXONOMIC RESULTS}

The results of the phenetic and phylogenetic analyses of the skeletal characters of herons are generally alike and are similar also to traditional classifications of herons based on nonoperational taxonomic treatments (Peters, 1931; Bock, 1956; Curry-Lindahl, 1971). Among the areas of general agreement in the phenetic and phylogenetic analyses are the following: (1) Four main groups of herons are recognizable-(a) the day herons Ardea, Egretta, Ardeola, Agamia, Pilherodius, and Syrigma, (b) the night herons Nycticorax, Nyctanassa, and Cochlearius, (c) the tiger herons Tigriornis and Tigrisoma, and (d) the bitterns Zebrilus, Ixobrychus, and Botaurus. These four groups are recognized as subfamilies in the systematic arrangement. (2) Syrigma and Pilherodius are each distinct from the other day herons (although Pilherodius was not distinct from Ardea species in the principal components analysis). (3) Zebrilus is associated with the bitterns rather than with the tiger herons. (4) The two New World tiger herons Tigrisoma are more closely associated with each other than either is to the African tiger heron Tigriornis leucolophus. (5) Species members of geographic superspecies are usually not distinct from each other in the kinds of skeletal characters examined, whereas most other species not members of geographically replacing forms are distinct.

The agreement among the results of the different phenetic analyses (minimally connected graphs, distance matrix phenograms, and principal components ordinations) suggests that these are 
all appropriate descriptions of resemblances and differences among the herons. The agreements between the phenetic and the phylogenetic results might be interpreted as support for the suggestion of Sneath and Sokal (1973:46-47) that phenetic similarities usually result from close phylogenetic relationships and so are good estimates of natural relationships, or that the phylogenetic programs give reasonable results when checked against the standard of phenetics. In this instance, regardless of any bias towards a phenetic or phylogenetic emphasis, the agreement among the results of the different analytical methodologies provides some degree of rigor to the conclusions about heron relationships. The results do not suggest any evidence of similarities due to convergence.

Although the results of the two different approaches in describing relationships are generally similar, there are some conflicting systematic conclusions that might be drawn from the differences. We have attempted to provide a pragmatic resolution of these differences one at a time for purposes of presenting a systematic classification. The classification is based in part on the estimate of cladistic relationships, but it is not entirely congruent with the "best" available estimate of cladistics as summarized in Figure 42. Nor is there any single "best" classification to be expected (Sneath and Sokal, 1973:60-67). Theoretical cladists argue for basing systematic classifications entirely on cladistics, with all cladistic changes assumed to be dichotomous and with all taxonomic hierarchies likewise paired (Hennig, 1966; Cracraft, 1974a, b). We agree that the geometry or topology of phylogeny is cladistic, but historical phylogenetic changes may involve multiple radiations and not simply dichotomous splittings and so there is little biological justification for forcing a classification into a strict dichotomy. We argue that the true cladistics of herons is unknown and that we have provided only an estimation, but that we have an indication that there is some error inherent in that estimation as indicated by the differences among the cladistic results and by the failure of the compatibility tests to resolve the history of all cladistic events among the day herons from the skeletal characters. Historically the herons are separated cladistically and it is an artifact of the algorithm or the characters (or both) that we are unable to obtain an unambiguous estimation of the cladistic history. We also prefer to include phenetic information in the classification and so would give more emphasis to the greater differences between the tiger herons and the day herons than between the Syrigma-Ardea split. We also note the inherent instability of a classification based entirely on cladistic estimates since the discovery of additional characters may lead to revisions of the estimation of cladistic history, and this would involve a reordering of hierarchial systematic categories from the point of cladistic bifurcation upwards through the included genera and species. We have used the cladistic results to order our systematic classification roughly from the species with sets 
of character states most like the estimated ancestral states to those with the more highly derived conditions of these characters.

One conflicting conclusion about relationships that is evident in the results is the difference between the large Ardea species and the egrets Egretta. The Wagner Tree analysis and the compatibility analyses show no evidence that the egrets are cladistically distinct from the large Ardea species; rather, they suggest that egrets are derivatives of Ardea herons. In contrast the phenetic results show generally consistent differences between egrets and the large Ardea species, though the principal components analyses suggest much less distinction between them than do the phenograms. Sneath and Sokal (1973:264-265) note that the levels of bifurcation found in phenograms are subject to considerable error, and phenogram results in the present study may be subject to some distortion across the different groups. The only skeletal character that was consistently different between species regarded as Ardea and species regarded as Egretta was character 4, the shape of the posterior palatine (Table 2). To find whether the Ardea herons and Egretta egrets form recognizable groups even when this character is not considered, we dropped the character and analyzed the remaining characters by the same routines used earlier. In the resulting principal components analysis of the Ardeinae, Ardea and Egretta were still separated from each other, much as in Figure 28. This indicates that the groups are distinct in more than the single character of the posterior palatine. The characters responsible for the associations among species are those with high values for PC 1 and 2 in Table 5; for example, the egrets all had the prominent iliac recess and all the Ardea except $A$. purpurea had a shallow recess. The main change in configuration of the principal components graph is that Egretta rufescens and the Ardeola species appear close to the other Egretta species but on the side of the cluster furthest from Ardea. Analysis of similarity among the heron species by the clustering routines that produce the phenograms likewise resulted in separation of the Ardea and Egretta species when character 4 was omitted from the analysis. The results of some of the phenetic tests do not distinguish distinctly the Ardeola species and Agamia from the egrets, though again there are individualistic differences between the species groups when considered two at a time (character 4 separates Ardeola from Egretta, and characters 4, 14, 21 and 22 distinguish Agamia from the Egretta species). We find each of the above groups of the day herons to be sufficiently distinct in some of the phenetic results for us to recognize the genera Ardea, Egretta, Ardeola and Agamia. The relationships among the species in this complex are better represented by the set of phenetic and phylogenetic estimations of relationships together with the discussions of the groups than they are by the Linnaean binomial system of taxonomy.

Another difference between the phenetic and cladistic estimate 
of relationship is evident in the night herons. Cochlearius is phenetically distinct from all other herons in the principal components results but not in the phenograms. The cladistic results suggest that it is a derivative of the night heron group. The agreement across the phenograms and the phylogenetic estimate suggests that Cochlearius is better regarded as a member of the night heron assemblage, our subfamily Nycticoracinae. Also in the night herons the phenograms suggest a greater similarity between Nyctanassa violacea and Nycticorax nycticorax than between Nycticorax and N. melanolophus, whereas the principal components results suggest the reverse, and the phylogenetic estimates place $N$. melanolophus as a derivative of the $N$. nycticorax group that split at some time after Nyctanassa had differentiated from the group. Again we use the agreement between the two phylogenetic approaches and also between these and some of the phenetic results to decide that Nyctanassa is taxonomically more distinct from Nycticorax than is $N$. melanolophus. Although we did not have available any skeletons of the other night herons, this suggestion is supported by the plumage characters and bill shape of other night heron species as described in a later section. As Sneath and Sokal (1973: 350) have remarked, "It is not very satisfactory to have to choose between cladograms whose parsimony differs in only one or two evolutionary steps," let alone those of the same number (cf. Fig. 37). Perhaps routine application of several different algorithms in studies of systematic relationships will help resolve the relationships that a single algorithm might not.

The cladistic results indicate that bitterns are a highly derived group of herons and not the most "primitive" as suggested in other classifications. Bock (1956) suggested that, while the tiger herons might be the ones most like the ancestral heron stock, the bitterns might be regarded as primitive in behavior as they are solitary rather than colonial. Bock (p. 14) suggests that solitary nesting is primitive in the group because tiger herons and "Gorsachius" are solitary nesters (his stated reasons for saying the tiger herons are primitive are that they are solitary nesters, as well as their "general habits," plumes (i.e., lacking the display plumes of some egrets), and powderdown patches. The argument assumes that colonial nesting is a derived character state within the group. However, many other Ciconiiformes such as the storks, ibis, and flamingos often nest in dense colonies (Kahl, 1971a; Allen, 1947; Brown, 1959) and it is impossible to test or to verify the hypothesis that the first ciconiiforms with heron-like characters were not colonial. Colonial nesting has led to solitary nesting as well as the reverse in heron phylogeny, we can guess, because there is considerable geographic variation in the extent of coloniality even within single species. The Great Blue Heron Ardea herodias nests in dense colonies in much of the northern part of its range such as Michigan and British Columbia (Cottrille and Cottrille, 1958; Krebs, 1974), but in Florida Bay many small islands each 
covering several hectares have but one or two nests of the white color phase (W. B. Robertson, pers. comm.; Payne, field observations). The Green Herons Ardeola striata are usually solitary in the north but are densely colonial in some tropical areas (Meyerriecks, 1960; Dickerman and Gavino, 1969). Least Bitterns Ixobrychus exilis are usually solitary marsh birds (Weller, 1961) but in certain habitats may nest in close proximity to each other (Kushlan, 1973). In addition it should be noted that the occurrence of several primitive character states in a group of species, even if the character states actually are unchanged from the ancestral stock of the group, does not necessarily mean that other character states-such as nesting dispersion-are primitive within that group. As character states that occur in species with primitive states of other characters are not necessarily primitive themselves, the primitive pattern of nesting dispersion in herons may well have been colonial. Inasmuch as nesting dispersion responds within a single heron species to local habitat differences, it does not seem that the usual highly dispersed nesting pattern of the bitterns establishes their phylogenetic "primitiveness."

The number and degree of fusion of powderdown patches varies among the herons and has been one of the main traditional bases for classification of heron subfamilies. All herons have powderdown, the special feathers that grow continually and that are used to condition the other feathers. In the herons the powderdown is used to clean fish oil and other oils from the feathers (Wetmore, 1920; Percy, 1951). Bitterns have two pairs of powderdown patches, most herons have three pairs, and Cochlearius has four (Miller, 1924; Bock, 1956; Payne's examination of museum specimens). The tiger herons are variable with three pairs in the Old World Zonerodius and Tigriornis and in the New World Tigrisoma lineatum and with four in the New World T. fasciatum and T. mexicanum. Finally, Zebrilus has three, not two as in the other bitterns, but the phenetic and phylogenetic relationships suggested in Figures 25, 30, 31, and 35 all suggest that this species is a bittern with many primitive character states, and the occurrence of three patches in Zebrilus is probably a primitive state. The occurrence of four patches in some of the tiger bitterns was then interpreted by Bock (1956) as being primitive, but without reference to the number of powderdown patches in the related non-heron Ciconiiformes there is no way to evaluate this opinion. Powderdown patches are absent from the other Ciconiiformes except for Balaeniceps rex, which is said to have two pairs (Schüz, 1927). Because powderdown is absent in most ciconiiforms, with the exception of the herons, it is not possible to apply the related-group criterion for the determination of the primitive condition of powderdown in the herons.

Other possible reasons for regarding the bitterns as primitive appear to be no more convincing than the nesting dispersion or powderdown arguments; for these additional characteristics D. W. 
Mock (in litt.) writes that "bitterns ... breed solitarily (sometimes), boom (sometimes), have some common and unshared displays (e.g., Pfahlstellung of Portielje, 1926), point their bills skyward when frightened (so do young Ardea, adult Tigrisoma, and hunting Casmerodius and E. tricolor) and are cryptically colored and behaviored." The streaked plumage of adult Botaurus bitterns (and of some species of Ixobrychus) resembles the juvenal plumage of some other herons (Nycticorax, Nyctanassa, the Ardea cinerea superspecies), but the suggestion that bitterns are "primitive" because adults resemble the juveniles of other more "derived" herons is based on an erroneous historical conception that the development of individuals of derived species recapitulate the adults of the ancestral, primitive paleospecies (Gould, 1975), and it ignores the adaptive significance of cryptic plumage in these solitary marsh birds. Egg color in Botaurus is brown, uncommonly spotted. No other herons or Ciconiiformes are known to have unmarked brown eggs, so the egg color appears to be derived, not primitive. Perhaps bitterns have been regarded as primitive because they live in marshes, considered a simple habitat and perhaps like that of a geological period preceding the first herons. None of these characteristics of bitterns appears to be primitive in a phylogenetic sense, and the available evidence on behavior, plumage, and egg color does not support the idea that bitterns are primitive. Bitterns are less like the other Ciconiiformes than are the other herons in their skeletal characters, and they appear to be a highly derived, not a primitive, group of herons.

A detailed comparison of the occurrence and context of the ritualized displays of the herons would provide an additional set of characters by which to evaluate the relationships proposed from the skeletal characters. We had initially intended to compare the results of the graphs of skeletal relationships to those of behavioral character states, but we found that although several heron species have been the subject of detailed behavior studies, many studies have been so incomplete that it is unclear whether a display not seen in the repertoire was actually lacking or was merely overlooked. In addition, studies on some of the major groups have yet to be completed before any species has been described in detail, and we lack the detailed observations on any Botaurus and Ixobrychus and on any tiger heron that have been made for other herons (Gentz, 1970; Weller, 1961; Dathe, 1941). Furthermore, it remains to be determined how the various displays among heron species can best be related in terms of homologies. The status of the comparative studies of heron displays today is like that of the early 1940's on duck displays, before the time when it was realized that nearly all of the displays of many Anas species were nearly identical and many of the apparent differences in the occurrence of displays were due to incomplete observations (Kaltenhaüser, 1971). Detailed observations of displays of several herons have been made; the earlier studies are summarized by 
Meyerriecks (1960) and additional comparisons have been made on several Ardea and Egretta species by Blaker (1969a, b) and Tomlinson (1974). In general most displays appear to be shared among species across the boundaries of genera recognized by Bock (1956), and displays are shared by day herons and night herons. At the present time the behavioral information appears to be useful mainly. in comparing relationships among closely related species and genera rather than at the level of groups of genera. Hopefully a comprehensive status report on the study of displays of herons will be completed by the current students of heron behavior.

Other recent studies bearing on the relationships among groups of herons include examination of the occurrence of the variable leg muscles by Vanden Berge (1970). Leg muscles are variable in their taxonomic distribution among the non-heron ciconiiforms as well as among the herons, so no clear picture of cladistics can be made at the present time from the muscle data. Cochlearius is much like the other herons, and it resembles the day herons but not the night herons in lacking one vinculum between the flexor tendons of the foot. The bitterns lack both vincula. Non-heron ciconiiforms appear to have both vincula, so bitterns are in this character the most highly derived among the herons, not the most primitive. The leg muscle formula ADEFGXY was found in species of Ardea, Egretta (including "Florida," "Dichromanassa," "Leucophoyx," and "Hydranassa"), Nycticorax, Ixobrychus, and Botaurus, as well as on one side of Agamia. Formula muscle A was found lacking in Nyctanassa, Cochlearius, and Tigrisoma mexicanum. The results suggest a relationship between the night herons and the tiger herons and also a considerable divergence between Nyctanassa violacea and Nycticorax nycticorax. The presence or absence of " $A$ " varied among non-heron Ciconiiformes so it is not possible to know the primitive character state of the muscle in the herons nor to use it in constructing heron phylogeny. The functional significance of the difference in the number of vincula is not known.

Gysels (1968) sampled eye-lens proteins and found some immunological similarities among Ardea cinerea, Egretta ibis, Botaurus stellaris, Cochlearius, and Balaeniceps, as well as one suggesting a close relationship between Cochlearius and the ducks! Another recent comprehensive biochemical study was an examination of electrophoretic mobilities of egg-white proteins by Sibley and Ahlquist (1972). Little variation was found among the herons. Cochlearius was similar to the herons, and the authors conclude that it is best regarded as an aberrant heron. Biochemical studies have not yet provided any other solutions to problems of relationships among the herons.

We agree with Mayr (1974) and Michener (1970) that a systematic classification should be based on both cladistic and phenetic information, not simply upon cladistic hypotheses (Hennig, 1966; 
Cracraft, 1974a), and we agree with Sneath and Sokal (1973) that phenetic analysis is an essential part of a systematic study. The systematic classification derived from the results of the phenetic and phylogenetic analyses study is summarized in Table 7.

\section{RELATIONSHIPS AMONG THE GENERA AND SPECIES OF HERONS}

\section{ARDEINAE, THE DAY HERONS}

The day herons are not distinguished by any single character from all the other groups of herons, though they are distinct in combinations of characters from each of those groups. These differences will be described in the following subfamily sections.

The taxonomic allocation of species of the day herons to genera presents several problems. Syrigma and Pilherodius are cladistically separate from the other herons; Syrigma is strongly different from the other herons in the phenetic analyses as well. The other day herons all appear to be very closely associated with each other. The egrets Egretta appear to be phenetically somewhat distinct from the large day herons Ardea (Figs. 28, 29, 32-35, 38A) although our programs failed to show that they were cladistically distinct (Figs. 34-37). In several estimations of phenetic and phylogenetic relationships E. rufescens is not associated with the other egrets, and it is possible that this species is not a member of a monophyletic group with the other egrets. Phillips, Marshall, and Monson (1964) include the North American day herons of these groups (except for this species, for which they use the genus "Dichromanassa") in a single genus Ardea; we have tentatively included rufescens in the genus Egretta. Ardeola ("Butorides") striata and rufiventris are skeletally nearly identical with the Ardeola pond heron allospecies and differ only in plumage, size (slightly), and tarsal scutellation; we include "Butorides" in the genus Ardeola.

Skeletal characters have not supported the validity of the group "Hydranassa" as proposed as a genus distinct from Egretta by Bock (1956). In none of the phylogenetic or phenetic program results did his included species tricolor, rufescens, caerulea, ardesiaca and picata form a single monophyletic or exclusive branch. The only plumage character shared among these species is the presence of straplike "lanceolate to filamentous" feathers on the back, and here similar feathers occur in other herons, e.g. striata. The apparent intermediacy of other characteristics among the species of "Hydranassa" may be coincidental. All of these species are here included in the diverse genus Egretta in a sequence reflecting their apparent relationship to each other. 


\section{TABLE 7}

A CLASSIFICATION OF THE ARDEIDAE ${ }^{a}$

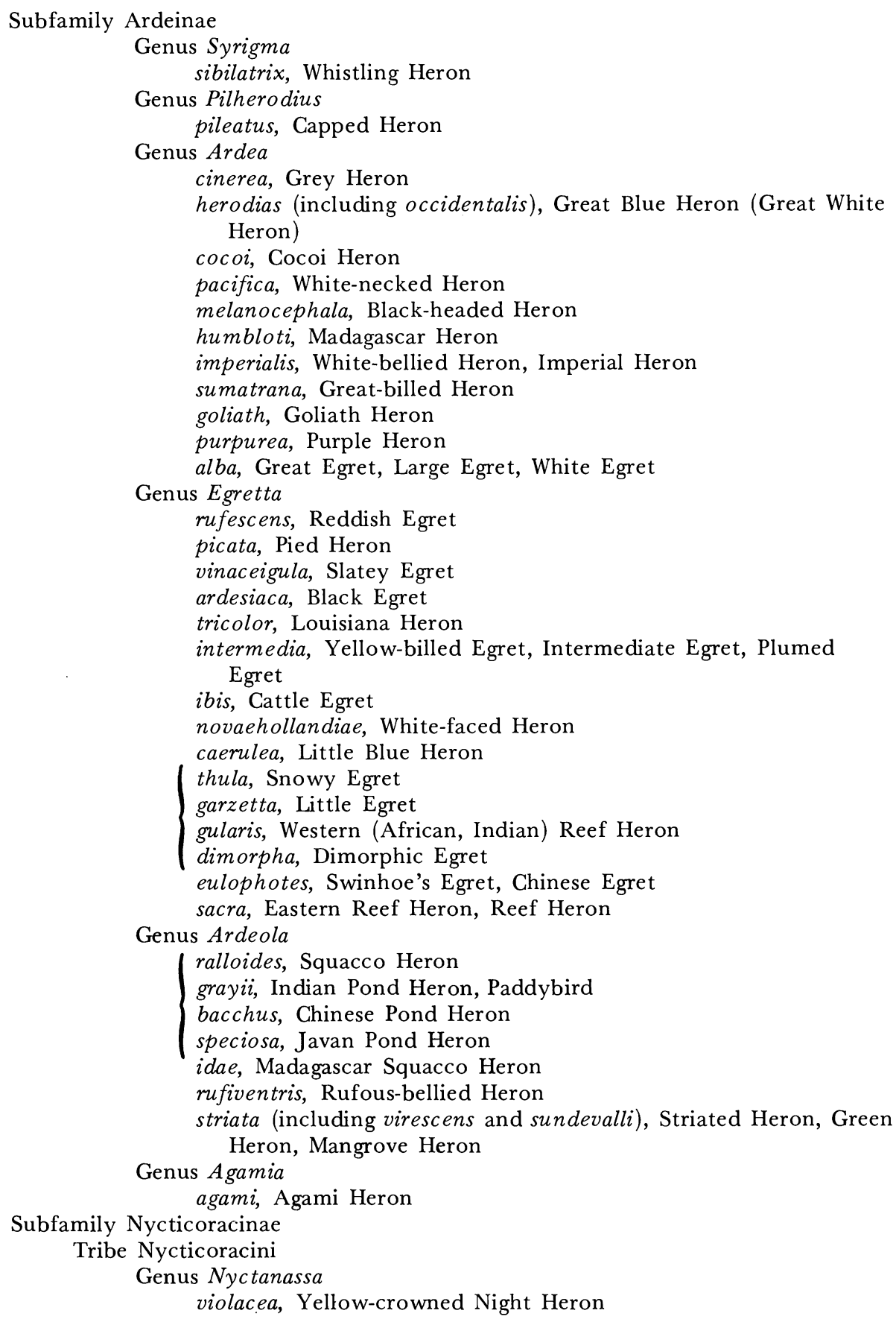




\section{A CLASSIFICATION OF THE ARDEIDAE ${ }^{a}$}

Table 7, Continued

Genus Nycticorax

$\{$ nycticorax, Night Heron, Black-crowned Night Heron

$\{$ caledonicus, Nankeen Night Heron

leuconotus, White-backed Night Heron

magnificus, Magnificent Night Heron

$\{$ goisagi, Japanese Night Heron

Tribe Cochlearini

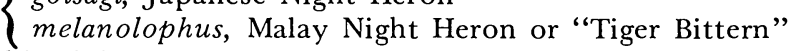

Genus Cochlearius

Subfamily Tigrisomatinae

cochlearius, Boat-billed Heron

Genus Tigrisoma

mexicanum, Mexican Tiger Heron, Bare-throated Tiger Bittern

fasciatum, Salmon's Tiger Heron

lineatum, Lined Tiger Heron, Banded Tiger Bittern

Genus Zonerodius

heliosylus, New Guinea Tiger Heron

Genus Tigriornis

Subfamily Botaurinae leucolophus, White-crested Tiger Heron, African Tiger Heron

Tribe Zebrilini

Genus Zebrilus

Tribe Botaurini undulatus, Zigzag Heron

Genus Ixobrychus involucris, Streaked Bittern

exilis, Least Bittern

$\{$ minutus, Little Bittern

sinensis, Yellow Bittern

eurhythmus, Schrenck's Bittern

cinnamomeus, Chestnut Bittern, Cinnamon Bittern

sturmii, African Dwarf Bittern

flavicollis, Black Bittern, Mangrove Bittern

Genus Botaurus

pinnatus, South American Bittern

lentiginosus, American Bittern

\{stellaris, Palearctic Bittern

$\{$ poiciloptilus, Brown Bittern, Australian Bittern

${ }^{\mathrm{a}}$ Brackets indicate members of a superspecies.

No confirmed instances of hybridization between any of the egret species or other day herons are known and the congeneric status of the egrets was determined independently of the hybrid argument developed by Dickerman and Parkes (1968). A supposed hybrid thula $\mathrm{x}$ caerulea was observed feeding much like thula, with short, rapid dashes, and was collected and described by Sprunt (1954). Examination of this specimen (NMNH 421325) shows it to be more like an oddly colored thula. The plumage is mottled, white and blue-gray; many of the dark feathers are white at the base. One 
feather on the upper breast is partly rufous as in caerulea. The dark hackles on the lower neck are lanceolate and loosely webbed as in caerulea. Similar lanceolate, loosely webbed feathers occur in garzetta. The blue and white plumes on the back of the supposed hybrid are varied, some are lax as in thula, and others are lanceolate as in caerulea. The shape and interlocking of the barbs of the dark feathers may be due to a developmental correlation of feather shape with the degree of melanin in it, as suggested by some cross-species comparisons of feather color and shape-there are melanistic morphs of sacra, gularis, and some of the other egret species. The crest plumes are filamentous and the tips of the primaries are all white, as in thula. The bill is slender and straight, the tarsi have small, less prominent scutes, and the toes (especially the claws) appear slender and small, all as in thula. In all measurements and other features the partly melanistic specimen appears to resemble thula.

Another possible hybrid egret was photographed and thought to be intermediate between thula and tricolor (Dickerman and Parkes, 1968). Other specimens regarded as possible hybrids between caerulea and tricolor in the past have proved to be aberrant caerulea with some chestnut coloration on the head and back of juveniles (Dickerman and Parkes, 1968). A specimen with some appearances of a hybrid (NMNH 60319) from Puerto Rico is an adult with a gray back and a light gray neck; some crest feathers are purple-chestnut. The plumes of the back are mottled in color. The shape of all these feathers resembles caerulea (the crest plumes are long and slender, not broad as in the central feathers of tricolor). The bill is rounded and decurved in caerulea with no trace of the long, slender form of tricolor, and the specimen appears to be simply a melanic caerulea.

Syrigma-Whistling Heron

Included species: $S$. sibilatrix.

Diagnosis: Terrestrial herons with pied plumage and buffy-yellow lanceolate scapular feathers.

Whistling Herons of South America have impressed recent field workers as resembling the diurnal ardeine herons in their behavior (Humphrey and Parkes 1963, Short 1969, Kahl 1971). The plumage is distinctive, and as Humphrey and Parkes (1963) have described, the juvenal plumage closely resembles the adult plumage, unlike the night herons. Much of the yellowish color of the scapular feathers of Syrigma appears to result from staining after the feathers have grown, as in the buffy display plumes of the Cattle Egret Egretta ibis (Humphrey and Parkes, 1963). As Bock (1956) has noted, Syrigma sibilatrix resembles the night herons in the black crown, lanceolate crown plumes, gray back, and pale underparts, but these features occur also in some species of Ardea, Egretta, and Pilherodius, so they do not provide strong evidence of close relationship of $S$. sibilatrix 
with the night herons. The tarsi are scutellate, unlike most night herons.

Several skeletal characters of Whistling Herons are more often found in the ardeine herons than in night herons: the deltoid crest of the humerus is high, the sternal ventral manubrium is long, the sternocoracoidial process is directed less forward than backward, the temporal muscle scar is not enlarged to form a midline ridge, the dorsal ridge of the iliac crest is rounded, and the back margin of the palatines is not distinctly notched. Syrigma lacks the lateral basitemporal flange that is found in all the night herons. On the other hand, Syrigma resembles the night herons in having only a slight lateral projection overhanging the lateral lacrimal groove, a small interorbital septum (as in Pilherodius), and unfused medial palatine flanges, and in lacking a lateral canal on cervical vertebra no. 17. The axis vertebra is narrower and has less of a ventroposterior emargination than in the night herons, though it is somewhat intermediate in shape between the ardeine herons and the night herons (Figs. 11, 12). The cervical vertebrae are generally longer and more slender than in the night herons. Syrigma differs from the other herons examined in the short, bifurcate external spine of the furculum (Fig. 17), though this bone varies considerably among some other genera of herons (Ardea, Egretta, Ixobrychus, Botaurus). Although Syrigma sibilatrix has no unique morphological features, it does not appear to be closely related to any other species of ardeine heron, and in its combination of skeletal characters, Syrigma is rather distinctive from the other herons (Table 2, Figs. 26-35, 38).

It would be of interest to record the details of display of this heron. The long, black crest plumes are erected in display at the nest as seen by Payne in a pair at the Dallas Zoo (Fig. 43). Display of Syrigma described by Short (1969) and Kahl (1971b) seems to differ considerably from the agonistic behavior of other day herons and of night herons.

\section{Pilherodius-Capped Heron}

Included species: $P$. pileatus.

Diagnosis: Whitish heron with a bare blue face and a black cap.

The South American Capped Heron is a distinctive species of eastern Panama southward to South America as far as Bolivia, Paraguay, and southern Brazil. Peters (1931) included it within the ardeine herons, and Bock (1956) listed it as a night heron, congeneric with Nycticorax nycticorax. The tarsi are reticulate as in night herons and in some ardeines. The plumage pattern of Pilherodius pileatus resembles that of the night herons in the black crown, the long, lanceolate crown plumes, the gray back, and the white underparts. However, several other genera of herons include species with black crown, the long lanceolate crown plumes are also like the white 


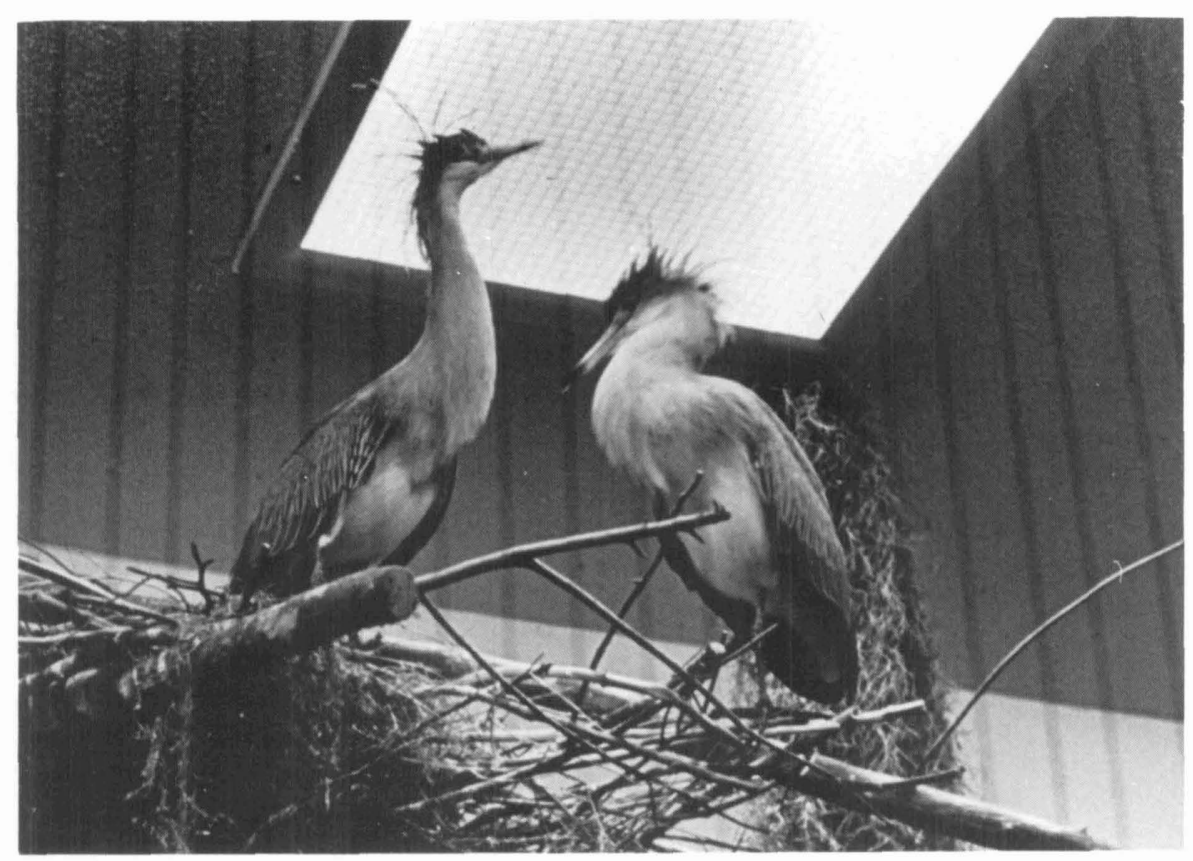

Fig. 43. Erected crest of two Whistling Herons Syrigma sibilatrix at a nest in the Dallas Zoo. Photograph by James Williams.

plumes of several egrets (Egretta garzetta, eulophotes, and sacra) and herons (Ardea herodias and insignis), several species of ardeine herons and egrets have unstreaked gray backs, and the back is very pale (nearly whitish) in Pilherodius. The bare skin of the head is unusual among herons in its extent and in its bright blue color in the live adults. The plumage of the back lacks the ornamental plumes of other day herons (and of some night herons). The juvenal plumage of Pilherodius is nearly identical to the adult plumage; five specimens of young birds in the AMNH series show long $(30 \mathrm{~mm})$, adherent white down on the black crown feathers. The juvenal feathers on the forehead are broadly rounded rather than pointed or lanceolate as in the adults. The color pattern is the same in young and adults, as noted also by Wetmore (1965: 98). The bill is pale above in some of the young. Birds in juvenal plumage have the long white crown plumes (to $220 \mathrm{~mm}$ in AMNH 278544) as long as in the adults, and one specimen (AMNH 241140) has the downy tips still intact on the crown plumes. Pilherodius thus differs in plumage sequence from the night herons in the tribe Nycticoracini, which have a distinctive, streaked juvenal plumage unlike the adult plumage.

The skeleton of Pilherodius pileatus is more like that of Ardea than like that of the night herons. Characters with states like those found in some of the Ardeinae and not generally in the Nycticora- 
cinae are the low deltoid crest of the humerus, the shape of the sternocoracoidial process, the relatively pronounced lacrimal lateral process, the temporal muscle scar, the rounded shape of the iliac crest, the relatively long internal spine of the furculum, and the presence of a lateral vertebral canal on cervical vertebra 17. Character states found in night heron species but not in ardeine species include only the interorbital septum, which is peculiarly small in P. pileatus, Syrigma sibilatrix, and Nyctanassa violacea (but not in Nycticorax nycticorax or $N$. melanolophus). The shape of the posterior portion of the palatines is more like that of night herons than of most ardeines, but a few other ardeines are like Pilherodius (Table 2). The axis is broader than that of most ardeine herons but narrower than that of all the night herons (Figs. 11, 12). In other skeletal characters, Pilherodius resembled the day herons more than Nycticorax in having an elongated (less round) pneumatic foramen of the humerus, a more pronounced external tuberosity of the humerus, and a sternal keel shallow anteriorly (as in Egretta novaehollandiae). In contrast the configuration of the base of the skull appears somewhat more like Nycticorax, though Pilherodius clearly lacks the distinctive basitemporal ridge of the night herons. Though some character states are intermediate between night herons and ardeines and a few are more characteristic of the night herons, the skeleton is more like that of other ardeines than like the night herons.

Ardea-Typical herons

Synonyms: Casmerodius, Pyrrherodias

Included species: alba, cinerea, cocoi, goliath, herodias (including "occidentalis"), humbloti, imperialis, melanocephala, pacifica, purpurea, sumatrana.

Diagnosis: These are large herons and include the largest species of all the herons. Most species have lanceolate crest plumes and scapular plumes, but these are short in the three large species (goliath, imperialis, sumatrana) and in the white form "occidentalis" of $A$. herodias and the crest plumes are lacking in alba. A. alba has a slender bill and an all-white plumage; the three species goliath, imperialis, and sumatrana have a large, deep bill; and the other species have large bills slimmer than the second group but considerably more robust than in alba.

The three species cinerea, herodias, and cocoi comprise a single superspecies with each form morphologically distinct and allopatric to the other. Ardea cinerea is widespread in the Old World in Europe, Asia, Africa, Madagascar, and Indonesia, and $A$. herodias breeds in North America and locally in Mexico as far south as Tamaulipas, Campeche, Yucatan, and islands off Venezuela. A. cocoi occurs in eastern Panama and South America, but few breeding sites are known. The courtship behavior of the first two species has been 
studied closely and consists of nearly identical displays, sequences, and situations (Verwey, 1930; Cottrille and Cottrille, 1958; Meyerriecks, 1960, 1962a; Spillner, 1968; Milstein, Presst, and Bell, 1970; D. W. Mock, unpublished observations). Ardea herodias appears to lack the advertising call that is the first step in pair formation in $A$. cinerea, so the difference might be an effective isolating mechanism that would prevent interbreeding (D. W. Mock, unpublished observations). The two forms are considered to be distinct species. Behavior of $A$. cocoi has not been studied.

The question of specific status of the "Great White Heron" $A$. (herodias) occidentalis should remain if such systematic questions are needed to stimulate comparative observations on the biology of different populations, as further observations are desirable. The white form of these herons breeds mainly on small mangrove islands in Florida Bay and on the outer Keys, but also very locally on coastal peninsular southern Florida. The evidence presently available indicates that the white herons are conspecific with $A$. herodias. Several mixed pairs of white and blue herons have been observed breeding and rearing young, and the young of some mixed pairs include both white and dark birds (Mayr, 1956; Meyerriecks, 1957, 1960), indicating that these birds are conspecific. According to Meyerriecks (1960, 1962a) the behavior of the white and blue birds is the same. Nevertheless, the timing of the breeding seasons of dark and white birds differs somewhat. Moreover, a strong tendency for white-white matings and dark-dark assortative mating occurs where the forms breed together in Florida Bay (W. B. Robertson, Jr., in prep., pers, comm.). In the Florida Keys, the dark birds in the mixed breeding areas vary considerably in color. Some appear to be a distinctive form ("wurdemanni") with plumage color mainly like mainland $A$. herodias but with crest plumes small and white, whereas other breeding birds (birds at nests and with reddish bills and tarsi in their winter breeding season) are indistinguishable in color from breeding birds nesting later in spring hundreds of miles north. Intermediate birds with much white in the dark plumage also are known to breed here (W. B. Robertson, Jr., pers, comm.). There is no series of specimens of study skins of local breeding birds, nor have there been field studies with standardized descriptions of mated pairs. There is however a large series of skeletons of hurricane-killed birds of both color forms in the University of Miami research collection that would be of considerable interest to examine. White herons occasionally interbreed with blue birds on the mainland in Florida (Bancroft, 1969), but this occurs along the coast not inland and at a coastal site within the former breeding range of the white form (W. B. Robertson, Jr., pers. comm.). The West Indies are said to have had breeding herons of both white and blue phases (Bond, 1971), but there are no definite observations of any white birds breeding in the West Indies. Indeed, the only specimen records of any breeding of large Ardea from the 
West Indies are two sets of eggs, one a set of eggs from St. Thomas, Virgin Islands, said to be of blue birds, and the other from Camaguey Province, Cuba (Bond, 1965), said to be of white birds. Other references to nesting herons in the West Indies appear not to be supported by any definite breeding specimens, nestlings, eggs, or photographs, descriptions, or observed localities of nesting sites. Off the coast of Yucatan, Griscom (1926) saw "twenty-five pairs ... breeding on the Culebra Keys, and adults in full breeding plumage were approached to within 20 feet on their nests," all birds in dark plumage. No birds were collected; a young taken at a nest in 1918 and kept for four years in the Bronx Zoo before it became specimen AMNH 325350 is the only known local breeding Ardea herodias from Yucatan. The bird resembles herons breeding in the eastern United States. The only other confirmed breeding locality in the Caribbean is on the Islas los Roques off the Venezuelan coast, where nets have been observed and where nonbreeding herons, both white and mottled birds, occur, and where fishermen say that "both gray and white young occupy the same nests" (Bond, 1961:6). The white color of the Great White Herons may, as Murton (1970) has suggested for other white herons, be a specialization for feeding in the open, or in a hot climate. The coastal race $A$. cinerea monicae in Mauritania also is very pale. Payne's brief observations indicate that white birds sometimes hold large feeding territories on the shoals of Florida Bay, and white plumage may be an effective agonistic signal visible at a distance to other herons.

Skeletal comparison of $A$. cinerea, A. herodias (including occidentalis), and $A$. cocoi showed only minor differences among these members of a single superspecies. The tarsi are equally scutellate in all. The only noticeable differences among these three species were minor differences in the shape of the ectethmoid, lacrimal, and in the extent of the temporal muscle depression on the skull, and all these skeletal features vary within a single population of $A$. herodias sampled in Michigan.

The Australian $A$. pacifica has been regarded as a member of the A. cinerea superspecies (Mayr and Short, 1970), but it is considerably smaller and has some maroon feathers at the base of the neck and on the back unlike the other herons in this group. We think it less closely related to this complex than the other allospecies are to each other. The white of the head and neck suggests the South American A. cocoi. The tarsi are more reticulate than scutellate. The skeleton of $A$. pacifica differs slightly from $A$. cinerea in the shape of the ectethmoid complex, and in a somewhat larger tibiotarsus: humerus length ratio perhaps reflecting the smaller size of pacifica. Apart from its smaller size its skeleton is similar to that of $A$. cocoi (Table 2). No details are available on its courtship displays. It is probably an aberrant member of the $A$. cinerea superspecies.

The African A. melanocephala is a terrestrial heron that feeds on 
land on large insects, frogs, lizards, and small mammals (Chapin, 1932; Taylor, 1972). Mayr and Short (1970) have included it in the $A$. cinerea superspecies. As both $A$. melanocephala and $A$. cinerea breed throughout much of Africa, they are not geographic replacements and therefore are not allospecies of a geographically defined superspecies. The tarsi are scutellate, the skeleton is similar to that of $A$. cinerea, and except for the size of some elements, a slightly different shape of the ectethmoid, a less pronounced lateral projection of the lacrimal and a broader axis vertebra, the two species are morphologically rather alike.

A. humbloti of Madagascar is similar to A. melanocephala but has a deeper bill and the plumage is darker gray. Ecologically the two species differ, as A. humbloti feeds in mangroves, muddy flats, and marshes on fish (Rand, 1936). Zoogeographically the two species replace each other, and they may be regarded as allospecies of a single superspecies.

The Indian $A$. imperialis and the Southeast Asian-IndonesianPapuan-Australian $A$. sumatrana are similar in size and plumage pattern, and are geographic equivalents that form a superspecies. These are large-billed, large-bodied birds without conspicuous display plumes, though $A$. imperialis has long white plumes on the crest. The skulls are similar except that imperialis has a smaller bump below the ectethmoid. The species appear identical in the shape of the lacrimals, the supraorbital foramen and processes, the shape of the interorbital foramen, and the configuration of the nasals. A. imperialis lives largely along the big rivers of India (Ali and Ripley, 1968), whereas $A$. sumatrana is a coastal bird associated with mangroves (Seton, 1973). The largest heron, A. goliath of Africa, is allopatric with these two. It lives along rivers and large lakes. It differs from the two eastern species in all of the skeletal characters described above. It is also considerably larger than either imperialis or sumatrana, it has much purplish-red in the plumage of the head, neck, and underparts, unlike the gray-brown of the eastern species, and its tarsi are scutellate not reticulate.

The Purple Heron A. purpurea of the Old World is distinct from the above species in its peculiarly long toes and claws, which appear to be adaptations for increased surface area, allowing the bird to walk on floating vegetation, and for increased length for grasping clusters of reeds and twigs. A. purpurea lives in swamps, reedbeds and marshes dominated by vegetation such as Cladium and Phragmites and it nests usually near the ground, not high in trees (Witherby, 1939; Owen and Phillips, 1956; Tomlinson, 1974). The sternum and synsacrum are narrow, probably an adaptation for a slender body for thick marsh vegetation (Vasvari, 1931). Purple Herons often feed by remaining motionless on a river bank, like Ardeola striata and Agamia agami, and like them have relatively shorter legs, longer femora (compared with the distal leg bones), and a long neck. The longer- 
legged forms of herons usually feed both by waiting and by active wading (Meyerriecks, 1960, 1962b). The short legs and long femur appear to allow the bank-feeding herons to maintain a nearly horizontal body posture in peering over the water, as the center of gravity would be more directly above the supporting tibia, and the long neck would allow a long thrust from the bank. The tarsus is broadly scutellate. A purpurea differs from the other large Ardea species in having a pronounced iliac recess in the synsacrum. Other notable features of the skeleton differing from those of other large Ardea are the shape and large size of the ectethmoid and lacrimals, a long internal furcular spine, and a rather deeply grooved hypotarsus.

The cosmopolitan Great Egret A. ("Casmerodius") alba is included in the genus Ardea rather than Egretta largely on the basis of the skeletal characteristics which indicate a close association of this form with the other Ardea species (Figs. 24, 26, 29, 32-34, 38). It is intermediate in size between the other Ardea species and the smaller egrets, and it lacks the crown plumes found in most egrets. The lacrimal differs in form from that of other ardeine herons (Figs. $2 \mathrm{~A}, 6 \mathrm{~B})$. The size and shape of the lacrimal-ectethmoid complex, suggested by Bock (1956) as perhaps simply correlated with size in the Ardea herons and the egrets, do not seem to be related directly to the size of the birds (Figs. 2, 6). The tarsi are scutellate as in some of the larger Ardea. The palatines are of the configuration of the other large Ardea, not of Egretta. The species does not appear sufficiently distinctive in its combination of skeletal character states or in the appearance of several unique skeletal character states to be recognized as a monotypic genus. Observations by Payne of its feeding behavior show that it tilts the head towards the shaded side of the body and strikes into its shadow to avoid the glare of the sun on the surface of the water, much as does Ardea herodias (Krebs, 1973). Its display behavior as described by Meyerriecks (1960) lacks the rapid movements of the smaller egrets, and Meyerriecks pointed to Ardea as the closer relative of "Casmerodius". However, recent observations on the behavior suggest that the displays are more like those of the egrets (McCrimmon, 1974; Wiese, in press; Mock, unpublished observations; Fig. 44). Further studies of behavior in these species should help to clarify their relationships.

\section{Egretta-Egrets}

Synonyms: Bubulcus, Demigretta, Dichromanassa, Florida, Hydranassa, Leucophoyx, Melanophoyx, Mesophoyx, Notophoyx.

Included species: ardesiaca, caerulea, dimorpha, eulophotes, garzetta, gularis, ibis, intermedia, novaehollandiae, picata, rufescens, sacra, thula, tricolor, vinaceigula.

Diagnosis: The genus Egretta includes a variety of herons of small to medium size. Typical egrets are white and have long, filamentous 


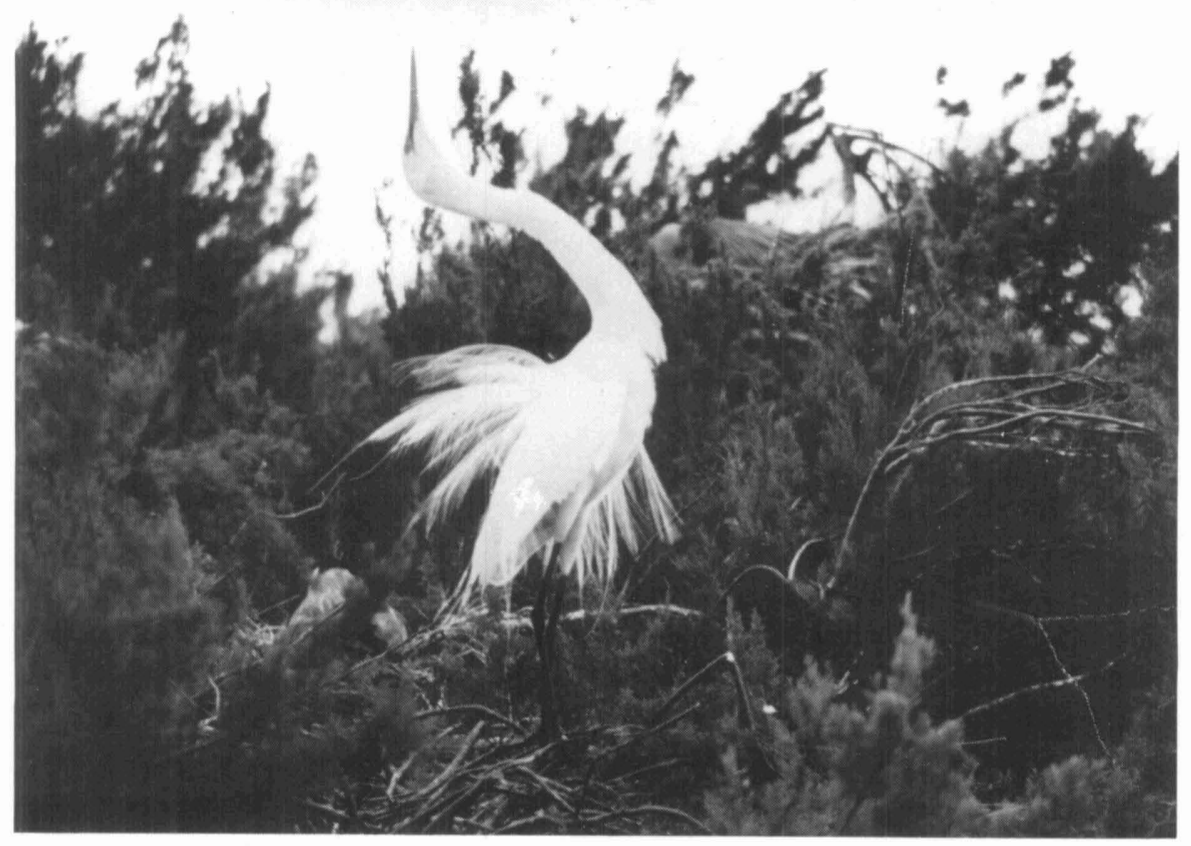

Fig. 44. Great Egret Ardea ("Casmerodius") alba in stretch display, Texas. Photograph by D. W. Mock.

aigrettes, plumes on the back, but some are dimorphic, others are pied or black, and one species of Ardea as recognized here (A. alba) has filamentous aigrettes. The less typical species included in this genus are linked through intermediate species to the birds with the filamentous, white plumage. The old classification of egrets (Bock, 1956) that depended on their breeding plumes may reflect the working definition of the plume hunters of the turn of the century of egrets as birds with "marketable plumes." The tarsi are scutellate in all species. The only skeletal feature found that characterizes the Egretta species from other day herons is the extent of the lateral process of the palatines. This difference may be related functionally to size, though we noted no distinct variation among the egret species of different size of body and bill, and the small Ardeola species resemble the large Ardea species in this character.

The Reddish Egret Egretta ("Dichromanassa") rufescens, appears to be an aberrant egret, though it may be cladistically distinct from them. Rufescens feeds along the warm coasts of North America and the Caribbean and is a counterpart of the Old World reef herons in habitat and plumage dimorphism as well as in bill shape and in the short toes. Both are active feeders making quick turns and darts in catching fish. The back feathers of rufescens are similar to the aigrettes of thula, garzetta, and gularis, with the barbs partly inter- 
webbed near the base but with most of the barbs long and free and attached to a stiff shaft of more than $100 \mathrm{~mm}$ length. Rufescens also has many very long, lanceolate feathers on the neck and back, where they intergrade with the aigrettes. These lanceolate feathers are similar to the somewhat shorter but purplish neck feathers of caerulea and novaehollandiae. Rufescens has two distinct color phases in its adult plumage, a reddish morph found throughout the species range, and a white morph, common only in the Bahamas. The reddish morph is pale in the Bahamas, averages somewhat darker in the Gulf of Mexico, and is noticeably darker in Baja California. Downy young also occur in two color phases, an all-white morph with a whitish crest and a rufous-gray morph with a white belly and reddish crest. The white phase is much less frequent now than it was before the plume-hunting depredations of men exterminated the Florida population around the turn of the century (Allen, 1954-55). Rufescens shares several displays both with other egrets and with the larger Ardea species (Meyerriecks, 1960). The skeleton of rufescens differs from that of other egrets in the shape of the posterior palatine, the ventral manubrium of the sternum, the strongly bifurcate external spine of the furculum, and the very reduced internal spine of the furculum (Table 1). These specializations may be functionally related to the feeding behavior of rufescens.

Three small egrets of uncertain relationships are the darkplumaged African species ardesiaca and vinaceigula and a pied Australian one, picata. They lack aigrettes but have long strap-like lanceolate plumes on the back. In size they are similar to garzetta. Ardesiaca often feeds by shading the water with both wings spread out and around to the head; apparently fish are attracted to the shade, or perhaps they are startled out of concealment by the wing movements (Meyerriecks, 1962; Henwood, 1973; Milstein and Hunter, 1974). The tips of the primaries, secondaries, and scapulars are broad and lax in ardesiaca, an apparent adaptation for canopy feeding (Irwin, 1975). Garzetta, gularis, thula, and sacra occasionally spread their wings while feeding; the behavior is more commonly seen in rufescens (Meyerriecks, 1962; Recher and Recher, 1972). The feet of ardesiaca are bright yellow as in non-breeding garzetta and thula. The skeleton of ardesiaca differs from those species in having a smaller ventro-lateral ectethmoid process, a shorter internal spine on the furculum, a strongly bifid furcular internal spine, the temporal muscle depressions meeting in the midline of the skull in a ridge, and the ventral manubrial spine of the sternum being more rounded (less pointed). Ardesiaca differs from rufescens in several skeletal characters (Table 2). Ardesiaca appears to be distinctive as indicated in the Wagner Tree analysis, but is probably best included in the genus Egretta. Vinaceigula is rare and local in southern Africa; five specimens are known (Benson, Brooke, and Irwin, 1971; Irwin, 1975). It differs from ardesiaca with which it is sympatric in having a 
vinaceous throat and whitish bases to the shafts of the primaries, a yellowish-green tarsus, a pale base of the lower mandible, and a shorter wing and culmen, and it lacks the broad tips to the flight feathers (Irwin, 1975). Vernon (1971) reports that he did not see it umbrella-feed. Vinaceigula also differs from ardesiaca in having narrower, more attenuated and twisted tips to the back plumes. The wing, culmen, and toe length differences of specimens described by Benson et al. (1971) and Irwin (1975) indicate that vinaceigula is a distinct species. The Pied Heron picata of the Australian region has strap-like plumes above much like those of ardesiaca, and its body proportions are similar, though the bill is slightly heavier. The juvenal plumage includes a white head and neck; the adult has a black crown and crest. The species is not known to spread its wings while feeding (R. Schodde, pers. comm.), and its flight feathers are narrow and stiff, unlike ardesiaca. The skeleton of picata is similar to that of ardesiaca; only minor differences were found-the external spine of the furculum is entire in picata and slightly forked in ardesiaca, though this character varies among specimens within some other heron species and may not always differentiate picata and ardesiaca. Uncoded skeletal differences noted are a more pointed ventral sternal manubrium and a broader lateral vertebral process on the posterior cervical vertebrae in picata. The two species are nearly identical in the other skeletal features including the shape of the lacrimal and ectethmoid bones. The similarity of the skeletons of picata and ardesiaca supports the idea of a close relationship as suggested from the proportions and the plumes. The sequence of species picata-vinaceigula-ardesiaca in the classification reflects the Wagner Tree estimate of picata as less derived than ardesiaca in its skeletal characters, the highly specialized flight feathers of ardesiaca contrasted with those of vinaceigula (Irwin, 1975), and the similarity between vinaceigula and ardesiaca that led to their being regarded as conspecific in earlier studies.

Egretta tricolor, considered intermediate between rufescens and the smaller "Hydranassa" species by Bock (1956), has some back feathers with the same filamentous aigrette structure as rufescens; it also has short, pointed lanceolate display feathers on the neck. Tricolor differs from most other egrets in having a bifurcate lacrimal and a narrow axis (this last is more like Agamia). The skeletal characters suggest that tricolor is not very closely related to rufescens. These two differ in the shape of the posterior palatines, the ventral manubrium of the sternum, and the external and internal spines of the furculum (Table 2). Possibly these character differences are functional correlates of the feeding mechanism specializations in these two species. Tricolor is an active feeder and often walks belly-deep in water in coastal marshes or mangroves and darts its neck nearly horizontally to catch surface fish, whereas rufescens flaps and chases its prey, often capturing the fish by a downward stabbing 
stroke (Meyerriecks, 1962b). Interspecific attacks of Snowy Egrets $E$. thula on feeding Louisiana Herons E. tricolor as seen by Payne in Florida and Virginia (Fig. 45) suggest some degree of interference competition between these two egrets.

The Yellow-billed Egret Egretta intermedia, of the Old World has aigrettes on the back and less-specialized, long, lax feathers on the lower neck, but it lacks the head plumes of other egrets. It is larger than most of the typical egrets such as Egretta garzetta and smaller than Ardea alba. It is not very similar to the typical egrets in its skeleton. Skeletal differences between E. intermedia and the typical egrets include widely separated lateral temporal muscle depressions, a lacrimal with strong ventromedial and ventrolateral projections, absence of a tubercle or ridge below the ectethmoid, and synsacral antitrochanters that are not strongly lateral to the dorsal ridge of the sacrum (probably correlated with the broad shape of the synsacrum).

The Cattle Egret Egretta ibis is smaller, the legs are short, and the plumage undergoes a seasonal change in color unlike that of any other egrets, due largely to buffy adventitious pigment added after the plumes have grown from the feather sheaths (Humphrey and Parkes, 1963). The plumes are loose-webbed though not as loosely structured as in intermedia. Cattle Egrets nest in colonies and feed in

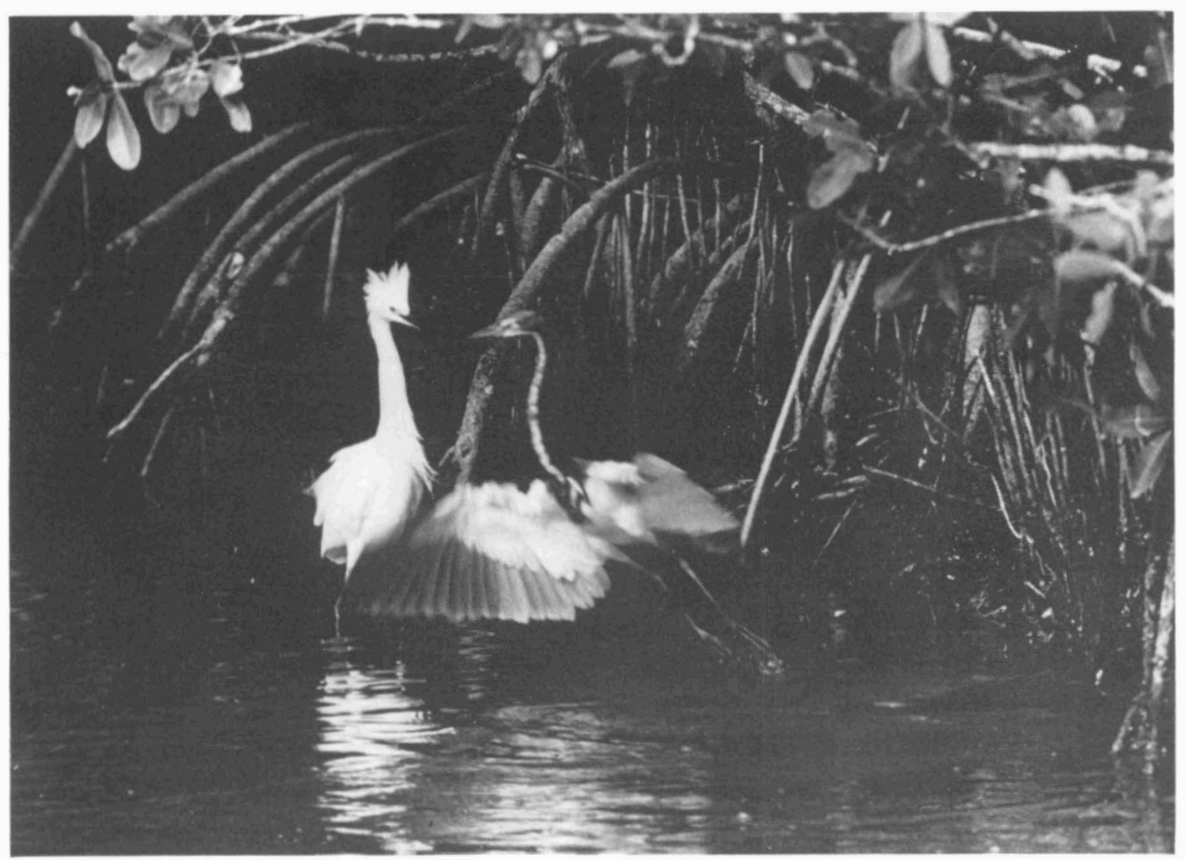

Fig. 45. Agonistic interaction between Egretta thula and E. tricolor that were feeding together in a pond lined by mangroves, Everglades National Park, Florida. The Snowy Egret erected the crest and lunged at the Louisiana Heron, which flew away. Photograph by R. B. Payne. 
groups, usually terrestrially in association with wild or domestic ungulates. The nonbreeding plumage is unstreaked white. The bill is shorter and thicker, and the neck is shorter, than in most other egrets though the bill is much like that of intermedia.

Cattle Egrets of Africa (E. $i$. ibis) and India (E. $i$. coromanda) have very different breeding plumages and might better be regarded as two species or at least two allospecies of a superspecies. African birds have orangish-buff display feathers coloring the entire head, neck, and upper breast; long plumes of similar color cover the lower back and rump. Indian birds have pinkish-buff plumes and these are restricted to the crest, the upper breast, and the lower back; the neck and throat are white. The bill is shorter and stouter in ibis. The extent of feathering on the tarsus above the distal tarsometatarsal joint is greater in ibis (about $12 \mathrm{~mm}$ bare tarsus) than in coromanda (about $24 \mathrm{~mm}$ bare tarsus), but some overlap occurs between specimens of the two groups. Wing lengths differ on the average (Ali and Ripley, 1968; Mackworth-Praed and Grant, 1970) but the ranges of wing lengths overlap. The two forms are geographically separated from each other. Cattle Egrets of the Seychelle Islands have been regarded as intermediate between the Indian and African birds, but only one specimen in breeding plumage is known, and it has not been possible to test further the idea that Seychelle birds (described as a subspecies "seychellarum") are hybrid results of independent invasions and establishments on the islands from Africa and India (Benson and Penny, 1971). It is possible that the differences in breeding plumage would act as behavioral isolating mechanisms between the two forms of Cattle Egrets, and it would be of interest to complement the study of behavior of African birds (Blaker, 1969a) with a study of behavior of birds in India or Australia. Examination of skeletons in the present study showed no differences in the coded character states in the two forms, though the interorbital foramen was slightly more rounded anteriorly in the African specimens.

Cattle Egrets are more similar to E. intermedia in their skeletal characters than to any other species of heron. The skeletal similarities between intermedia and ibis which differ from those of the other egrets are a deeply notched posterior emargination of the palatines, an absence of a subectethmoid tubercle, and a subequally bifurcate ventral projection of the lacrimal (this last state is shared with tricolor). The first similarity may be related to the biomechanics of the short, thick bill, as the palatine is the point of insertion of the pterygoideus muscle that depresses the mandible. The functional significances of the subectethmoid tubercle and the lacrimal bifurcation are not known. It is possible that these character states are independently derived in the two species as functional correlations of their method of feeding, and we do not find other evidence of any particularly close relationship between these two egrets. We empha- 
size however that there appears to be no skeletal difference between $i b i s$ and the other species of egrets, and morphologically the Cattle Egret is a "good" egret.

Egretta $i b i s$ has often been regarded as an "Ardeola" on the basis of some plumage characters (both are whitish and most species of Ardeola pond herons have some buff in breeding plumage) and their small size and short legs. As in the other egrets, the colors of the bill, lores, and legs of Cattle Egrets change through the breeding cycle (Palmer, 1962; Skead, 1966). Proportions while similar are not identical in these birds, as the tarsometatarus is longer than the humerus in ibis, shorter in Ardeola species. Cattle Egrets lack the streaked non-breeding plumage of Ardeola. Skeletally E. ibis differs from Ardeola in having a deeper bill, a more pronounced ventrolateral position of the lacrimal, no shelf overhanging in lacrimal groove, more fused medioventral palatines, a less posterior-extending lateral palatine process, and the marked tuberosity ventral to the ectethmoid is lacking. The synsacrum is broader. The muscles of the hyoid complex differ in size and form between $E$. ibis and $A$. grayii (Dubale and Mansuri, 1971). Ripley (1961, p. 14) comments, "the Cattle Egret in its behaviour seems more of an egret, less of a paddybird to me..." Cattle Egrets occasionally feed with other egrets; Payne has seen them in tidal flats with garzetta and gularis in Sierra Leone. Other egret and heron species such as Egretta thula (Rice, 1954; Carr, 1966) and Ardea melanocephala sometimes feed with herds of ungulates, but no species does this as regularly as $E$. ibis, nor do they as consistently fly as a flock and feed together. Feeding has been studied in detail by Heatwole (1965) and Siegfried (1972). Cattle Egrets appear to be specialized egrets with broad synsacra and short legs modified for terrestrial feeding.

Blaker (1969a) has described upright displays, forward displays, snap displays, and stretch displays apparently identical in $E$. ibis, intermedia, and garzetta; these are also similar to displays of other egrets (and some other day herons) as described by Meyerriecks (1962a). Ibis also shares with other egrets the behaviors of circling flights, flap flights, mutual feather nibbling, and twig passing. E. ibis differs in its copulatory postures from E. garzetta and intermedia and is generally less mobile than these egrets. It differs from most egrets also in some displays, e.g. wing open, not found in these egrets, and in not erecting the crest in greeting of members of a pair at the nest, though the crest is erected at other times in agonistic contexts. $E$. $i b i s$ also appears to lack the advertising croaking calls of E. garzetta and intermedia. In all of the described minor differences in displays in $E$. $i b i$ s the features may be derived, and the behavioral evidence available supports the idea that Cattle Egrets are related to other egret species.

Egretta caerulea and novaehollandiae are similar in skeletal characteristics to the thula-garzetta group and they link those species 
to the other egrets, particularly in the evolutionary sequence indicated in the Wagner Tree and in the cladistic compatibility analyses. These egrets have lanceolate scapular plumes rather than the filamentous white aigrettes characteristic of the smaller white egrets. Probably the form of the plumes is a specialization for breeding displays; they are used in conspicuous displays at the nest (Meyerriecks, 1960, 1962a; Blaker, 1969a, b), and they have almost certainly evolved rapidly and independently in these species. The texture of feathers varies and their form intergrades between lanceolate and filamentous forms even within many individual birds, as Dickerman and Parkes (1968) have noted. The most striking case of closely related forms having different plumes are the crest plumes of E. garzetta and thula, the former with two long strap-like plumes and the latter with a bushy white crest. Plumes of the egrets appear to be characters of doubtful taxonomic value above the species level.

Egretta novaehollandiae is a medium-sized, dark bird of the Australian region and was regarded by Bock (1956) as a species of Ardea. Bock's taxonomic treatment was guided mainly by the view that Peters' (1931) check-list of herons recognized far more genera than were compatible with current taxonomic trends. Bock included the genus "Notophoyx" in Ardea with no discussion of the similarities of novaehollandiae to the characters of egrets versus those of the herons. In our analyses of associations of skeletal character states as well as in sharing the palatine characteristics of the other egrets, novaehollandiae is associated with the egrets rather than with the large heron species. Novaehollandiae resembles caerulea in the slender, curved bill, in plumage (back plumes broader and less filamentous in novaehollandiae), and in the skull, which is very similar except for the ectethmoid complex. E. novaehollandiae is larger, has longer, stouter toes, and differs in the broader synsacrum. Distributionally the species are separated by the Pacific Ocean, but E. caerulea disperses widely (Dusi, 1967) and its range extends into South America, while E. novaehollandiae also makes seasonal movements of hundreds of kilometers (White, 1974). A trans-Pacific dispersal of an American bird followed by isolation and differentiation may have been involved in the speciation of $E$. novaehollandiae or vice versa.

The similarity of $E$. caerulea to the small egrets in the $E$. thula-garzetta species group has been pointed out by Dickerman and Parkes (1968). The plumage of the juvenile is white, suggesting the white adult plumage of these smaller egrets. The skeletal characters indicate that caerulea is closely related to these small egrets.

The small egrets garzetta, gularis, and dimorpha of the Old World and thula of the New World largely replace one another geographically and comprise a single superspecies. Garzetta and thula differ in the form of the plumes; the former has two long, lanceolate plumes on the crown whereas the latter has many filamentous aigrettes smaller than but similar in structure to the aigrettes of the 
back of both species. The displays and feeding behavior are similar (Meyerriecks, 1960; Helbig, 1968; Blaker, 1969b). No skeletal differences are evident. Because the plumes are used in courtship behavior it is likely that the two forms would respond differently to a potential mate with plumes unlike their own than to one like their own, and that the differences would be potential barriers to interbreeding. Garzetta and thula are probably distinct species.

The African Reef Heron A. gularis is similar to A. garzetta in West Africa, where gularis mainly occurs in mangroves and estuaries, with garzetta inland. Gularis is polymorphic in plumage color. The most common phase is blackish with a white chin and throat (sometimes with a few white feathers especially on the wing), a second phase is paler slate-gray (sometimes with a whitish belly)-perhaps all these are young birds, and a third phase, not mentioned in Bannerman (1930) but described by Good (1952) and Amadon (1953), is all white. The white phase has been reported only from Cameroon and São Tomé, with one additional specimen "nearly white" from Senegal (Bannerman and Bannerman, 1968:234). The only known difference between white-phase gularis and garzetta is bill color, pale in gularis and black in garzetta. Bill color of gularis is said to range from yellowish (Amadon, 1953) through dark flesh-color (Bannerman, 1930) to blackish-brown, with part of the lower mandible light (Good, 1952), and may change with the breeding condition of the bird. Bill color of blackish-plumaged birds that we observed in November, 1975, at Elmina and Weija salt pans in Ghana ranged from mostly pale gray with a black tip to dark gray or blackish. Although the feet are often described as greenish, the birds observed in Ghana had black tarsi with bright yellow toes, and the extent of the yellow varied from the lower third of the tarsus plus the toes to only the soles of the toes. Color photographs show no difference in the tarsus or toe color between blackish-plumaged gularis and white-plumaged garzetta (with slender, black bills in the latter) at Weija. The shape of the bill is more slender and straight in garzetta than in gularis, though the difference is slight and the curvature of West African gularis is not nearly as marked as in the East African-Indian Ocean form of gularis. Although garzetta and gularis are largely allopatric in breeding range they do breed in the same colonies in some areas. Naurois (1969) found both locally on the Banc d'Arguin, Mauritania, in the Senegal Delta, and in the Bijagos Archipelago of Guinea-Bissau, and he reports no mixed pairs, only gularis-gularis and garzetta-garzetta pairs, at the nests. The two forms also both breed in mangroves near the Weija salt pans along the Densu River estuary west of Accra, Ghana (Grimes, 1972). Both kinds of egrets are active feeders that find much of their food by actively pursuing small fish in shallow water, and Payne's field observations have not revealed any difference in the behavior of the two forms feeding together in estuaries near Freetown, Sierra Leone, or in the salt pans near Accra, Ghana. 
In southeastern Europe dark-phase egrets are occasionally seen feeding in estuaries, though no local breeding is known. These dark egrets have usually been identified as a dark phase of garzetta, but the bill color suggests they are dark gularis wanderers from coastal West Africa. The two species overlap considerably in their measurements (Amadon, 1952) and the size of these birds does not permit further identification (Fabian and Sterbetz, 1966; Hiraldo, 1971; Bernis, 1971). Photographs and drawings of other dark egrets from southern Europe closely resemble the dark West African gularis (Fabian and Sterbetz, 1966; Voisin and Voisin, 1975), and a specimen of dark gularis taken in the Azores (Bannerman and Bannerman, 1968: 184) further suggests long distance wanderings of the West African birds.

Reef Herons of northeast Africa and the western Indian Ocean, E. gularis asha (this name has priority over schistacea, Payne, in prep.), are larger on the average, and the bill is longer and deeper, than in West African gularis. They are dimorphic with a dark phase ashy gray, not as blackish as in the West African birds, and a white phase. The white phase is most common in the north end of the Red Sea, the dark phase in the south end, the Persian Gulf, and the Indian subcontinent shelf (Meinertzhagen, 1954).

Dimorpha of Madagascar is larger on the average than asha, and the dark phase has less white on the chin (or none at all) than the dark phase of gularis or asha. Dimorpha has been considered a species, a subspecies of gularis, and a subspecies of garzetta, the last an idea supported by the black bill color (Amadon, 1953). Dimorpha of light and dark phase usually mate assortatively within a colony, and the proportion of dark-phase birds varies among colonies (Milon, 1959).

The relationships among garzetta, gularis, asha, and dimorpha are complicated by the fact that some egrets of the east coast of Africa (Tanzania) are intermediate in size between most garzetta of the continent and the larger dimorpha of Madagascar (Steinbacher, 1936), though these birds ("cineracea") may as well be intermediates between asha and dimorpha, or may be simply large garzetta, as the size falls within the upper measurements of African garzetta. Field observations and collections or careful measurements of individual breeding birds may help to resolve the complexity of polymorphism and geographic variation in coastal African egrets, which is certainly greater than that of the Ardea herodias-occidentalis complex in the New World.

Swinhoe's Egret E. eulophotes, restricted to a few breeding localities in Hong Kong, coastal China, Taiwan, and northern Korea, has been regarded as very closely related to thula because of the many-feathered, loose-webbed crest (Bock, 1956; Murton, 1972). It is however shorter-legged, and it differs from thula and garzetta by having a yellow bill. In the two incomplete skeletons available, eulophotes was similar to thula, garzetta, and sacra (Table 2). 
The Eastern Reef Heron E. sacra is polymorphic through its range in the east Indian Ocean and western and middle Pacific Ocean. The proportion of dark-phase birds and light-phase birds (both of them having the two lanceolate crest plumes much like those of garzetta and eulophotes and both of them having both aigrettes and lanceolate plumes on the back) differs from region to region (Mayr and Amadon, 1941). Populations living along coasts in hot, clear sky areas (including coral reefs) have a higher proportion of white-phase birds; birds of some cooler temperate regions such as New Zealand are all dark-phase (Recher, 1972; Holyoak, 1973). Recher and Recher (1972) found no difference in the tactics or success in feeding behavior of the two color phases. A few birds occur in a pied plumage with a mixture of white and blackish flight feathers. The thick bill and relatively short legs of sacra are presumably specializations for feeding in often rocky coastal habitats.

\section{Ardeola-Pond Herons and Striated Herons}

Synonyms: Butorides, Erythocnus

Included species: ralloides, idae, grayii, bacchus, speciosa, rufiventris, and striata (including virescens and sundevalli).

Diagnosis: The pond herons are small, short-legged herons of the Old World. Several species have a marked seasonal change in plumage. The bill is relatively short and slender. Breeding plumage is whitish in most species, particularly on the body, with darker buffs or purples above. The plumes of the back of the whitish species are broad and filamentous or loose webbed; they vary in color from white to buff-brown to dark slaty-blue. The non-breeding plumage in ralloides, idae, grayii, bacchus, and speciosa is mainly white with the back brown and the head, neck, and breast streaked brown and white (Table 8). The tarsi are scutellate. Pond herons breed in small to large colonies (Rand, 1936; Ali and Ripley, 1968; Mackworth-Praed and Grant, 1970), often with other species. The striated herons rufiventris and striata are small herons with streaked underparts and long lanceolate plumes above, and the tarsi are reticulate.

The species $A$. ralloides, grayii, bacchus, and speciosa form a single superspecies with each form mainly replacing each other geographically. The Squacco Heron $A$. ralloides breeds in southern Europe, the Middle East and Africa, and also in Madagascar where it is sympatric with the Madagascar Squacco Heron $A$. idae and sometimes breeds in the same colonies (Benson and Penny, 1971; Rand, 1936; R. W. Storer, unpublished observations). Northern populations of ralloides are migratory, wintering in Africa between the Sahara and Equator; Yugoslav-ringed birds have been recovered in Nigeria and Cameroun (Moreau, 1972). Madagascar idae in nonbreeding plumage have been collected in east and central Africa.

The Indian Pond Heron $A$. grayii and Chinese Pond Heron $A$. bacchus overlap somewhat in southeastern Asia, particularly in Burma 
TABLE 8

PLUMAGE VARIATION IN THE POND HERONS

\begin{tabular}{|c|c|c|c|c|c|}
\hline \multirow[b]{2}{*}{ Species } & \multirow{2}{*}{$\begin{array}{l}\text { Nonbreeding } \\
\text { Plumage }\end{array}$} & \multicolumn{4}{|c|}{ Breeding Plumage } \\
\hline & & Crown & Head & Neck & Back \\
\hline idae & $\begin{array}{l}\text { heavily } \\
\text { streaked }\end{array}$ & white & white & white & white \\
\hline ralloides & $\begin{array}{l}\text { streaked, } \\
\text { buff neck }\end{array}$ & $\begin{array}{l}\text { streaked } \\
\text { brown }\end{array}$ & $\begin{array}{l}\text { streaked } \\
\text { above, } \\
\text { white below }\end{array}$ & buff & $\begin{array}{l}\text { brown } \\
\text { (gray to } \\
\text { purple shades) }\end{array}$ \\
\hline grayii & $\begin{array}{l}\text { streaked, } \\
\text { no buff } 1\end{array}$ & gray & gray & gray & gray \\
\hline bacchus & $\begin{array}{l}\text { streaked, } \\
\text { no buff } 1\end{array}$ & purple & purple & purple & blue \\
\hline speciosa & $\begin{array}{l}\text { lightly } \\
\text { streaked }\end{array}$ & buff-white & buff-white & $\begin{array}{l}\text { rusty- } \\
\text { buff }\end{array}$ & $\begin{array}{l}\text { dull blue- } \\
\text { purple }\end{array}$ \\
\hline
\end{tabular}

1-No consistent differences are known in nonbreeding plumage of $A$. grayii and $A$. bacchus.

where grayii occurs mainly in the central plains and bacchus mainly in the north and east (Smythies, 1950). No hybrids are known. The more northern bacchus are migratory. The Javan Pond Heron $A$. speciosa has a continental race $A$. s. continentalis, in Thailand, distinguishable by its larger size.

No detailed accounts are available for the display behavior of any of the pond herons, though Lamba (1963) has completed some notes on grayii.

The various geographic forms of "Butorides" appear to comprise a single species, Ardeola striata, in the $A$. striata-virescens-sundevalli complex. Only a single form is known to breed within any one area. Locally distinct populations occur, especially in the islands of Wallacea (Mayr, 1940, 1943; Ripley, 1969), and also along the northern coast of Australia (Mayr, 1943). As many as 30 subspecies may be recognized in the species, mainly on tropical island groups (Mayr, 1940, 1943; Payne, in prep.). On the other hand, single forms may occur across thousands of kilometers in continental regions (Payne, 1974). Birds of North America (the Green Herons) have long been recognized as a distinct species ("virescens") but no areas of sympatry are known for breeding dark-necked virescens and palenecked striata, and populations of breeding birds in Panama, the southern Caribbean islands, and the Caribbean coastal plain of South America (excluding the wintering migrants) are intermediate in appearance (Payne, 1974). The Galapagos Islands birds are variable in appearance but nearly all are considerably darker than the popula- 
tions of South America, and the palest birds are distinct from those of mainland South America. These Galapagos birds are apparently not specifically distinct (they have been called sundevalli, the Lava Heron) but are regarded as a subspecies of Ardeola striata (Payne, 1974). In a behavior study B. Snow (1975) remarked on the apparent absence of advertising displays in the Galapagos. The absence of these displays was evidently related to the sedentary existence and permanent pair bond of the Galapagos population (B. Snow, 1975). No mutually exclusive displays are known. No consistent differences were found among the skeletons of striata, virescens, and sundevalli.

The African Rufous-bellied Heron A. rufiventris is intermediate in plumage characteristics between the pond heron species complex and $A$. striata, and it links these forms together into a single genus. It has lax plumes on the back, like the back plumes of bacchus and speciosa in form and vinaceous color, but it is darker than these pond herons, with a slate- or blue-gray back, neck, and breast, and a vinaceous belly. Rufiventris lacks the long crown plumes of the ralloides superspecies. The juvenal plumage of rufiventris resembles that of striata in having a pale streak down the throat and a gray-brown throat with pale buffy center-streaking, but it resembles the pond herons in having an unstreaked belly. Rufiventris differs from all other day herons in being markedly sexually dimorphic, and the differences between males and females in museum specimens indicate that they could be sexed on sight in the field. Males are darker above with long $(100 \mathrm{~mm})$, lax, bluish plumes on the back, and have the chin and throat dark bluish-gray like the neck. Females are paler, dull gray above, some have a brownish cast; their back plumes are lax but shorter $(70-80 \mathrm{~mm})$, and they have a buff or white stripe down the chin and throat. The belly is slightly paler in the females. Unlike the pond herons, rufiventris has no obvious seasonal plumage dimorphism.

In R. B. Payne's experience, rufiventris is more closely restricted to the marshy vegetation of flood plains than is ralloides, which also feeds along river banks and in grazed grassland, although Karen Payne has observed rufiventris feeding in numbers in the termite zone above the Kafue River flood plains in grassland heavily grazed by lechwe, in a year of high floods when little emergent vegetation remained closer to the river channel. Rufiventris also nests in small colonies (Uys and Clutton-Brock, 1966); so do both some striata (Dickerman and Gavino, 1969) and the pond herons.

Skeletal differences between $A$. striata and rufiventris and the pond heron species are slight but consistent in the specimens examined. Striata and rufiventris are smaller, the tarsi are more finely reticulate, and the hypotarsus is more highly ridged. These details are compatible with the plumage pattern in suggesting that rufiventris is more closely related to $A$. striata than to the pond herons. 


\section{Agamia-Agami Heron}

Included species: agami

Diagnosis: The Agami Heron of the tropical Americas has a very long neck and long slender bill, and it is apparently a specialized bank feeder (Wetmore, 1965). The plumage is brightly colored with chestnut below, dark glossy green above, and blue on the neck, crown, and scapular feathers. The sides of the face, the forehead, and part of the neck are black. This heron has a peculiar kind of plume, short, slender, and curved; these lie along the neck. The dark plumage may be an adaptation for the Agami's forest habitat, and the narrow pale blue-gray plumes of the neck and flimsy egret-like plumes of the back in the breeding adults contrast with the dark plumage.

The brightly colored plumage and the long bill suggest Egretta tricolor and the rich chestnut color suggests Ardea purpurea but it is not clear what species of heron is most closely related to the Agami. The juvenal plumage is unstreaked brown above; the crown is black. Below the young is streaked rather like a young $A$. striata, with many feathers dark along the edges and white along the shaft. The neck has a narrow ventral white streak from the white chin to the upper breast; a thin line of brown divides the white streak much as in the adult. The neck otherwise is unstreaked brown, rather unlike juvenile striata in which the sides and underparts of the neck are heavily streaked. A downy young, in the collection of R. W. Dickerman, is uniformly blackish, unlike any other heron of the New World. The eggs are a deeper, more intense blue than are eggs of other New World herons (R. W. Dickerman, unpublished observations).

Although it is a bank feeder that ambushes fish from the edge of a stream bank or perches on a log much like Ardeola striata, the Agami heron is not unusually short-legged, as the tarsometatarsus is nearly equal in length to the humerus. The tarsi are largely scutellate but are reticulate on the lower fourth. The skeleton is much like that of many species of Ardea and Egretta, though the synsacrum of Agamia has a slightly more prominent nearly angulated dorsal ridge of the iliac crest and a laterally prominent antitrochanter (the latter less prominent than in the bitterns), and the furculum has a long, unified external spine (Fig. 17). The sternocoracoidial process of the sternum is narrower and slopes forward more than in any other ardeine heron (Fig. 16B). The long, slender bill is the only conspicuously distinct feature of the skull. The skeletal differences between Agamia agami and other herons, though fewer in number than those between $E$. rufescens and the other egrets, appear to be qualitatively greater between Agamia and the other day herons, and the skeletal peculiarities, the eggs, the plumage of the downy young, and the unique plumes lead us to recognize the genus Agamia. 


\section{NYGTICORACINAE, THE NIGHT HERONS}

The night herons are distinguished skeletally from all other herons by an enlarged basitemporal ridge. Night herons are further distinguished from the Ardeinae by the following characters: shape of the interorbital foramen, broad axis, lack of lateral vertebral canal on vertebra 17 (lacking in Syrigma also), and the bicipital rib articulation on vertebra 17 . Night herons are separated cladistically and phenetically into two tribes, the night herons Nycticoracini and the boatbilled herons Cochlearini. Bill size and shape vary considerably from the slender bill of Nycticorax melanolophus, to the broad, deep bill of the western Mexican and the Lesser Antillean populations of Nyctanassa violacea, to the extremely broad bill of the Boat-billed Heron Cochlearius cochlearius. The phenetic and phylogenetic results indicate that Nyctanassa is distinct from the Nycticorax species available in the skeletal sample, and the genus Nyctanassa is recognized. The species of "Gorsachius" (goisagi and melanolophus) form an extreme in the variation of development of rufous plumage and slender bills seen among other species in the genus Nycticorax, and these are all regarded as Nycticorax species, at least until skeletal material of the apparently intermediate species becomes available.

Tribe-Nycticoracini

Nyctanassa-Yellow-crowned Night Heron

Included species: violacea

Diagnosis: Night herons with moderately broad, deep bills.

Nyctanassa violacea differs in many ways in plumage and morphology from Nycticorax nycticorax, and it is a more distinctive bird than any of the recognized genera or subgenera among the ardeine herons except Syrigma. $N$. violacea differs from the Nycticorax species in having streaked, lanceolate back and scapular plumes ( $N$. nycticorax has no back plumes), a whitish crown, black throat, and gray underparts (the South American dark phase "obscurus" of $N$. nycticorax is a lighter gray below). It has longer, more slender tarsi (a good mark for field identification, Robbins et al. 1966), a broader stouter bill (especially in Pacific subspecies and in birds of the Lesser Antilles) and a less grooved bill (Adams, 1955).

The skeletal differences between Nyctanassa violacea and Nycticorax nycticorax are dramatic; several were described by Adams (1955). Nyctanassa violacea has a differently shaped interorbital foramen, no supraorbital foramen, much less deeply recessed temporal muscle depressions that barely meet in the midline, fused posterior margins of the palatines, a broader more inflated ectethmoid, a more rounded orbital process of the quadrate, a broader axis 


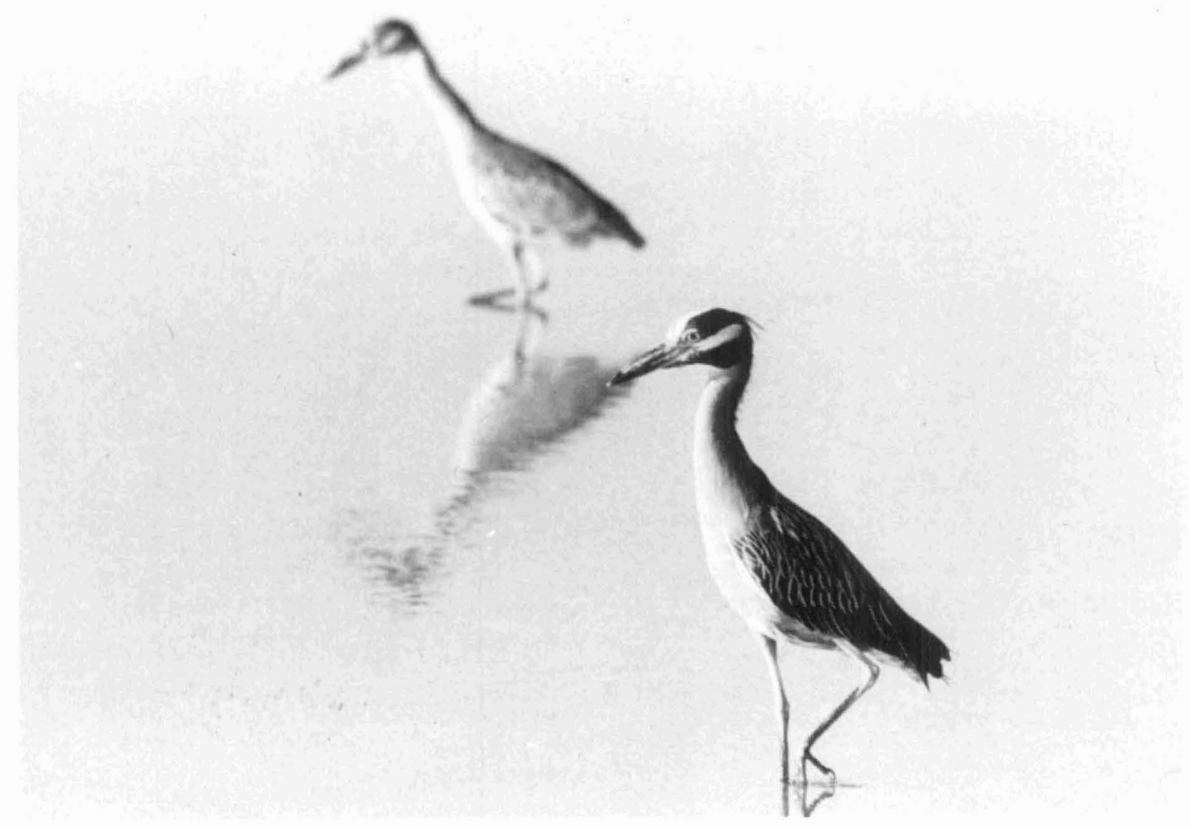

Fig. 46. Feeding postures of Yellow-crowned Night Herons Nyctanassa violacea, Everglades National Park, Florida, 25 December 1974. Photograph by R. B. Payne.

vertebra, a distinct tubercle but no ridge below the ectethmoid, a more pronounced internal furcular spine, a pointed ventral sternal manubrium, a low deltoid crest on the humerus, a broader synsacrum with less vertical sides, and a more elongate, less rounded ilio-ischiatic foramen in the synsacrum. Adams (1955) documents additional species differences in the lengths and ratios of bones. The skeletal differences are distributed throughout the skeleton and not confined to the skull in association with the broad bill. The differences between Nyctanassa and Nycticorax and the numerical taxonomic analyses of associations of character states indicate that the two should be recognized as distinct genera.

Juvenal plumages are rather similar in Nyctanassa violacea and Nycticorax nycticorax, more so than in the other species of Nycticorax. Streaked juvenal plumage is a primitive condition in the group, not a uniquely derived condition relating violacea and nycticorax. The tarsi are mainly scutellate, the distal end being reticulate.

Behavioral studies of $N$. violacea are now in progress by A. J. Meyerriecks, and some conspicuous differences are evident in the displays of this species and N. nycticorax. Nyctanassa violacea differs from $N$. nycticorax in frequently giving an upright stretch display, like the day herons, and in having a wing-stretch accompanying the 


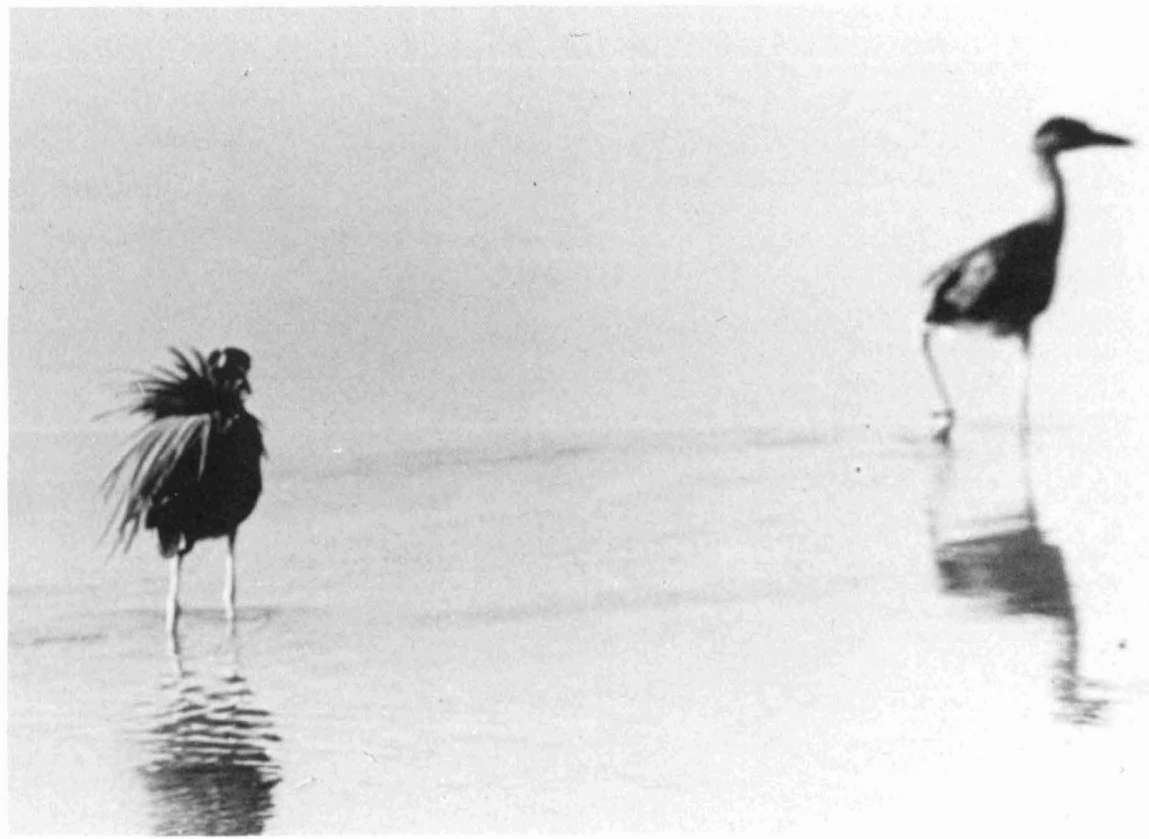

Fig. 47. Agonistic display of foraging Yellow-crowned Night Herons Nyctanassa violacea. The adult on the left has its head thrust forward and its display plumes on the back raised. Just before this, the back plumes were raised and spread much more conspicuously toward the heron in immature plumage. The young bird was supplanted by the adult when it followed too closely behind the foraging adult, Everglades National Park, Florida. Photograph by R. B. Payne.

upright neck stretch (A. J. Meyerriecks, pers. comm.). Meyerriecks notes that the displays leading up to mating are similar. Feeding in Nyctanassa violacea appears to be much more common in the daytime than in Nycticorax nycticorax. Payne's brief field observations of $N$. violacea along the mud beaches of mangrove areas of southern Florida suggest that the species often feeds in the day with individual birds holding feeding territories on the mud flats (Figs. 46 and 47); the birds eat mainly $U_{c a}$ crabs and also crayfish. Birds also are on the mud flats at low tide at night and have loud calls. Some feeding occurs at night when the herons could be heard crunching crab shells for a few hours before dawn.

\section{Nycticorax-Night Herons}

Synonyms: Calherodius, Gorsachius, Oroanassa.

Included species: caledonicus, goisagi, leuconotus, magnificus, melanolophus, and nycticorax.

Diagnosis: Night herons with long, slender bills, plumage unmarked gray and black or rufous above, finely vermiculated in goisagi and 
melanolophus. The crest is black (rufous in goisagi). Plumage of the immature is streaked and brown. The tarsi are reticulate.

$N$. nycticorax and $N$. calendonicus are geographically replacing forms, with nycticorax breeding through much of the New World, Eurasia, and Africa, and caledonicus breeding in the Phillippines, Indonesia, New Guinea, Australia, and other islands of the western Pacific. Limited interbreeding occurs between the two where their breeding ranges come together in western Java and possibly Sulawesi (Celebes) (Hoogerwerf, 1966; White, 1973). In other areas the two occur together where migratory non-breeding $N$. nycticorax winter in the range of $N$. caledonicus, including the Ogasawara (Bonin) Islands, the Philippine Islands, Lesser Sunda Islands, and Micronesia. An uncommon rufous phase of nycticorax, resembling the color and pattern of caledonicus, occurs rarely in western North America (Van Rossem, 1936). Many adults of nycticorax in southern South America are very dark with mottled underparts, whereas others are intermediate in color between these dark birds and the paler North American subspecies. The displays of $N$. nycticorax have been described by Meyerriecks (in Palmer, 1962) and by Voisin (1970). The behavior of $N$. caledonicus as observed in the Philippines is similar (A. J. Meyerriecks, pers. comm.).

$N$. goisagi and N. melanolophus (often regarded as a distinct genus, Gorsachius) have short, slender, curved bills unlike those of the other herons. They appear to form a superspecies, with goisagi breeding on Japan and melanolophus breeding through Taiwan, southern China, southeast Asia, India, Indonesia, and the Philippines. They differ in bill length and in plumage (crest longer and black in melanolophus, rufous in goisagi), color (more rufous in goisagi), and the presence of a long crest in the juvenile (only in melanolophus). N. melanolophus is variable in size but variation is greater within than between the geographic regions of its range. Plumage is rufous above with fine vermiculations, the neck is unbarred rufous and gray, and the underparts are streaked with some barring on individual feathers. The crest is black in melanolophus, rufous in goisagi, and unmarked. Juvenal plumage in melanolophus is brown (less rufous than goisagi) above with fine buff and sandy barring, the crest is spotted with white, the neck is spotted and barred, and the underparts are more heavily marked with irregular streaking and V-marks than in the adults.

N. melanolophus differs from $N$. nycticorax and caledonicus in plumage pattern and in the short, slender bill. The skull differs in having a typically large ardeid supraorbital foramen, strongly bifurcated ventral projection of the lacrimal (Figs. 3, 7), a shorter and ventrally directed ectethmoid, a distinct tubercle and no ridge below the ectethmoid (Fig. 7), a smaller supraorbital process, and a more anteriorly extensive temporal muscle ridge on the midline of the 
skull. The skeleton also differs in having a strongly bifurcate external furcular spine, a more deeply notched sternum, a shorter and more pointed ventral sternal manubrium, an ilioischiatic foramen more restricted posterio-dorsally, and a lack of any pronounced iliac recess in the synsacrum.

The African White-backed Night Heron N. "Calherodias" leuconotus and the rare $N$. "Oroanassa" magnificus of Hainan and Fukien are included in Nycticorax in part because they appear to share some character states with both Nycticorax nycticorax and "Gorsachius" and because "Gorsachius" appears in the cladistic compatibility test and the Wagner Tree estimate of evolution to be a derived Nycticorax. These two Old World night herons also share some characteristics with Nyctanassa that are not shared with the other two groups. It is difficult to determine which character states are the derived ones in the night heron group.

Features that the two herons share with both the $N$. melanolophus-goisagi superspecies and the $N$. nycticorax-caledonicus superspecies (and differ from Nyctanassa) are the reticulate tarsal scalation, the rufous plumage, the black crest, and the slender bill. The form of the bill is intermediate, with leuconotus more like N. nycticorax, and magnificus more like $N$. goisagi; the most slender-billed night heron is $N$. melanolophus. The juvenal plumage of leuconotus and magnificus resembles the adult plumage above, but has round whitish spots like the Nyctanassa juvenal plumage. On the breast and belly, leuconotus juveniles are marked less distinctly than are juvenal magnificus, which have many feathers tan on one side and blackish on the other, and others $\tan$ in the center but edged heavily with an inverted blackish $\mathrm{V}$, as in melanolophus. Magnificus also is more like the east Asian melanolophus on the underwing coverts which are boldly patterned in the latter, but are uniformly dull rufous in leuconotus. The crest of the juvenile leuconotus is dark but has narrow white shaft streaks, suggesting a relationship to $N$. melanolophus which has the distinct white and black bars in the juvenal crest. In the adult plumage, leuconotus is plain rufous below with only indistinct streaking on the neck and belly, magnificus is boldly marked below with V-edged feathers, and melanolophus is even more boldly patterned. Plumage and bill shape suggest the sequence nycticorax-caledonicus-leuconotusmagnificus-goisagi-melanolophus, with only a slightly larger gap separating the first two and the last four species.

No skeletons of leuconotus or magnificus were available for study, but one study skin of leuconotus was examined by exposing part of the skull by lifting a flap of skin from the face. The leuconotus specimen has a small interorbital foramen, lacks a supraorbital foramen, and has a rounded tubercle below the lateral ectethmoid (all as in Nyctanassa) and has a bifurcate lacrimal (as in N. melanolophus). It had none of the distinctive character states of $N$. 
nycticorax. These few skeletal characters suggest a possible relationship with Nyctanassa, but the plumage and tarsal scutellation suggest a close relationship with Nycticorax.

Bock (1956) considered the four species goisagi, melanolophus, magnificus, and leuconotus to comprise a genus "Gorsachius", in part because of their nesting in isolated pairs rather than in colonies. Leuconotus is generally solitary like goisagi and melanolophus (Irwin and Benson, 1967; Keep, 1973); recent observations of magnificus are lacking. As discussed earlier in this paper, nesting dispersion has probably been selected to be colonial or dispersed repeatedly within some species and among closely related species, and at least some night herons may vary locally in their nesting dispersion (Meyerriecks, in Palmer, 1962).

\section{Tribe-Cochlearini \\ Cochlearius-Boat-billed Heron}

Included species: cochlearius.

Diagnosis: Very broad, scoop-like bill. Plumage is gray to blue-gray above and unstreaked buff, chestnut, and black below; the fan-like frontal crest is black. Plumage of immature is brown and buff, unstreaked or faintly streaked, and the crest is black. The tarsus is reticulate as in Nycticorax.

The Boat-billed Heron has often been placed in a family of its own, Cochleariidae (Peters, 1931; Wetmore, 1960). Mayr and Amadon (1951) placed it in the Ardeidae, and Bock (1956) has discussed reasons for considering the species an aberrant night heron and as no more than generically distinct from the other night herons. Dickerman (in Dickerman and Juarez, 1971) suggested that a distinctive tribe Cochlearini be recognized. Most of the unusual skeletal characters of the boat-bill appear to be related to its broad bill. Cochlearius also is peculiar in the posterior cervical vertebrae, and the form of the sternal manubrium, and the prominent deltoid crest and pneumatic fossa on the humerus, characters that are not obviously a single adaptive unit with the broad bill. The plumage color and pattern above is much like that of Nycticorax nycticorax, but the brown and black underparts are unique.

Cochlearius also differs from the other night herons in having four (not three) patches of powderdown (Ridgway, 1878; Miller, 1924; our inspections of museum skins). Although it does differ in number of patches from the other night herons, abnormal patches have been noted in Nycticorax nycticorax (Schneider, 1937), and the number and fusion of pairs is variable also among species in the tiger herons. Fresh eggs are pale blue fading rapidly to whitish and normally have speckles (Wetmore, 1960; Dickerman and Juarez, 1971). The eggs are unlike the unmarked blue eggs of Nycticorax nycticorax and Nyctanassa violacea, though Mackworth-Praed and Grant (1970) describe the eggs of Nycticorax leuconotus as whitish. Wetmore 
notes that the eyes of Cochlearius may reflect orange light at night, though only weakly (Dickerman, pers. comm.). Eye-shine is not known for other herons.

The color pattern of the downy young is distinctive, with a sooty-gray crown contrasting with the light gray of the cheeks and back, and the crown down is short, not long as in the bushy-crested young of other herons (Dickerman and Juarez, 1971). The juvenal plumage is brown and unstreaked above, in contrast to the streaked plumage of Nycticorax and Nyctanassa.

The skeletal characteristics of Cochlearius show it to be more like Nycticorax or Nyctanassa than like any other heron (Figs. 24, $25,26-28,30-35,37 \mathrm{~A})$. It differs in several features that are apparently related in a functional sense to the broad, scoop-like bill (Figs. 3, 7, 9). The palatines are exceptionally broad, inflated laterally, and the lateral process posteriorly is well forward of the mediopalatine area, and the orbital process of the quadrate is short and thick, and the mandibular articulation is narrowed (as noted earlier by Wetmore, 1960). Probably related either to the broad bill or to the enlarged eyes and the huge orbits are the reduced lacrimal and ectethmoid and a relatively large supraorbital process. The enlarged eyes are related to the nocturnal feeding behavior (Wetmore, 1960, 1965). Perhaps associated with the biomechanics of the large bill is the broad axis (Fig. 11). The humerus has a prominent peneumatic fossa (Fig. 18) unlike other herons. The deltoid crest is high, unlike Nyticorax nycticorax but like other night herons. Other postcranial differences of Cochlearius and some other herons have been described (Cracraft, 1967) but are barely perceptible. The postcranial skeleton is very like that of $N$. nycticorax, and the similarity indicates that Cochlearius is a night heron with a special feeding apparatus.

Recent behavior studies indicate that Cochlearius has several displays unlike the other night herons. Unique features of its behavior include a bill-clappering display, allopreening, prolonged extendedwing display, frontal erection of the black crest (forming a broad fan as seen from the front, not a sagittal crest as in the other herons) (Carpenter, 1971; Dickerman and Juarez, 1971 (Fig. 8); Mock, 1976). The frontal crest and its frontal display may be related to the broad bill, and the other components may have been selected for their value in the dense mangroves where these birds nest (Mock, 1976). The many unique behavioral and morphological features of Cochlearius indicate that it should be recognized as a distinctive tribe, Cochlearini, within the night herons, Nycticoracinae.

\section{TIGRISOMATINAE, THE TIGER HERONS}

Tiger herons are found in the Old World and New World tropics, often in forested habitats. The plumage of most forms is barred and the coloration is generally brown. Skeletally the tiger herons are 
characterized by the degree of fusion of the sacral parapophyses with the synsacrum and the ligamental furrow of the humerus. The New World species have derived character states including a small interorbital foramen, an angulated iliac crest, and enlarged lacrimals that contact the jugal. Tiger herons differ further from the Ardeinae in the following skeletal characters: lacrimal strongly bifurcate, ridge present below main ectethmoid projection, and sternocoracoidial angle inclined forward. They differ from the night herons in the palatine shape, the form of the interorbital foramen, the lacrimal bifurcation, the lack of a prominent basitemporal ridge, the narrower axis, and the presence and absence of a lateral vertebral canal and an articular surface for a bicipital rib on vertebra 17 .

Tigrisoma-American Tiger Herons

Included species: mexicanum, lineatum, fasciatum

Diagnosis: Large tiger herons with distinct immature and adult plumages. Adult plumage is finely barred or vermiculated above, mostly gray; the belly is unbarred and ranges from gray to buff to light rufous. Immature plumage is broadly barred or spotted above and is largely buff or rufous, the belly is whitish and barred or spotted. A short crest of black, rufous, or barred gray feathers. is present. The scales on the front of the tarsus are large and reticulate.

Species relationships in the fasciatum-lineatum complex have been reviewed by Eisenmann (1965). Plumages of the juvenile and adult are each more similar between the two species than are the different age plumages within a species. Eisenmann recognizes the forms lineatum and marmoratum (syn. bolivianus) as subspecies of $T$. lineatum, and salmoni, fasciatum' (syn. brevirostre), and pallescens as subspecies of $T$. fasciatum. $T$. lineatum appears to live mainly in "wooded or marshy borders of the more slowmoving rivers, swamps, and lakes," and T. fasciatum is found along "rapid streams in mountainous, or at least hilly, humid forest." Eisenmann separates the two species, which are broadly sympatric in much of Central and South America, on several characters, including the presence of interscapular powderdowns, a shorter, more arched bill, a black crest and crown and gray face in the adult plumage, buff bars (not fine vermiculations) above, and less fully feathered throat in T. fasciatum; the extent of the gular feathering varies geographically and is least in the northern populations of both species. The species T. mexicanum was earlier recognized as generically distinct (Peters, 1931; Wetmore, 1965) because its throat and foreneck are bare, but as the extent of throat feathering varies within the other species this difference is minor. The plumage pattern of $T$. mexicanum is similar to the other two species; the sequence differs as mexicanum molts from juvenal plumage to adult plumage whereas lineatum has a distinctive intermediate plumage as illustrated by Eisenmann (1965). 
Skeletal characteristics of Tigrisoma include highly prominent hypotarsal ridges, a large lacrimal (Figs. 4, 8) extending to the jugal where it slides in a groove in the jugal, a large lateral projection on the ventral surface of the lacrimal, a large projection above the lateral lacrimal groove, a prominent dorsally angulated iliac crest, and a somewhat more rounded, less angulated intercotylar prominence on the tarsometatarsus (intermediate in form between that of the bitterns and the other herons). T. lineatum differs from $T$. mexicanum in the presence of a slight pneumatic fossa in the humerus, a narrower synsacrum (especially the posterior iliac shelf), a less prominent medial ridge between the temporal muscle scars, and a shorter bill, a more deeply notched posterior border of the palatine, a less prominent medial projection on the ventral side of the lacrimal, a pointed ventral manubrium, and a more rounded nostril, but the differences in at least these last skeletal features are no greater than the differences among the Ardea species.

\section{Zonerodius-New Guinea Tiger Herons}

Included species: heliosylus

Diagnosis: Tiger herons with banded plumage in immature and adult, crest black with white bases of feathers. The chin and throat are completely feathered.

The New Guinea tiger heron, restricted to New Guinea and nearby islands, appears to have a relict distribution in the Old World tropics much as does Tigriornis leucolophus in Africa. The species is solitary and lives in forests and its habits are not well known. It has white powderdown, the neck and upper breast are banded as on the back, and the belly is whitish. In the absence of any available skeletons of the species, we partially dissected a skin of Zonerodius to examine certain readily visible skull characters (Fig. 4). The skeleton appears on this basis to resemble the African Tigriornis more closely than either species of Tigrisoma examined but is nevertheless distinct in several characters, and the Old World tiger herons are probably best regarded as generically distinct. The lacrimal of $Z$. heliosylus is slender but differs from that of T. leucolophus in being undivided at the tip of the ventral projection; it does not appear to contact the jugal. The configuration of the supraorbital process, the interorbital foramen, and the supraorbital foramen is similar to that in $T$. leucolophus. The ectethmoid differs in being a distinct, flat plate, a simple lobe in shape, directed ventrolaterally, and there is a ridge below the ectethmoid, long and slender in shape, not swollen as in the New World forms (T. leucolophus lacks a distinct ectethmoid and a subectethmoid ridge). It would be of interest to compare the complete skeletons of the two Old World tiger herons when more complete skeletal material of Zonerodius heliosylus becomes available. 
Included species: leucolophus

Diagnosis: Tiger herons with banded plumage in immature and adult, and a white nape crest. Tarsus is reticulate.

The tiger heron of west and central Africa lives a solitary life in the forest and is little-known in the field (Chapin, 1932). The plumages of immature and adult are more alike than those of the other tiger herons. The plumage below is salmon-color, the feathers white along the shaft, black near tip, pink along edge. The crest is absent in the juvenal plumage. The species was described as generically distinct from other tiger herons on the basis of the reticulate tarsus. The bill is as long as in other tiger herons (contra Bock, 1956) but is more slender. As Bock (1956) notes, the powder down is gray, not white. Except for these characteristics the species is rather similar to the New Guinea tiger heron Z. heliosylus. Indeed, the latter has scutellate tarsi but the large tarsal scutes wrap less than halfway around the tarsus. T. leucolophus resembles $Z$. heliosylus in the barred pattern in immature and adult plumage, in the short black crest with white bases to the feathers, and in the fully feathered chin and throat.

The skeleton of Tigriornis leucolophus is remarkably different from the New World tiger herons. The sternum is unlike that of any other heron examined in having extremely long sternal notches and a second small medial pair of notches (Figs. 14, 15). The humerus has a shorter, more rounded deltoid crest, the condyle is flatter, and the surface from the deltoid crest to the distal condyle is rounder. The synsacrum is more slender and the ilioischiatic fenestrum is more elongate than in the New World species. The axis is somewhat like that of Tigrisoma lineatum but is more slender, and the shape of the pneumatic fossa is less rounded. In the skull the supraorbital foramen is well developed (absent in Tigrisoma), the quadrate is more slender, the interorbital septum is more complete, and the palatines are less notched posteriorly. The lacrimal is bipartite but is more slender on the lateral proportion, and the projection above the lateral groove on the lacrimal protrudes from the anterior portion of the lacrimal (Figs. 4, 8). The lacrimal of Tigriornis appears to contact the jugal, but less intimately than in Tigrisoma, and the jugal lacks the lacrimal groove of those New World species.

\section{BOTAURINAE, THE BITTERNS}

Bitterns are characterized from all the other herons skeletally by an ischiopubic symphysis. They differ further from the day herons in the shape of the sternocoracoidial process on the sternum, the position of the posterior sternal facet on the coracoid, a more rounded and nonprominent deltoid crest on the humerus, a more 
angulated iliac crest, and a more rounded intercotylar prominence on the tarsometatarsus (Table 2). From all of the night herons examined they differ in the shape of the palatines, the low prominence of the basitemporal ridge, the narrower axis, the position of the posterior sternal facet of the coracoid, and the shape of the deltoid crest on the humerus (Table 2). Bitterns differ from the tiger herons in palatine shape, size and shape of the lacrimal, extent of the lateral ectethmoid, sternal facet position of the coracoid, humerus deltoid crest size and shape, ligamental furrow, synsacral parapophysial fusion, iliac recess, and intercotylar prominence of the tarsometatarsus in the species available. Among the bitterns Zebrilus is strongly differentiated cladistically and phenetically from the other herons (Figs. 25, 30, 31, 35), and it is placed in a tribe Zebrilini. The other bitterns Ixobrychus and Botaurus are placed in a tribe Botaurini.

\author{
Tribe-Zebrilini \\ Zebrilus-Zigzag Heron
}

Included species: undulatus

Diagnosis: Small, solitary, forest heron of South America with alternating light and blackish bands above producing a zigzag appearance. Immatures are mainly black above with rufous bands; the underparts are rufous, the belly paler. Adults are zigzagged black and buff or light gray above, and are buff below. Adults have a broad black crest. Wings and tarsi are short. The tarsi are broadly scutellate; the large scales wrap more than halfway around the tarsus. Three pairs of powderdown patches are present, on the rump, the breast, and (small patch) inguinal regions. Rectrices number ten.

Zebrilus is the most enigmatic of the herons. Some of its characteristics are like those of the bitterns, others like tiger herons. In its zigzag history in systematics it has been regarded as a bittern by Sharpe (1898) and Peters (1931) and as a tiger heron by Ridgway (1878) and Bock (1956). Bittern-like features include the 10 tail feathers (other herons have 12), the tarsal scutes (though some of the smaller Ardeinae herons are scutellate), the barring (resembles Botaurus pinnatus and especially immature Ixobrychus sturmii), dark shaft streaks on some feathers of the underparts, and the inner toe is longer than the outer (though in the night herons these toes are subequal in length). On the other hand, it is unlike the bitterns and resembles the tiger herons in the fine detail of the zigzag pattern on the feathers of the upper parts, the largely unstreaked plumage especially of the juvenile, and the occurrence of three pairs of powderdown patches (bitterns have two).

The skeleton shows a much closer affinity of Zebrilus with the bitterns than with any other group of herons. Bittern-like characters include the absence of a projection over the indistinct lateral lacrimal 
groove, well-developed supraorbital foramina (absent in Tigrisoma), a rounded tarsal intercondylar prominence, a synsacrum with 4 vertebral recesses anterior to the pectineal region (5 in all tiger herons; 4 in all bitterns and other herons), and a well-developed hypotarsus (the hypotarsus of the Zebrilus specimen examined is nearly as well-developed as in an adult Ixobrychus sturmii). The supraorbital process is narrow and directed slightly forward-unlike Ixobrychus or Botaurus, though it is not like Tigrisoma either-it goes only down, not back as the bitterns do. The only tiger heron-like character states noted include a short internal furcular spine (though some Botaurus and Ixobrychus spines resemble the tiger herons in this character), and a lateral projection on the ventral lacrimal (this occurs also in some Botaurus and in I. flavicollis, and it is absent in the New Guinea tiger heron Zonerodius). It differs from both the tiger herons and the other bitterns in other characters including the shape of the axis and the dorsally-directed orbital process of the quadrate.

The evolutionary pathway suggested by the cladistic compatability test and the phylogenetic Wagner Tree analysis suggests that Zebrilus may have retained the primitive character state of 3 pairs of patches of the ancestral form. The barring of the plumage and the plumage sequence have their counterpart within the bitterns particularly Botaurus pinnatus. Zebrilus may be best considered a highly aberrant bittern which has retained several primitive character states of the bittern ancestors. In the shape of the interorbital foramen, in the bifurcate lacrimal, and in cervical vertebrae 16 and 17, Zebrilus resembles "Gorsachius" among the night herons rather than the bitterns, and the Zigzag Heron appears to be intermediate between this night heron and the bitterns, but with the other distinctive skeletal characters of the bitterns. The bill shape and angle with the skull and the form of the keel of the sternum are unique among herons. The cladistic relationships suggested in the phylogenetic estimate (Fig. 35) indicate that Zebrilus is an offshoot of the primitive bitterns, and a separate tribe Zebrilini is recognized for it.

Tribe Botaurini

Ixobrychus-the Small Bitterns

Included species: cinnamomeus, eurhythmus, exilis, flavicollis, involucris, minutus, sinensis, sturmii.

Diagnosis: Small bitterns with variable plumage patterns and with ten rectrices. The tarsi are scutellate.

The small South American involucris is slender-billed and heavily streaked above; the sexes are alike. In the widespread superspecies exilis-minutus-sinensis the birds are slender-billed and uniformly colored above (sinensis females are indistinctly streaked, and the local, uncommon all-dark phase "neoxena" is known from part of the range of exilis in North America). In these three the males and 
females are dimorphic in plumage. The two species cinnamomeus and eurhythmus have largely overlapping ranges and are distinct in size; cinnamomeus is larger and eurhythmus has a rather short bill. The African sturmii is solidly slate gray above and streaked only on the throat, neck, and breast, and the Australasian flavicollis is polymorphic with six distinct plumages (Mayr, 1945). Some plumage morphs are restricted to one sex, and some morphs have a very local distribution. The plumage morphs appear to be (1) all black (apparently restricted to males from islands near New Guinea), (2) blackish with white throat streaks, (3) similar but also with white cheeks, (4) vinaceous brown-black, marked as no. 2, (5) streaked, pale rufous (including the females from Timor and Rennel Island and most females from New Guinea and northern Australia), and (6) white, with few scattered black feathers (known only from New Britain, both males and females). The immature plumage in all species is streaked and distinct from the adult plumage.

There is little variation in the skeleton among the species of Ixobrychus, and what variation was noted was restricted mainly to the length and shape of minor processes such as the sternal manubrium, the external and internal spines of the furculum, and the details of the ectethmoid. Skeletal variation does not closely parallel the relationships among species as indicated by plumage and by geographic distribution, and in these birds it appears that skeletal character states may have been independently derived in different species groups. All of the species appear to be similar enough to be recognized as congeneric. I. sturmii has been called a distinct genus "Ardeirallus" by Curry-Lindahl (1971) because it differs from other species of Ixobrychus in lacking sexual dimorphism, in lacking "acrobatics," in apparently lacking tail-flicking, and in other undescribed features. However, I. involucris also lacks sexual dimorphism, the behavioral differences may reflect lack of observations, and any single-species differences may be specialized, derived features rather than the result of cladistic divergence. Examination of the skeleton suggests no marked distinctiveness of I. sturmii from the other species of Ixobrychus. The species I. flavicollis is often recognized as a monotypic genus "Dupetor" but although it is much larger than the other species its only distinctive skeletal character state is the bifurcate lacrimal (Table 2). It may be distinctive in behavior as Curry-Lindahl (1971) notes that it has "a deep booming sound in the breeding season," unlike the behavior described for other species of Ixobrychus. La Rue has used X-rays of study skins to compare the angles between the brain stem and vertebral axis and certain other bones of the skull, and his measurements indicate that flavicollis has a distinct skull shape, but these angles seem simply to reflect the long bill of flavicollis. In our study we found the shape of the interorbital foramen and the ectethmoid of flavicollis to be similar to sturmii, the species which it most closely resembles in 
plumage color and pattern. The eggs are white as in other species of Ixobrychus (UMMZ egg collection). A pickled nestling (AMNH 4435) of $I$. flavicollis has the same pattern of feather tracts as nestling $I$. exilis, and no gross morphological differences other than the larger size of flavicollis are evident in the specimens. Though flavicollis is somewhat aberrant in size there are no obvious morphological differences between it and other species of small bitterns, and it appears to be best recognized as Ixobrychus.

\section{Botaurus-the Large Bitterns}

Included species: lentiginosus, pinnatus, stellaris, poiciloptilus.

Diagnosis: Large Bitterns with streaked, brown plumage. The tarsi are scutellate. Rectrices number 10.

The two New World bitterns (pinnatus and lentiginosus) are each distinctive in plumage, with the former barred on the crown and richly colored rufous buff and the latter with an unbarred head and with grayer feathers. The two Old World species stellaris and poiciloptilus are unbarred on the head and similar to each other in plumage pattern. The Old World species and pinnatus differ from lentiginosus in color as they are paler, more streaked with buff above. Bock (1956) suggested that all the bitterns may be conspecific and Mayr and Short (1970) listed them as a superspecies.

A species of tropical Central and South America, B. pinnatus differs from the North American species $B$. lentiginosus in several skeletal characters-the temporal muscle scars have a different configuration, the supraorbital process is less prominent, the anterior extension of the interorbital foramen is less well developed, the synsacral antitrochanter is laterally less prominent, and the hypotarsus is less prominently ridged and only a simple central hypotarsal canal is formed. The two Old World bitterns are very similar to each other and remarkably different from the New World bitterns. If only skeletons were available, the Old World bitterns and the New World bitterns would be regarded as different genera. The synsacrum of the Old World group has a particularly prominent lateral projection of the iliac crest, the synsacrum appears lyre-shaped from above, and the configuartion of the posterior edge of the ischium is distinct (Figs. 19, 20). The skull also differs with the lacrimal groove and the ectethmoid bifurcate ventrolaterally in the New World forms but not in the Old World species. These skeletal differences between the Old World and New World bitterns, like those between the two New World bitterns, are greater than in other speciesmembers of superspecies in the herons, and it seems likely that only stellaris and poiciloptilus are sufficiently similar to be regarded as a superspecies. The four bitterns are allopatric and obviously are geographic differentiates of a single kind of bittern in the remote past, but they are too distinct to be regarded as a single superspecies. 


\section{SUMMARY}

The heron family Ardeidae includes 62 species that are thought to be more closely related to each other than to any other ciconiiform birds. Partial or complete skeletons of 53 species were compared with each other in an attempt to find skeletal characters useful for estimating the evolutionary relationships among the herons. A total of 33 characters were found that both (a) varied in a discontinuous manner with distinct states among the heron species and (b) had comparable character states among the other non-heron Ciconiiformes. These included 13 skull characters, 3 vertebral characters, 6 characters of the pectoral girdle and sternum, 4 humerus characters, 5 synsacral characters, and two characters of the tarsometatarsus. Additional skeletal characters that varied among herons, either in a continuous manner among the species or in a manner that did not allow comparison with the different character states of the related non-heron Ciconiiformes, were used for comparing certain herons, as were plumage and behavior.

Skeletal characters of the 48 species for which complete specimens were available were used to describe the pattern of phenetic similarities and to estimate the evolutionary relationships among the herons. Numerical taxonomic analyses used were a minimally connected graph or Prim Network analysis, principal components analysis, cluster analysis using simple matching coefficients and also product-moment correlation coefficients, phylogenetic or Wagner Tree analysis, and a cladistic compatibility analysis. Each of these programs gave somewhat different results when the skeletal character-states were altered for only a few species, but some groupings of species were common to all of the programs, and some cladistic relationships remained consistent through various runs of the two programs estimating phylogeny (phylogenetic or Wagner Tree, and cladistic compatibility). Additional characters such as uncoded skeletal features, plumage differences, and display behavior were used in selecting among the various alternatives suggested in the results and in supplying information for estimating relationships when the results of numerical taxonomic analysis of skeletal characters showed no resolution of certain evolutionary problems. The systematic classification of the family is based on the results of the phenetic and the phylogenetic analyses.

Four major groups were found by numerical taxonomic analysis and these corresponded closely to the four tribes recognized by Bock (1956), with three species and genera changing groups. The four groups were recognized as the subfamilies Ardeinae (day herons, egrets, and related herons), Nycticoracinae (night herons), Tigrisomatinae (tiger herons), and Botaurinae (bitterns). Syrigma sibilatrix and Pilherodius pileatus are more closely associated with the day herons than with the night herons. The Boat-billed Heron Cochlearius 
cochlearius was separable by cladistic criteria within the night herons and was phenetically distinct from them, and it is recognized as a separate tribe Cochlearini within the Nycticoracinae. Zebrilus undulatus is most closely related to the bitterns, though it retains some primitive characteristics common to other groups of herons and not shared by the more highly derived bittern genera Ixobrychus and Botaurus. It is cladistically separate from the other bitterns and is placed in a tribe Zebrilini.

A hypothetical set of primitive character states was constructed to represent the most likely skeletal character states of the ancestral heron "primardea" by determining the most frequent character states in a representative sample of non-heron Ciconiiformes. The phylogenetic consequences of this assumption, as reasoned through both the phylogenetic Wagner Tree and the cladistic compatibility algorithms, indicate that the day herons or night herons are most like the ancestral heron and that the bitterns are the most different, i.e., have undergone more changes in character states.

Cladistic and phenetic distinctiveness in the numerical taxonomic analyses was the basis for recognizing higher taxa in the systematic classification, the subfamilies, tribes, and genera. Members of Bock's genus "Hydranassa" do not form a distinct group by any phenetic or cladistic criteria in their skeletal or other available characters and the included species are regarded as members of the large genus Egretta. "Butorides" is indistinguishable in the skeletal characters examined (though distinguishable in size at the species level) from Ardeola and is included in that genus. Other relationships within the Ardeinae that differ from some previous suggestions include the following: (a) Ardea ("Casmerodius") alba is best regarded as a heron in which the aigrette display feathers have independently evolved from those in the egrets, (b) Egretta। ("Bubulcus") ib is is not close to the Ardeola pond herons but is similar to other species of Egretta, especially to $E$. intermedia, and (c) "Notophoyx" novaehollandiae is an Egretta with similarities to $E$. caerulea.

Among the night herons Nyctanassa violacea is cladistically and phenetically well differentiated from Nycticorax nycticorax and the genus Nyctanassa is retained. The Old World species "Calherodius" leuconotus, "Oroanassa" magnifica, "Gorsachius" goisagi, and "G." melanolophus are probably differentiates of Nycticorax and are included in that genus, largely on the basis of features of the plumage. Cochlearius has a strongly differentiated skull related to its specialized bill, but most of the postcranial skeletal characters are similar to those of Nycticorax.

Two New World tiger herons Tigrisoma appear to be more like each other than they are to the Old World forms. Tigriornis leucolophus has a deeply notched sternum unlike the other known herons; no complete skeletons of Zonerodius heliosylus were available for study. 
Zebrilus resembles the bitterns rather than the tiger herons in most of the skeletal character states that differentiate these two groups and that were represented in the incomplete specimen available. Minor character differences among the Ixobrychus species are as great as in the one differentiating character (a ventrally bifurcated lacrimal) of $I$. ("Dupetor") flavicollis, and all of the small bitterns included by Bock (1956) in Ixobrychus are so included here. The Old World and New World species of large bitterns are strongly differentiated from each other and are too divergent to be recognized as members of a common superspecies; they are included in a single genus, Botaurus.

Several species problems involving mainly allopatric forms remain to be investigated. Field studies including detailed comparisons of behavior are suggested for populations of Ardea herodias and occidentalis in the Gulf of Mexico and the Caribbean, for the Australasian and African Egretta ibis, and for the African and Malagasay Egretta garzetta-gularis-dimorpha complex. Detailed observations of the display behavior of herons are suggested as an independent source of data to test the set of hypotheses of evolutionary relationships indicated by the skeletal characters. Behavior observations would be especially desirable for Syrigma, Pilherodius, the Ardeola pond herons, Nycticorax leuconotus, N. magnificus, $N$. melanolophus, and $N$. goisagi, the tiger herons, and all of the bitterns including Zebrilus.

General results of the study are that phenetic and phylogenetic analyses may give similar results of patterns of relationships and that phenetic descriptions and phylogenetic estimates have practical compatibilities which may allow them to be used together to construct a systematic classification. It is suggested that systematic studies of other groups may lead to more robust conclusions when relationships are estimated and compared by both descriptive phenetic and interpretive phylogenetic methods.

\section{APPENDIX I}

\section{SPECIMENS EXAMINED (SKELETONS)}

Specimens numbers listed before the semicolons for each species were examined in closest detail; those after the semicolons were examined for any possible sexual dimorphism, age variation, and individual variation. Characters that were variable within these series of single species were not included in the analyses of species differences. Unless otherwise noted the entire skeleton was available for study.

\section{A. Ardeidae.}

Syrigma sibilatrix-UMMZ 158606, 158607.

Pilherodius pileatus-UMMZ 156863;208468, NMNH 345759.

Ardea cinerea-UMMZ 119287; 135790.

Ardea herodias-UMMZ 107419; 74219, 99473, 107057, 107058, 107060, $107061,107369,107370,107377,113778,151585$. 
Ardea (herodias) occidentalis-AMNH 1228, NMNH 347292 (trunk). Ardea cocoi-NMNH 3260, 5881, 429394 (skull only).

Ardea pacifica-UMMZ 214144.

Ardea melanocephala-NMNH 292894, 322536.

Ardea humbloti-none.

Ardea imperialis-UMMZ 140271 (skin, partial dissection of lacrimal-ectethmoidorbital region), BM (NH) 1845-1-12-3-11 (trunk only).

Ardea sumatrana-NMNH 488342.

Ardea goliath-NMNH 224819 (skull and lower legs), 322068 (head of humerus, vertebrae, pectoral and pelvic girdles).

Ardea purpurea-UMMZ 154435; 154434, 156446, 156447.

Ardea alba-UMMZ 216106; 216104, 216105.

Egretta rufescens-UMMZ 136370; 152627.

Egretta picta-AMNH 529178 (skin, partial dissection of the head), CSIRO 16957.

Egretta vinaceigula-none.

Egretta ardesiaca-NMNH 432188.

Egretta tricolor-UMMZ 71894; 130934, 219164.

Egretta intermedia-UMMZ 152683; 152681, 214348.

Egretta ibis-NMNH 430524, 430525, UMMZ 209241; 156533, 216107, 219883

(all E. i. ibis); NMNH 292028, 318236 (all E. i. coromandus).

Egretta novaehollandiae-UMMZ 210671; 213095, 214145.

Egretta caerulea-UMMZ 133601; 216100, 216102.

Egretta thula-UMMZ 133603; 133604, 159091.

Egretta garzetta-UMMZ 208226; 154437, 208227.

Egretta gularis-none.

Egretta dimorpha-none.

Egretta eulophotes-MVZ 148770 (trunk only), 148771 (trunk only).

Egretta sacra-UMMZ 210384.

Ardeola ralloides-UMMZ 154440; 152868, 154438, 154439.

Ardeola grayii-BM (NH) 1923-5-14-3.

Ardeola bacchus-NMNH 292032, 292033.

Ardeola speciosa-none.

Ardeola idae-none.

Ardeola rufiventris-UMMZ 152869; PB 18784, 18785.

Ardeola striata-UMMZ 107345 (A. s. virescens), UMMZ 158162 (A. s. atricapilla); 152622 (A. s. striata), MVZ 130101 (A. s. sundevalli); UMMZ 85095, 107300, 107345, 107349, 107353,155867 (A. s. virescens).

Agamia agami-UMMZ 209712.

Nyctanassa violacea-UMMZ 85046, $130935,133607$.

Nycticorax nycticorax-UMMZ 72836; 73849, 74808, 135678, 154441, 158599.

Nycticorax caledonicus-MVZ 95061.

Nycticorax leuconotus_USNM 264973 (skin, dissected head).

Nycticorax magnificus-none.

Nycticorax goisagi-none.

Nycticorax melanolophus-AMNH 4928, NMNH 488330.

Cochlearius cochlearius-UMMZ 153061; 70076, 133614, 153062, 210629.

Tigrisoma mexicanum-UMMZ 107380, 133608, 133609, 133612, 151585, 151866.

Tigrisoma fasciatum -none.

Tigrisoma lineatum-UMMZ 156133, 208469.

Zonerodius heliosylus-AMNH 302732 (skin, partial dissection of lacrimalectethmoid-orbital region).

Tigriornis leucolophus-AMNH 2658.

Zebrilus undulatus-AMNH 3637 (body skeleton), AMNH 247248 (skin, skull and tarsometatarsus removed, same specimen as number 3637 ). 
Ixobrychus involucris-UMMZ 210501.

Ixobrychus exilis-UMMZ 73868; 151812, 159426, 216116.

Ixobrychus minutus-UMMZ 151097.

Ixobrychus sinensis-NMNH 291696, 488913.

Ixobrychus eurythmus-UMMZ 152350.

Ixobrychus cinnamomeus-NMNH 343193; 291372.

Ixobrychus sturmii-UMMZ 208228.

Ixobrychus flavicollis-UMMZ 140345 (skull and tarsometatarsus), UMMZ 214146 (juvenile, poor condition); AMNH 10562 (skin, dissected head).

Botaurus pinnatus-UMMZ 210500.

Botaurus lentiginosus-UMMZ 107421; 75360, 107069, 107358, 107374.

Botaurus stellaris-UMMZ 219800.

Botaurus poiciloptilus-UMMZ 213096.

B. Other Ciconiiformes.

Balaenicipitidae

Balaeniceps rex-UMMZ 215884.

Scopidae

Ciconiidae

Scopus umbretta-UMMZ 158435.

Ibis ibis-UMMZ 215038.

Anastomus osculans-UMMZ 216573.

Ciconia alba-UMMZ 151110.

Leptoptilus crumeniferus-UMMZ 218203.

Threskiornithidae

Hagedashia hagedash-UMMZ 214345.

Plegadis chihi-UMMZ 156985.

Ajaia ajaja-133621.

Phoenicopteridae

Phoeniconaias minor-UMMZ 208289.

\section{LITERATURE CITED}

Ackerman, A. 1967. Quantitative Untersuchungen an Körnfressenden Singvögeln. J. Ornithol., 108: 430-473.

Adams, C. T. 1955. Comparative osteology of the night herons. Condor, 57: $55-60$.

1956. Comparative osteology and phylogeny of the family Ardeidae. Ph.D thesis, (unpublished), University of Florida.

Ali, S., and S. D. Ripley. 1968. Handbook of the Birds of India and Pakistan. vol. 1. Oxford University Press, Bombay.

Allen, R. P. 1942. The Roseate Spoonbill. Nat'l. Aud. Soc. Res. Rept. 2. 24-27.

Amadon, D. 1953. Avian systematics and evolution in the Gulf of Guinea. Bull. Amer. Mus. Nat. Hist., 100 (3): 393-452.

Andrews, C. W. 1897. On some fossil remains of carinate birds from Central Madagascar. Ibis, 1897: 343-359.

Bancroft, G. 1969. A Great White Heron in Great Blue nesting colony. Auk, 86: 141-142.

Bannerman, D. A. 1930. The Birds of Tropical West Africa. vol. 1. Crown Agents for the Colonies, London.

Bannerman, D. A., and W. M. Bannerman. 1968. Birds of the Atlantic Islands. vol. 3. Oliver and Boyd, Edinburgh. 
Benson, C. W., R. K. Brooke, and M. P. S. Irwin. 1971. The Slatey Egret Egretta vinaceigula is a good species. Bull. Brit. Orn. Cl., 91: 131-133.

Benson, C. W., and M. J. Penny. 1971. The land birds of Aldabra. Phil. Trans. Roy. Soc. London B, 206: 417-527.

Bernis, F. 1971. Reconsideracion del ejemplar melanico de Egretta spp., obtenido en Doñana en 1956. Ardeola, 15: 107-110.

Blaker, D. 1969a. Behaviour of the Cattle Egret Ardeola ibis. Ostrich, 40: 75-129.

1969b. The behaviour of Egretta garzetta and E. intermedia. Ostrich, 40: 150-155.

Bock, W. J. 1956. A generic review of the family Ardeidae (Aves). Amer. Mus. Novitates 1779 .

19-55.

1963. Relationships between the birds of paradise and the bower birds. Condor, 65: 91-125.

Bock, W. J., and A. McEvey. 1969. Osteology of Pedionomus torquatus (Aves: Pedionomidae) and its allies. Proc. Roy. Soc. Victoria, 82: 187-232.

Bond, J. 1961. Sixth supplement to the Check-list of Birds of the West Indies (1956). Acad. Nat. Sci. Phila. 12 pp.

1965. Tenth supplement to the Check-list of Birds of the West Indies (1956). Acad. Nat. Sci. Phila. 16 pp.

1971. Birds of the West Indies. 2nd ed. Houghton Mifflin, Boston.

Brodkorb, P. 1963. Catalogue of fossil birds, part 1 (Archaeopterygiformes through Ardeiformes). Bull. Florida State Museum, Biol. Sci., 7(4): 179-293.

Brown L. H. 1959. The Mystery of the Flamingos. Country Life, London.

Brunet, J. 1970. Oiseaux de l'Eocene superieur du Bassin de Paris. Annls. Paleont. (Vert.), 56: 3-65.

Carpenter, J. W. 1971. Notes on the biology and behavior of captive Boat-billed Herons, Cochlearius cochlearius. South western Nat., 16: 31-41.

Carr, A. 1965. Ulendo, Travels of a Naturalist in and out of Africa. W. Heinemann, London.

Chapin, J. P. 1932. The Birds of the Belgian Congo. Part I. Bull. Amer. Mus. Nat. Hist. 65.

Cooley, W. W., and P. R. Lohnes. 1971. Multivariate Data Analysis. Wiley, New York.

Cottrille, W. P., and B. D. Cottrille. 1958. Great Blue Heron: behavior at the nest. Univ. Mich. Mus. Zool., Misc. Publ. 102.

Cracraft, J. 1967. On the systematic position of the Boat-billed Heron. Auk, 84: $529-533$

1968. The lacrimal-ectethmoid bone complex in birds: a single character analysis. Amer. Midl. Natl., 82: 316-359.

Cracraft, J. 1974a. Phylogenetic models and classification. Syst. Zool., 23: 71-90. $1974 \mathrm{~b}$. Phylogeny and evolution of the ratite birds. Ibis, 494-521.

Curry-Lindahl, K. 1971. Systematic relationships in herons (Ardeidae), based on comparative studies of behaviour and ecology, a preliminary account. Ostrich, Suppl. 9: 53-70.

Dathe, H. 1941. Beobachtungen an einer balzenden Tigerrohrdommel, Tigrisoma lineatum (Bodd.). Zool. Garten Leipzig (N.F.), 13: 280-292.

Diamond, J. M. 1972. Avifauna of the eastern highlands of New Guinea. Publ. Nuttall Ornith. Club, 12. 438 pp. Cambridge, Massachusetts.

Dickerman, R. W., and G. Gaviño T. 1969. Studies of a nesting colony of Green Herons at San Blas, Nayarit, Mexico. Living Bird, 8: 95-111.

Dickerman, R. W., and C. Juarez L. 1971. Nesting studies of the Boat-billed Heron Cochlearius cochlearius at San Blas, Nayarit, Mexico. Ardea, 59: $1-16$. 
Dickerman, R. W., and K. C. Parkes. 1968. Notes on the plumages and generic status of the Little Blue Heron. Auk, 85: 437-440.

Dubale, M. S., and A. P. Mansuri. 1970. A comparative account of the dimensions of bony elements of the feeding apparatus of certain herons (family Ardeidae). Proc. Nat. Acad. Sci. India, B, 39: 226-232.

Dusi, J. L. 1967. Migration in the Little Blue Heron. Wilson Bull., 79: 223-235.

Eisenmann, E. 1965. The tiger-herons (Tigrisoma) of Argentina. Hornero, 10: 225-234.

Estabrook, G. F. 1972. Cladistic methodology: a discussion of the theoretical basis for the induction of evolutionary history. Ann. Rev. Ecol. Syst., 3: $427-456$.

Estabrook, G. F., C. S. Johnson, Jr., and F. R. McMorris. 1975. An idealized concept of the true cladistic character. Math. Biosci., 2(23): 263-272.

Farris, J. S. 1970. Methods for computing Wagner trees. Syst. Zool., 19: 83-92.

Fabian, G., and I. Sterbetz. 1966. Black Little Egrets [Egretta g. garzetta (L.)] in Europe. Aquila, 71-72: 99-112.

Gentz, K. 1970. Die Grosse Dommel. Neue Brehm-Bücherei, Leipzig.

Good, A.-I. 1952. The Birds of French Cameroon. Part 1. Ser. Sciences Naturelles, 2. Mem. Inst. Francais d'Afrique Noire.

Gould, S. J. 1975. Racism and recapitulation. Nat. Hist. 86 (6): 16-25.

Grimes, L. 1972. The Non Passerine Birds of the Accra Plains, Ghana. University of Ghana, Legon.

Griscom, L. 1926. The ornithological results of the Mason-Spinden expedition to Yucatan, part 1. Amer. Mus. Novitates, 235: 1-19.

Gysels, H. 1968. Biochemical approach of the central systematic position of the Ciconiiformes. Ardea, 56: 267-280.

Heatwole, H. 1965. Some aspects of the association of Cattle Egrets with cattle. Anim. Behav., 13: 79-83.

Helbig, L. 1968. Ethologische Beobachtungen an gefangen-gehaltenen Egretta garzetta, Leucophoyx thula und Ardeola ibis ausserhalb der Brutzeig. Beitr. Vogelk., 13: 397-454.

Hellmayr, C. E., and B. Conover. 1948. Catalogue of Birds of the Americas. Field Museum Nat. Hist., Zool. Ser; Publ. 615, vol. 13, part 1, number 2.

Henwood, P. 1973. (letter to the editor) Honeyguide, 75: 34-36.

Hennig, W. 1966. Phylogenetic Systematics. Univ. Illinois Press, Urbana.

Hiraldo, C., F. 1971. Primera captura segura de Egretta gularis gularis en España. Ardeola, 15: 103-107.

Holyoak, D. T. 1973. Significance of colour dimorphism in Polynesian populations of Egretta sacra. Ibis, 115: 419-420.

Hoogerwerf, A. 1966. The occurrence of Nycticorax caledonicus in Java. Ardea, 54: $81-87$.

Howard, H. 1929. The avifauna of Emeryville shellmound. Univ. Calif. Publ. Zool., 32: 301-394.

Humphrey, P. S., and K. C. Parkes. 1963. Plumages and systematics of the Whistling Heron (Syrigma sibilatrix). Proc. XIII Internat. Orn. Congr., pp. 84-90.

Hyman, M., and G. Rabb. 1972. Phyletic analysis of 50 characters of advanced snakes. Fieldiana, 63: viii and $321 \mathrm{pp}$.

Irwin, M. P. S. 1975. Adaptive morphology in the Black and Slatey Egrets Egretta ardesiaca and Egretta vinaceigula, and relationships within the genus Egretta (Aves: Ardeidae). Bonn. zool. Beitr., 26: 155-163.

Irwin, M. P. S., and C. W. Benson. 1967. Notes on the birds of Zambia: part IV. Arnoldia (Rhodesia), 3(8): 1-27.

Johnston, R. F. 1969. Character variation and adaptation in European sparrows. Syst. Zool., 18: 206-231.

Kahl, M. P. 1971a. Social behavior and taxonomic relationships of the storks. Living Bird, 10: 151-170. 
1971b. Some observations on the behavior of Whistling Herons. Wilson Bull., 83: 302-303.

Kaltenhäuser, D. 1971. Über Evolutionsvorgänge in der Schwimmentenbalz. Z. Tierpsychol., 26: 481-540.

Keep, M. E. 1973. A breeding record of the White-backed Heron. African Wild Life, 27: 182-183.

Kluge, A. G., and J. S. Farris. 1969. Quantitative phyletics and the evolution of anurans. Syst. Zool., 18: 1-32.

Král, B. 1965. Functional adaptations of Ciconiiformes to the darting stroke. Vestnik Ceskoslovenske Spolencnosti Zoologicke, Acta. Soc. Zool. Bohemoslovenicae, Svazek 29(4): 377-391.

Krebs, J. R. 1973. Significance of head tilting in the Great Blue Heron. Nature, 242: 533-535.

1974. Colonial nesting and social feeding as strategies for exploiting food resources in the Great Blue Heron (Ardea herodias). Behaviour, 51: 99-134.

Kushlan, J. A. 1973. Least Bittern nesting colonially, Auk, 90: 685-686.

La Rue, C. J. 1970. A comparative study of the skull in the Ciconiiformes. Ph.D thesis (unpublished), Univ. of Maryland. $167 \mathrm{pp}$.

Lamba, B. S. 1963. Nidification of some common Indian birds. No. 6. The Indian Pond Heron or Paddybird [Ardeola grayii (Sykes)]. Pavo, 1: 35-43.

Le Quesne, W. J. 1969. A method of selection of characters in numerical taxonomy. Syst. Zool., 18: 201-205.

Ligon, J. D. 1965. A Pleistocene avifauna from Haile, Florida. Bull. Fla. State Mus., Biol. Sci., 10: 127-158.

Mackworth-Praed, C. W., and C. H. B. Grant. 1970. Birds of West Central and Western Africa. African Handbook of Birds, series 3, vol. 1. Longman, London.

Mayr, E. 1940. Notes on New Guinea birds, VI. Amer. Mus. Novitates, 1056: 1-12.

1943. Notes on Australian birds (ii). Emu, 43: 3-17.

1945. Birds collected during the Whitney South Sea Expedition. 55. Notes on the birds of northern Melanesia. 1. Amer. Mus. Novitates, 1294: 1-12.

1956. Is the Great White Heron a good species? Auk, 73: 71-77.

1974. Cladistic analysis or cladistic classification? Z. f. Zool. Syst. u. Evolutionsforschung, 12: 94-128.

Mayr, E., and D. Amadon. 1941. Birds collected during the Whitney South Sea Expedition. 46. Geographic variation in Demigretta sacra (Gmelin). Amer. Mus. Novitates, 1144: 1-11. $1-42$.

Mayr, E., and L. L. Short. 1970. Species taxa of North American birds. Publ. Nuttall Orn. Cl., 9.

McCrimmon, D. A. 1974. Stretch and snap displays in the Great Egret. Wilson Bull., 86: 165-167.

Meinertzhagen, R. 1954. Birds of Arabia. Oliver and Boyd, Edinburgh.

Meyerriecks, A. J. 1957. Field observations pertaining to the systematic status of the Great White Heron in the Florida Keys. Auk, 74: 469-478.

1960. Comparative breeding behavior of four species of North American herons. Publ. Nuttall Orn. Cl., 2.

1962a. In Handbook of North American Birds, 1. ed. R. S. Palmer. Yale Univ. Press. New Haven.

1962b. Diversity typifies heron feeding. Nat. Hist., 71: 48-59.

Michener, C. D. 1970. Diverse approaches to systematics. Evolut. Biol., 4: 1-38.

Miller, W. de W. 1924. Further notes on ptilosis. Bull. Amer. Mus. Nat. Hist., 50: 305-331. 
Milstein, P. le S., and H. C. Hunter. 1974. The spectacular Black Heron. Bokmakierie, 26: 93-97.

Milstein, P. le S., I. Prestt, and A. A. Bell. 1970. The breeding cycle of the Grey Heron. Ardea, 58: 171-257.

Milon, P. 1959. Observations biologiques sur Egretta garzetta dimorpha Hartert à Madagascar. Ostrich, Suppl. 3: 250-259.

Mock, D. W. In press. Social behavior of the Boat-billed Heron. Living Bird.

Moreau, R. E. 1972. The Palearctic-African Bird Migration Systems. Academic Press, New York.

Moseley, C., and A. Feduccia. 1975. Upper Pliocene herons and ibises from North America. Univ. Michigan Pap. Paleont., 12: 71-74.

Murton, R. K. 1971. Polymorphism in Ardeidae. Ibis, 113: 97-99. 1972. The ecology and status of Swinhoe's Egret, with notes on other herons in southeastern China. Biol. Conserv., 4: 89-96.

Naurois, R. de. 1969. Peuplements et cycles de reproduction des oiseaux de la Côte Occidentale d'Afrique. Mém. Mus. Natn. Hist. Nat., Paris, Sér. A, Zool. 56: 1-312.

Newton, A. 1896. A Dictionary of Birds. Adam and Charles Black, London.

Owen, D. F., and G. C. Phillips. 1956. The food of nestling Purple Herons in Holland. Brit. Birds, 49: 494-499.

Palmer, R. S. (ed.) 1962. Handbook of North American Birds. vol. 1. Yale Univ. Press, New Haven.

Payne, R. B. 1974. Species limits and variation of the New World Green Herons Butorides virescens and Striated Herons B. striatus. Bull. Brit. Orn. Cl., 94: 81-88.

in prep. Family Ardeidae. In Check-list of Birds of the World, vol. 1, ed. 2. E. Mayr, ed.

Percy, W. L. 1951. Three studies in bird character. Bitterns, herons and water rails. Country Life, Ltd., London.

Peters, J. L. 1931. Check-list of Birds of the World. vol. 1. Harvard Univ. Press, Cambridge, Massachusetts.

Phillips, A., J. Marshall, and G. Monson. 1964. The Birds of Arizona. Univ. Arizona Press, Tucson.

Portielje, A. F. J. 1926. Zur Ethologie bzw. Psychologie von Botaurus stellaris. Ardea, 15: 1-15.

Rand, A. L. 1936. The distribution and habits of Madagascar birds. Bull. Amer. Mus. Nat. Hist., 72 (5).

Recher, H. F. 1972. Colour dimorphism and the ecology of herons. Ibis, 114: $552-555$.

Recher, H. F., and J. A. Recher. 1972. The foraging behaviour of the Reef Heron. Emu, 72: 85-90.

Rice, D. W. 1954. Symbiotic feeding of Snowy Egrets with cattle. Auk, 71: $472-473$.

Ridgway, R. 1878. Studies of the American Herodiones. Part I. Bull. U. S. Geol. Geogr. Surv. Territories, 4: 226-237.

Ripley, S. D. 1961. A Synopsis of the Birds of India and Pakistan. Bombay Nat. Hist. Soc., Bombay. Archipelago. Ibis, 111: 101-102.

Robbins, C. S., B. Brunn, and H. S. Zim. 1966. A Guide to Field Identification, Birds of North America. Golden Press, New York.

Robertson, W. B., Jr. in prep. Species of special concern: Great White Heron. In Rare and Endangered Plants and Animals of Florida, ed. J. A. Layne.

Schneider, K. M. 1937. Eigentumliche Federbildurg an einem Nachtreiher. Nautr u. Volk, 67: 432-436.

Schnell, G. D. 1970. A phenetic study of the suborder Lari (Aves). Syst. Zool., 19: 35-57, 264-302. 
1973. A reanalysis of nest structure in the weavers (Ploceinae) using numerical taxonomic techniques. Ibis. 115: 93-106.

Schüz, E. 1927. Beitrag zur Kenntnis der Puderbildung bei den Vögeln. J. Orn., 75: 86-224, 6 plates.

Seton, D. H. C. 1973. Observations on breeding of the Great-billed Heron in northern Queensland. Emu, 73: 9-11.

Sharpe, R. B. 1898. Catalogue of the birds in the British Museum. vol. 26. British Museum (Natural History), London.

Shufeldt, R. W. 1901. Osteology of the Herodiones. Ann. Carnegie Mus., $158-249$.

Short, L. L. 1969. An apparent agonistic display of the Whistling Heron. Wilson Bull., 81: 330-331.

Sibley, C. G., and J. E. Ahlquist. 1972. A comparative study of the egg white proteins of non-passerine birds. Yale Univ. Peabody Mus. Nat. Hist., Bull. 39.

Siegfried, W. R. 1972. Aspects of the feeding ecology of Cattle Egrets (Ardeola ibis) in South Africa. J. Anim. Ecol., 41: 71-78.

Skead, C. J. 1966. A study of the Cattle Egret, Ardeola ibis, Linnaeus. Ostrich, Suppl. 6: 109-139.

Smythies, B. E. 1953. The Birds of Burma. ed. 2. Oliver and Boyd, Edinburgh.

Sneath, P. H. A., and R. R. Sokal. 1973. Numerical Taxonomy. W. H. Freeman, San Francisco.

Snow, B. 1975. The Plumbeous Heron of the Galapagos. Living Bird, 13: 51-72.

Snow, D. W. 1975. The classification of the manakins. Bull. Brit. Ornith. Cl. 95: 20-27.

Spillner, W. 1968. Zum Paarungs-und Brutbiologie des Graureihers (Ardea cinerea). Beitr. Vogelk., 14: 29-74.

Sprunt, A. 1954. A hybrid between the Little Blue Heron and the Snowy Egret. Auk, 71: 314, 1 plate.

Steinbacher, F. 1936. Ueber Egretta gularis und verwandte Formen in Afrika. Orn. Monatsber., 44: 19-22.

Storer, R. W. 1971. Classification of birds. In Avian Biology, vol. 1. pp. 1-19. Academic Press, New York, eds. D. S. Farner and J. R. King.

Taylor, J. 1972. The Black Headed Heron. Animals, 13: 688-689.

Tomlinson, D. N. S. 1974. Studies of the Purple Heron, Part 2: behaviour patterns. Ostrich, 45: 209-223.

Uys, J. M. C., and T. H. Clutton-Brock. 1966. The breeding of the Rufous-bellied Heron (Butorides rufiventris) in Zambia. Puku, 4: 171-180.

Vanden Berge, J. C. 1970. A comparative study of the appendicular musculature of the order Ciconiiformes. Amer. Midl. Natl., 84: 289-364.

Van Rossem, A. J. 1936. A red phase of the Black-crowned Night Heron. Auk, 53: 322-323.

Van Tyne, J., and A. J. Berger. 1959. Fundamentals of Ornithology. Wiley, New York.

Vasvári, N. 1931. Studien über die Ernährung des Purpurreihers (Ardea purpurea L.). Aquila, 36-37; 267-293.

Vernon, C. J. 1971. Observations on Egretta vinaceigula. Bull. Brit. Orn. Cl., 91: 157-159.

Verwey, J. 1930. Die Paarungsbiologie des Fischreihers. Zool. Jahrb., Abt. Allg. Zool. Physiol., 48: 1-120.

Voisin, C. 1970. Observations sur le comportement du Héron bihoreau Nycticorax n. nycticorax en périod de reproduction. L'Oiseau et Rev. Fr. Orn., 40: 307-339.

Voisin, C., and J.-F. Voisin. 1975. Aigrette garzette en phase sombre. L'Oiseau et Rev. Fr. Orn., 45: 93. 
Wagner, W. H. 1969. The construction of a classification. In Systematic Biology, pp. 67-90. Publ. 1692, National Academy of Sciences, Washington, D. C.

Weller, M. W. 1961. Breeding biology of the Least Bittern. Wilson Bull., 73: $11-35$.

Wetmore, A. 1920. The function of powder down in herons. Condor, 22: 168-170.

1960. A classification for the birds of the world. Smithson. Misc. Coll. 139 (11): 1-36.

1965. The birds of the Republic of Panama, part 1. Smithson. Misc. Coll. 150.

White, C. M. N. 1973. Night herons in Wallacea. Bull. Brit. Orn. C., 93: 175-176.

White, C. M. N. 1974. Three water birds of Wallacea. Bull. Brit. Orn. Cl., 94: 9-11.

Wiese, J. H. In press. Courtship and pair formation in the Great Egret Casmerodius albus (L.) Auk.

Williams, G. 1957. Some ecological observations on the Purple Heron in the Camargue. Stat. Biol. Tour du Valet, 1957: 104-120.

Wilson, E. O. 1965. A consistency test for phylogenies based on contemporaneous species. Syst. Zool., 14: 214-220.

Witherby, H. F., F. C. R. Jourdain, N. F. Ticehurst, and B. W. Tucker. 1939. The Handbook of British Birds. vol. 3. H. F. Witherby, London.

Accepted for publication February 7, 1976. 


$$
\text { , }
$$ 